Desenvolvimento de um gerador de carga de trabalho baseado em sessões para servidores Web

Dayse Silveira de Almeida 

SERVIÇO DE PÓS-GRADUAÇÃO DO ICMC-USP

Data de Depósito: 07/02/2011

Assinatura:

\title{
Desenvolvimento de um gerador de carga de trabalho baseado em sessões para servidores $W_{e}{ }^{*}$
}

\author{
Dayse Silveira de Almeida
}

Orientadora: Profa. Dra. Regina Helena Carlucci Santana

Dissertação apresentada ao Instituto de Ciências Matemáticas e de Computação - ICMC-USP, como parte dos requisitos para obtenção do título de Mestre em Ciências - Ciências de Computação e Matemática Computacional. VERSÃO REVISADA

USP - São Carlos

Junho/2011

* Agradecimentos ao CNPq pelo apoio parcial dado a este trabalho. 
Ficha catalográfica elaborada pela Biblioteca Prof. Achille Bassi e Seção Técnica de Informática, ICMC/USP, com os dados fornecidos pelo(a) autor(a)

Almeida, Dayse Silveira de

Desenvolvimento de um gerador de carga de trabalho baseado em sessões para servidores Web / Dayse Silveira de Almeida; orientadora Regina Helena Carlucci Santana -- São Carlos, 2011. $134 \mathrm{p}$.

Dissertação (Mestrado - Programa de Pós-Graduação em Ciências de Computação e Matemática Computacional) -Instituto de Ciências Matemáticas e de Computação, Universidade de São Paulo, 2011.

1. Carga de trabalho. 2. Sessões. 3. Servidor Web. 4. Controle de admissão. 5. Escalonamento. I. Santana, Regina Helena Carlucci, orient. II. Título. 


\section{Resumo}

Esta dissertação de mestrado apresenta o projeto, implementação e teste de um gerador de carga de trabalho para servidores $W e b$ que permite a caracterização de sessões e que representa uma carga real. O gerador desenvolvido gera carga visando à alimentar programas que simulam o comportamento de servidores Web. Para a definição dos parâmetros utilizados no gerador de carga sintética desenvolvido, diversos estudos sobre a carga em servidores $W e b$ encontrados na literatura, logs de servidores $W e b$ reais e benchmarks para servidores $W e b$, foram utilizados. Vários algoritmos de controle de admissão e de escalonamento de requisições descritos na literatura foram implementados para teste e validação do gerador desenvolvido. Visando a utilização de sessões, é proposto nesta dissertação um algoritmo de controle de admissão, RED-SB (Random Early Detection - Session Based) que se baseia em um algoritmo (RED) que não considera sessão. Esses algoritmos foram executados utilizando-se um modelo de simulação de servidor $W e b$ com suporte a diferenciação de serviços, chamado SWDS (Servidor $W e b$ com Diferenciação de Serviços). 



\section{Abstract}

This MSc dissertation presents the design, implementation and tests of a workload generator for Web servers that allows the characterization of sessions and represents a real workload. The generator developed generates a workload to be used as an input to programs that simulate the behavior of Web servers. For the definition of the parameters used in the synthetic workload generator developed, several studies about the web server load described in the literature, actual web server logs and benchmarks for Web servers were used. Several algorithms for admission control and scheduling of requests described in the literature were implemented for testing and validation of the generator developed. Aiming at the utilization of sessions, this dissertation proposes an admission control algorithm RED-SB (Random Early Detection - Session based) which is based on an algorithm (RED) that does not consider session. These algorithms were implemented using a simulation model of Web server that supports service differentiation, called SWDS (Web Server with Service Differentiation). 



\section{Sumário}

Resumo iii

$\begin{array}{lll}\text { Abstract } & \text { v }\end{array}$

Lista de Figuras $\quad$ xi

$\begin{array}{ll}\text { Lista de Tabelas } & \text { Xv }\end{array}$

Lista de Acrônimos $\quad$ xvii

1 Introdução 1

1.1 Contextualização e Motivação . . . . . . . . . . . . . . . . . . . . 1

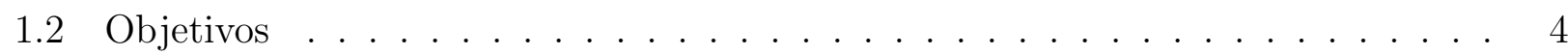

1.3 Estrutura da Monografia . . . . . . . . . . . . . . . . . 4

$\begin{array}{lll}2 & \text { A Internet e seus Serviços } & 7\end{array}$

2.1 Considerações Iniciais . . . . . . . . . . . . . . . . . . . . . . 7

2.2 A Pilha de Protocolos da Internet . . . . . . . . . . . . . . . . . . . . . 8

2.2.1 Camada de Aplicação . . . . . . . . . . . . . . . . . . . . . . . . 9

2.2 .2 Camada de Transporte . . . . . . . . . . . . . . . . . . . . . . 9

2.2 .3 Camada de Rede . . . . . . . . . . . . . . . . . . . . . . . 9

2.2 .4 Camada de Enlace . . . . . . . . . . . . . . . . . . . . . 10

2.2 .5 Camada Física . . . . . . . . . . . . . . . . . . . . . . 11

2.3 World Wide Web (WWW) . . . . . . . . . . . . . . . . . 11

2.4 Protocolo HTTP . . . . . . . . . . . . . . . . . . . . . . . . 13 
2.4.1 Conexões Não Persistentes e Conexões Persistentes . . . . . . . . . . . . . 14

2.4.2 Mensagens HTTP . . . . . . . . . . . . . . . . . . . . . . . 15

2.5 Considerações Finais . . . . . . . . . . . . . . . . . . . 17

3 Qualidade de Serviço na Internet $\quad 19$

3.1 Considerações Iniciais . . . . . . . . . . . . . . . . . . . . . . . . . . 19

3.2 Qualidade de Serviço (Quality of Service - QoS) . . . . . . . . . . . . . . 20

3.2 .1 Serviços Integrados . . . . . . . . . . . . . . . . . . 21

3.2.2 Serviços Diferenciados . . . . . . . . . . . . . . . . . . . 22

3.3 QoS em Nível de Aplicação . . . . . . . . . . . . . . . . . . . . . . . . . . . . . . 24

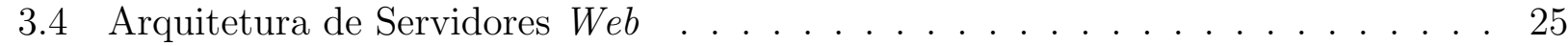

3.4.1 Organização dos Servidores Web . . . . . . . . . . . . . 25

3.5 Servidor Web com suporte a QoS . . . . . . . . . . . . . . 27

3.6 Sessões em Servidores $W e b \ldots \ldots \ldots \ldots$

3.7 Considerações Finais . . . . . . . . . . . . . . . . . . . 36

4 Políticas de Controle de Admissão e Diferenciação de Serviços $\quad 37$

4.1 Considerações Iniciais . . . . . . . . . . . . . . . . . . . . . . . . . 37

4.2 Controle de Admissão . . . . . . . . . . . . . . . . . . . . 38

4.2.1 Algoritmos para Controle de Admissão . . . . . . . . . . . . . . . . . . 39

4.2 .2 Mecanismos para Controle de Admissão . . . . . . . . . . . . . . . . . . 41

4.2 .3 Trabalhos Relacionados . . . . . . . . . . . . . . . . . . . 41

4.3 Diferenciação de Serviços . . . . . . . . . . . . . . . . . . . . . . 45

4.3 .1 Políticas de Escalonamento . . . . . . . . . . . . . . . 45

4.3 .2 Políticas de Particionamento . . . . . . . . . . . . . . . . . . . 47

4.4 Considerações Finais . . . . . . . . . . . . . . . . . . . . . . . . . . . . . . . . . 49

5 Geração da Carga de Trabalho $\quad 51$

5.1 Considerações Iniciais . . . . . . . . . . . . . . . . . . . . . . . 51

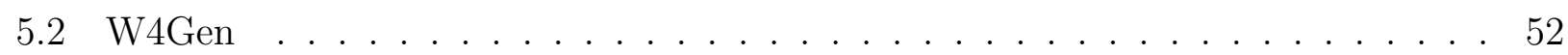

5.2 .1 Modelo de Carga de Trabalho . . . . . . . . . . . . . . . . . 52

5.3 JMeter . . . . . . . . . . . . . . . . . . . . . . . . . 54

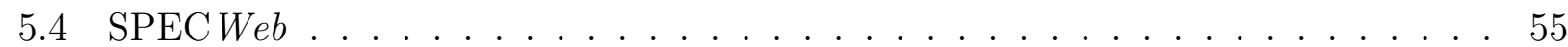

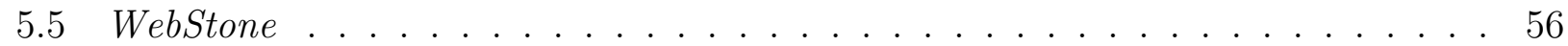

5.6 Httperf . . . . . . . . . . . . . . . . . . . . 57 
5.7 Comparação entre os Geradores de Carga Analisados . . . . . . . . . . . . . . . 59

5.8 Desenvolvimento de uma Carga de Trabalho Baseada em Sessões . . . . . . . . . 59

5.8 .1 Identificador da Sessão . . . . . . . . . . . . . . . . . . . . . . . . . . . 61

5.8 .2 Número de Sessões . . . . . . . . . . . . . . . . . . . . . . . . . . . 61

5.8 .3 Tamanho das Sessões . . . . . . . . . . . . . . . . . . . . . . . 61

5.8.4 Rajada e Tempo de Pensar . . . . . . . . . . . . . . . . . . . . 63

5.8.5 Tempo entre as Sessões . . . . . . . . . . . . . . . . . . 63

5.8 .6 Classe do objeto . . . . . . . . . . . . . . . . . . 64

5.8 .7 Código de resposta . . . . . . . . . . . . . . . . 65

5.8 .8 Tamanho do objeto . . . . . . . . . . . . . . . . 65

5.9 Gerador de Sessões Sintéticas _ . . . . . . . . . . . . . . . . . 65

5.9.1 Modelo da Carga de Trabalho . . . . . . . . . . . . . . . 66

5.9 .2 Modelagem do Gerador de Sessões Sintéticas . . . . . . . . . . . . . . 68

5.10 Considerações Finais . . . . . . . . . . . . . . . . . . . . . 70

$6 \quad$ Resultados Experimentais $\quad 73$

6.1 Considerações Iniciais . . . . . . . . . . . . . . . . . . . . . . . . 73

6.2 Avaliação de Desempenho . . . . . . . . . . . . . . . . . . . . . . 74

6.3 Planejamento de Experimento . . . . . . . . . . . . . . . . . . . 75

6.4 Algoritmos de Escalonamento . . . . . . . . . . . . . . . . . . 76

6.4 Experimento 1 - SBSA . . . . . . . . . . . . . . 77

6.4.2 Experimento 2 - SBSA-DS . . . . . . . . . . . . . 80

6.5 Políticas de Controle de Admissão . . . . . . . . . . . . . . . . . . . . . . 83

6.5.1 Experimento 3 - Mecanismo que Limita o Tamanho da Fila . . . . . . . . 87

6.5.2 Experimento 4 - Mecanismo que Limita a Utilização Média do Cluster . 90

6.5.3 Experimentos 3 e 4: Uma Comparação . . . . . . . . . . . . . . . . . 92

6.5.4 Experimento 5 - Drop Tail e RED: Tratamento de Requisições Individuais 94

6.5.5 Experimento 6 - RED-SB (RED Session Based) . . . . . . . . . . . 102

6.6 Considerações Finais . . . . . . . . . . . . . . . . . . . . . 109

7 Conclusão 113

7.1 Visão Geral . . . . . . . . . . . . . . . . . . . . . . 113

7.2 Conclusões . . . . . . . . . . . . . . . . . . . . . . . . 114

7.3 Principais Resultados e Contribuições . . . . . . . . . . . . . . . . . . 116 
7.4 Trabalhos Futuros . . . . . . . . . . . . . . . . . . . . . 117

Referências bibliográficas $\quad 119$

$\begin{array}{lll}\text { I Apêndice } & 131\end{array}$

A Alguns Parâmetros de Configuração do HTTPerf 133 


\section{Lista de Figuras}

2.1 Pilha de protocolos da Internet. . . . . . . . . . . . . . . . 8

2.2 Estrutura de uma URL [Teixeira 2004] . . . . . . . . . . . . . . . . . . 12

2.3 Funcionamento do protocolo HTTP $[$ Silva 2006] . . . . . . . . . . . . . . . . 14

2.4 Exemplo de uma mensagem de requisição HTTP. . . . . . . . . . . . . . . . . 16

2.5 Exemplo de uma mensagem de resposta HTTP. . . . . . . . . . . . . . . . 17

3.1 Modelo de um servidor Web distribuído [Chen and Mohapatra 1999]. . . . . . . 28

3.2 Servidor Web com Diferenciação de Serviços (SWDS) [Teixeira 2004]. . . . . . . 29

3.3 Modelos de servidores Web [Ye et al. 2005] . . . . . . . . . . . . . . . 30

3.4 QoS Apache $[$ Shan et al. 2005]. . . . . . . . . . . . . . . . . . . 31

3.5 Modelo de Servidor Web para E-Commerce (SWE-C) [Sabo 2006] . . . . . . . . 32

4.1 Classificação das políticas de Controle de Admissão [Barbato 2007]. . . . . . . . 40

5.1 Formato da requisição do W4Gen [Silva 2006] . . . . . . . . . . . . . . 53

5.2 Arquivo de texto produzido pelo W4Gen [Silva 2006] . . . . . . . . . . . 53

5.3 Porcentagem de sessões de determinado tamanho. . . . . . . . . . . . . . . . 62

5.4 Formato da requisição do Gerador de Sessões Sintéticas. . . . . . . . . . . . . 66

5.5 Arquivo texto reproduzido pelo Gerador de Sessões Sintéticas. . . . . . . . . . . 67

5.6 Participação dos trabalhos/ferramentas no desenvolvimento do Gerador de Sessões Sintéticas. . . . . . . . . . . . . . . . . . . . 69

5.7 Diagrama de classes do pacote sessoes. . . . . . . . . . . . . . . 70

6.1 Fator Algoritmo de Escalonamento. . . . . . . . . . . . . . . . 77

6.2 Tempo médio em fila das sessões finalizadas. . . . . . . . . . . . . . . . . . 79

6.3 Tempo médio de resposta das requisições pertencentes às sessões finalizadas. 80 
6.4 Tempo médio em fila das sessões finalizadas. . . . . . . . . . . . . . . . . . . 82

6.5 Tempo médio de resposta das requisições pertencentes às sessões finalizadas - $\mathrm{k}$

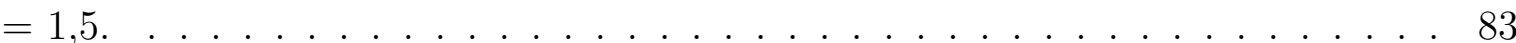

6.6 Fator Mecanismo de Controle de Admissão. . . . . . . . . . . . . . . . . . . . . 84

6.7 Fator Algoritmo de Controle de Admissão. . . . . . . . . . . . . . . . . . . . . . 85

6.8 Porcentagem de sessões finalizadas - mecanismo que limita o tamanho da fila. . . 89

6.9 Porcentagem de sessões finalizadas - mecanismo que limita a utilização média do

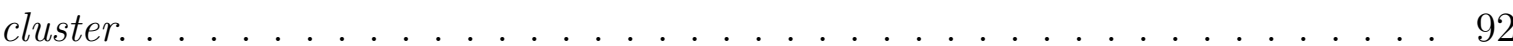

6.10 Influência dos fatores - mecanismos: que limita o tamanho da fila e a utilização média do cluster - algoritmos: CA-nBS e CA-BS. . . . . . . . . . . . . . . . . . 94

6.11 Influência dos fatores - mecanismos: que limita o tamanho da fila e a utilização média do cluster - algoritmos: CA-nBS e CA-Híb. . . . . . . . . . . . . . . . . . 95

6.12 Influência dos fatores - mecanismos: que limita o tamanho da fila e a utilização média do cluster - algoritmos: CA-BS e CA-Híb. . . . . . . . . . . . . . . . . 96

6.13 Porcentagem de descartes obtida pelos algoritmos Drop Tail e RED. . . . . . . . 98

6.14 Tempo de resposta das requisições. . . . . . . . . . . . . . . . . . . . . . . . . . 99

6.15 Influência dos fatores - algoritmos: Drop Tail e RED - limites para Drop Tail: 400 e 600 - limites THMIN-THMAX para o RED: 200-600 e 400-800 - peso da fila $(w q)$ para o RED: $0,2 \ldots \ldots \ldots$. . . . . . . . . . . . . . 100

6.16 Influência dos fatores - algoritmos: Drop Tail e RED - limites para Drop Tail: 400 e 700 - limites THMIN-THMAX para o RED: 200-600 e 550-850 - peso da fila $(w q)$ para o RED: $0,2 \ldots \ldots \ldots$. . . . . . . . . . . . . . . . . . . . . .

6.17 Influência dos fatores - algoritmos: Drop Tail e RED - limites para Drop Tail: 600 e 700 - limites THMIN-THMAX para o RED: 400-800 e 550-850 - peso da

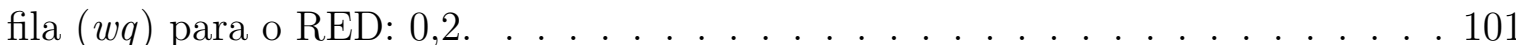

6.18 Influência dos fatores - algoritmos: Drop Tail e RED - limites para Drop Tail: 400 e 600 - limites THMIN-THMAX para o RED: 200-600 e 400-800 - peso da fila $(w q)$ para o RED: $0,42 \ldots \ldots \ldots$. . . . . . . . . . . . . . . . . . . . . . .

6.19 Influência dos fatores - algoritmos: Drop Tail e RED - limites para Drop Tail: 400 e 700 - limites THMIN-THMAX para o RED: 200-600 e 550-850 - peso da fila $(w q)$ para o RED: $0,42 \ldots \ldots \ldots$. . . . . . . . . . . . . . . . . . . . . . . .

6.20 Influência dos fatores - algoritmos: Drop Tail e RED - limites para Drop Tail: 600 e 700 - limites THMIN-THMAX para o RED: 400-800 e 550-850 - peso da fila $(w q)$ para o RED: $0,42 \ldots \ldots \ldots$. . . . . . . . . . . . . . . 102 
6.21 Influência dos fatores para o algoritmo RED - THMIN-THMAX: 200-600 e 400$800-(w q): 0,2$ e $0,42 \ldots \ldots \ldots \ldots \ldots \ldots$

6.22 Influência dos fatores para o algoritmo RED - THMIN-THMAX: 200-600 e 550$850-(w q): 0,2$ e $0,42 . \ldots \ldots \ldots \ldots \ldots$

6.23 Influência dos fatores para o algoritmo RED - THMIN-THMAX: 400-800 e 550$850-(w q): 0,2$ e $0,42 \ldots \ldots \ldots \ldots$

6.24 Porcentagem de sessões finalizadas - algoritmo RED-SB. . . . . . . . . . . . . 106

6.25 Influência dos fatores - mecanismo que limita o tamanho da fila e RED-SB algoritmos: CA-nBS e CA-BS. . . . . . . . . . . . . . . . . . 107

6.26 Influência dos fatores - mecanismo que limita o tamanho da fila e RED-SB algoritmos: CA-nBS e CA-Híb. . . . . . . . . . . . . . . . . 108

6.27 Influência dos fatores - mecanismo que limita o tamanho da fila e RED-SB algoritmos: CA-BS e CA-Híb. . . . . . . . . . . . . . . . . . . . . . . . 109

6.28 Influência dos fatores - mecanismo que limita a utilização média do cluster e RED-SB - algoritmos: CA-nBS e CA-BS. . . . . . . . . . . . . . . . . . 110

6.29 Influência dos fatores - mecanismo que limita a utilização média do cluster e RED-SB - algoritmos: CA-nBS e CA-Híb. . . . . . . . . . . . . . . . . 111

6.30 Influência dos fatores - mecanismo que limita a utilização média do cluster e RED-SB - algoritmos: CA-BS e CA-Híb. . . . . . . . . . . . . . . . 112 



\section{Lista de Tabelas}

2.1 Métodos definidos pelo protocolo HTTP/1.1. . . . . . . . . . . . 16

2.2 Classes de códigos de status das respostas HTTP. . . . . . . . . . . . . . . 18

5.1 Principais características das cargas de trabalho. . . . . . . . . . . . . 60

5.2 Distribuições para modelar os intervalos de chegada de requisições em uma sessão

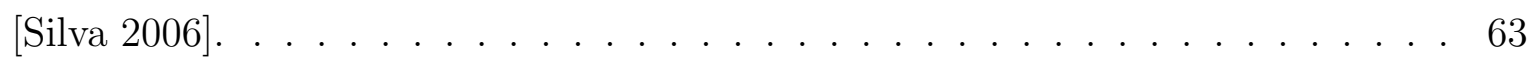

5.3 Domínio de valores para os componentes da requisição. . . . . . . . . . . . . 68

6.1 Avaliação dos algoritmos de CA - mecanismo que limita o tamanho da fila. . . . 88

6.2 Avaliação dos algoritmos de CA - mecanismo que limita a utilização média do cluster. . . . . . . . . . . . . . . . . . . . 91

6.3 Configuração dos testes realizados. . . . . . . . . . . . . . . . . . 98

6.4 Avaliação do mecanismo RED-SB . . . . . . . . . . . . . . . . . . . 105 



\section{Lista de Acrônimos}

API - Application Programming Interface

ASP - Active Server Pages

ATM - Asynchronous Transfer Mode

CA-BS - Controle de Admissão Baseado em Sessão

CGI - Common Gateway Interface

CA-Híb - Controle de Admissão Híbrido

CA-nBS - Controle de Admissão não Baseado em Sessão

DoS - Denial of Service

DNS - Domain Name Server

DSQ - Dynamic Single Queue

EBS - Exigency-Based Scheduling

EDF - Earliest Deadline First

FIFO - First In First Out

FCFS - First Come First Served

FTP - File Transfer Protocol

HTML - Hypertext Markup Language

HTTP - Hypertext Transfer Protocol

IETF - Internet Engineering Task Force

IP - Internet Protocol

JDBC - Java Database Connectivity

JMS - Java Message Service

JSP - Java Server Pages

LDAP - Lightweight Directory Access Protocol

MQ - Multiple Queue

PHP - Hypertext Preprocessor

PPP - Point-to-Point Protocol 
PCV - Proportional Cumulative Value Attribution

QoS - Quality of Service

QoWS - Quality of Web Services

RED - Randon Early Detection

RED-SB - RED Session Based

RSVAdap - Reserva Adaptativa de Recursos

RSVP - Resource Reservation Protocol

RTT - Round-Trip Time

SBAC - Session Based Admission Control

SBSA - Session-Based Scheduling Algorithm

SBSA-DS - Session-Based Scheduling Algorithm with Differentiated Services

SLA - Service Level Agreements

SMTP - Simple Mail Transfer Protocol

SPEC - Standard Performance Evaluation Corporation

SQ - Single Queue

SQF - Shortest Queue First

SWDS - Servidor Web com Diferenciação de Serviços

SWE-C - Servidor Web para E-Commerce

TCP - Transmission Control Protocol

ToS - Type of Service

UDP - User Datagram Protocol

UML - Unified Modeling Language

URL - Uniform Resource Locators

W4Gen - World Wide Web Workload Generator

WFQ - Weighted Fair Queuing

WWW - World Wide Web 
$\Gamma_{\text {Capítulo } 1 \longrightarrow}$

\section{Introdução}

\subsection{Contextualização e Motivação}

Até a década de 90, a Internet era usada basicamente nas comunidades científicas e acadêmicas, em geral para serviços como FTP e e-mail. Após o surgimento da World Wide $W e b$, diversas novas aplicações surgiram, como as aplicações multimídia, serviços bancários e e-commerce, aumentando de forma intensa o tráfego da Internet, e tornando-a um dos mais importantes meios de comunicação. No entanto, a Internet não foi projetada para o uso atual com o alto tráfego que suporta. Seu serviço é baseado no modelo de melhor esforço (Best Effort) e como conseqüência, não se pode dar às aplicações como e-commerce, que exigem também grandes esforços dos servidores $W e b$, as melhores condições de atendimento e garantias quanto ao serviço.

Para superar este serviço de melhor esforço, existem algumas opções disponíveis, como a arquitetura de Serviços Integrados [Braden et al. 1994] e a arquitetura de Serviços Diferenciados [Blake et al. 1998]. Estas arquiteturas possuem propostas diferentes para oferecer Qualidade de Serviço (Quality of Service - QoS) em nível de rede.

A arquitetura de Serviços Diferenciados tem se mostrado uma solução eficiente não só em nível de rede como também nível de aplicação, pois, para garantir QoS é necessário que todos os elementos envolvidos ofereçam essa qualidade de serviço, inclusive os servidores $W e b$. Como são os servidores $W e b$ os elementos finais envolvidos no processo e responsáveis pelo atendimento das requisições dos usuários, se elas forem todas tratadas igualmente por esses servidores, sem nenhum tipo de priorização, os esforços para oferecer QoS em nível de rede poderão ser perdidos. Além disso, verifica-se que nem todas as transações são equivalentes ou têm a mesma prioridade 
para os usuários [Dovrolis and Ramanathan 1999].

Neste contexto, Cardellini et al. [Cardellini et al. 2001] introduziram o conceito de "Quality of Web Services" (QoWS), inspirado nos Princípios de Garantia de QoS em nível de rede definidos por Kurose and Ross [Kurose and Ross 2010]. Esses princípios são: classificação, isolamento, alta utilização dos recursos e controle de admissão.

Cardellini et al. [Cardellini et al. 2001] e Andreolini et al. [Andreolini et al. 2004] mostram que para os servidores Web alcançarem os Acordos de Nível de Serviços (Service Level Agreements - SLA) firmados com os clientes, é preciso que todos os princípios de QoWS sejam satisfeitos. Caso o sistema use uma política que não satisfaça algum princípio de QoWS, os resultados podem estar dentro de níveis aceitáveis, mas não se pode garantir os SLAs para um cenário altamente variável, com diferentes cargas e condições, tal como ocorre em sistemas de servidores $W e b$.

As políticas para diferenciação de serviços e as políticas de controle de admissão são essenciais para que os servidores $W e b$ consigam fornecer QoS a seus clientes. O isolamento pode ser adquirido por meio de políticas de escalonamento e/ou de particionamento de recursos [Andreolini et al. 2004]. O controle de admissão, por sua vez, previne a sobrecarga do sistema e permite que os SLAs sejam respeitados, através das informações de carga coletadas do próprio sistema e dos acordos estabelecidos com os clientes.

As políticas de escalonamento e/ou particionamento e as políticas de controle de admissão para servidores Web têm sido bastante exploradas e, em geral, os trabalhos consideram a diferenciação de serviços tratando as requisições individualmente, sem considerá-las como parte de uma sessão, ou seja, uma seqüência de requisições relacionadas, pertencentes a um mesmo cliente [Arlitt 2000] [Chen and Mohapatra 2002] [Cherkasova and Phaal 2002]. Mas a maioria das requisições para servidores $W e b$, por exemplo, de e-commerce, estão contidas em sessões.

Além do fornecimento de QoS por meio de políticas, outros pontos devem ser ressaltados em relação aos servidores Web: a sua arquitetura, e a geração de uma carga de trabalho realista para avaliá-los.

Atualmente, devido ao aumento da quantidade de serviços e dados disponibilizados na Web, é importante que os servidores Web sejam escaláveis, ou seja, tenha-se condições de aumentar a sua capacidade gradativamente, para suportar a quantidade de carga que lhe é imposta, mantendo assim, o desempenho. A escalabilidade pode ser obtida através de uma arquitetura distribuída. Assim, além da escalabilidade, o servidor pode fornecer todas as vantagens de um sistema distribuído, como confiabilidade e aumento do desempenho, características importantes para que os servidores $W e b$ forneçam melhores serviços. 
O outro ponto a ser considerado é a dificuldade de se obter uma carga ou modelo de carga de trabalho que represente a carga da $W e b$ fielmente, por este ser um ambiente altamente variável e imprevisível. Muitos trabalhos encontrados na literatura usam logs de acesso a sites reais para saturar o sistema a ser avaliado, entretanto, esses logs podem não representar toda a carga imposta a $W e b$.

Traldi et al. [Traldi et al. 2006] e Barbato et al. [Barbarto et al. 2006] analisaram o comportamento de políticas de escalonamento e de controle de admissão para servidores Web, considerando como carga de trabalho o log coletado através dos acessos feitos ao site da copa do mundo de 1998. Como as avaliações foram feitas considerando um único log, a influência de diferentes tipos de carga de trabalho não foi avaliada.

Mourão [Mourão 2006] propõe uma forma de reconhecer sessões, também baseada nos acessos descritos no log da copa de 1998.

Modesto [Modesto et al. 2005] realizou um estudo sobre a Web brasileira, utilizando-se de um log coletado em março de 2005. Assim, foram obervadas características como tipos de domínios, código de resposta, tipos de arquivos transferidos, número de páginas por site Web. O trabalho não incorporou as características das sessões de usuários.

Silva [Silva 2006] realizou um estudo sobre caracterização de cargas de trabalho, tendo identificado quatro tipos de carga e suas principais características, e desenvolveu um gerador de cargas de trabalho sintéticas. O trabalho realizado também não considerou sessões.

Chehadeh et al. [Chehadeh et al. 2006] realizaram um estudo baseado em acessos a sites Web, e obtiveram estatísticas para tamanhos e ocorrências de tipos de objetos.

Tang [Tang 2007] desenvolveu um gerador de carga também baseado em requisições individuais, baseado em modelos estatísticos. A carga gerada pela ferramenta é baseada nas requisições de dois servidores de mídia da HP (Hewlett-Packard), em que um que servia a uma rede corporativa, e outro que servia uma rede acadêmica. Trata-se de um gerador sintético no qual é possível definir vários parâmetros em um arquivo de entrada, que irão influenciar diretamente o perfil da carga de trabalho gerada.

De La Sierra [de la Sierra 2009] realizou um estudo sobre tráfego da Internet, baseado em rajadas, e com intervalos de chegada que, normalmente, seguem uma distribuição de cauda pesada, e seu efeito nos servidores Web. E também implementou um benchmark para servidores $W e b$ que gera cargas com um comportamento pré-estabelecido, simulando as características das páginas acomodadas em um servidor Web.

Teixeira [Teixeira 2004] propôs um modelo de servidor Web distribuído modelado através de Rede de Filas. Ye et al. [Ye et al. 2005] propõe dois modelos para serviores Web, um 
com QoS sequencial, e o outro, com diferenciação de serviços. Shan et al. [Shan et al. 2005] implementam um prótotipo de servidor Web, chamado QoS Apache.

Sabo [Sabo 2006] propôs um modelo de servidor Web para e-commerce composto por um cluster de servidores Web. Neste trabalho empregou-se uma carga de trabalho sintética modelada usando os principais tipos de requisições que distinguem um site de e-commerce.

Guiesi Júnior [Guiesi Júnior 2008] apresenta um modelo de servidor Web baseado em Rede de Filas, que representa os elementos internos de um servidor Web. Esse modelo possui quatro módulos, sendo que cada um deles é responsável por uma etapa do atendimento de uma requisição, como a transferência de um arquivo para a memória principal e o seu envio ao cliente. Ao ser atendida por um dos módulos, é atribuído um tempo de execução, baseado em trabalhos que desenvolveram benchmarks para servidores $W e b$ reais.

\subsection{Objetivos}

O objetivo principal deste trabalho é o desenvolvimento de um gerador de cargas de trabalho para servidores $W e b$ que representem sessões. O gerador deverá gerar cargas para serem utlizadas em simulação de servidores $W e b$.

O gerador de carga deverá acrescentar o conceito de sessões ao gerador de carga de trabalho sintética desenvolvido por Silva [Silva 2006], o W4Gen. Esse gerador terá como base para a definição de sessões e seu desenvolvimento o benchmark HTTPerf.

Algoritmos para controle de admissão e escalonamento baseadas em sessões serão executados com a carga gerada visando a validação do gerador desenvolvido.

\subsection{Estrutura da Monografia}

Esta monografia está organizada no seguinte formato:

No Capítulo 2 é apresentada a infra-estrutura da Internet, e seus protocolos e, uma visão geral da $W e b$, discutindo-se sobre o protocolo da camada de aplicação responsável pela comunicação entre os servidores $W e b$ e seus clientes, o HTTP.

No Capítulo 3 discute-se o fornecimento de QoS em nível de rede e a importância do QoS em nível de aplicação. As arquiteturas para implementação de servidores $W e b$ são apresentadas e, discute-se o conceito de sessões para servidores $W e b$. Ao final, são apresentados alguns modelos de servidores $W e b$ com suporte a QoS encontrados na literatura. 
No Capítulo 4 são apresentados algoritmos para controle de admissão e algoritmos para diferenciação de serviços em servidores $W e b$, divididas em algoritmos de escalonamento e de particionamento de recursos.

No Capítulo 5, é apresentado o gerador de sessões sintéticas desenvolvido neste trabalho e discutida a sua implementação e modelo de carga gerada. Discute-se ainda sobre as ferramentas e trabalhos relacionados utilizados como base para o desenvolvimento do gerador.

No Capítulo 6, são apresentados os resultados obtidos com os experimentos realizados com algoritmos de escalonamento e de controle de admissão. Inicialmente, discuti-se os resultdos obtidos com algoritmos que possuem o tratamento de sessões de usuários, a fim de validar a carga de trabalho utilizada. Posteriormente, são experimentados dois algoritmos de controle de admissão baseados em requisições individuais. Finalmente, é definido um novo algoritmo de controle de admissão com tratamento de sessões, e os resultados obtidos por meio de experimentos são relatados.

Finalmente, no Capítulo 7 são mostradas as conclusões obtidas, apresentando uma visão geral do trabalho, discutindo-se as principais contribuições e fornecendo indicações para trabalhos futuros. 
${ }_{\text {Capítulo }} 2$

\section{A Internet e seus Serviços}

\subsection{Considerações Iniciais}

A Internet é um conjunto de redes formada por componentes de hardware e software, que provê serviços para aplicações distribuídas [Kurose and Ross 2010]. Trata-se de uma rede mundial de computadores, composta de diversas redes menores e distintas, que se comunicam e cooperam entre si [Meira et al. 2002].

O desenvolvimento da Internet se deu a partir dos anos 60, com o surgimento da comutação de pacotes, e a criação da ARPAnet, a primeira rede de computadores por comutação de pacotes e uma ancestral da Internet atual.

Financiada pelo Departamento de Defesa (Department of Defense) dos EUA, a Internet era usada basicamente por pesquisadores e acadêmicos para transferência de arquivos, troca de mensagens e pesquisas científicas, até a década de 90, quando surgiu a WWW (World Wide $W e b)$, tornando-a conhecida fora desses ambientes.

O uso da Internet se disseminou, passando a ser utilizada por qualquer pessoa que deseja publicar e/ou acessar informações e, cada vez mais para fins comerciais. Algumas das razões dessa grande disseminação da Web incluem: a facilidade de seu uso, a disponibilidade de uma interface gráfica amigável e simples e, o grande número de informações sobre diversos assuntos. Essa popularização tornou-a muito maior do que seus criadores poderiam presumir e, devido à intensidade do tráfego da rede, nota-se que ela está sobrecarregada, apresentando problemas de desempenho [Teixeira 2004].

Este capítulo aborda uma visão geral da Internet, apresentando a pilha de protocolos da arquitetura TCP/IP que constituem a sua infra-estrutura. Discute-se o principal serviço ofere- 
cido pela Internet, a World Wide Web, maior responsável pelo seu desenvolvimento. Também discute-se o paradigma cliente servidor e o protocolo de comunicação HTTP (Hypertext Transfer Protocol).

\section{$2.2 \quad$ A Pilha de Protocolos da Internet}

Um protocolo de comunicação define o formato e a ordem das mensagens trocadas entre duas ou mais entidades comunicantes, bem como as ações realizadas na transmissão e/ou recebimento de uma mensagem ou outro evento [Kurose and Ross 2010].

Os protocolos são organizados em camadas, para que haja uma estrutura que facilite seu projeto.

Quando os protocolos das várias camadas são tomados em conjunto, eles são chamados de pilha de protocolos. Essa pilha é formada por cinco camadas: de aplicação, de transporte, de rede, de enlace e física [Kurose and Ross 2010]. Na Figura 2.1 apresenta-se a pilha de protocolos da Internet, juntamente com o conceito de encapsulamento, em que a mensagem original recebida da camada anterior não é modificada, apenas é acrescentado um cabeçalho extra percentente à camada corrente.

\begin{tabular}{|c|c|c|}
\hline Camada 5 & Aplicação & Mensagem \\
\hline Camada 4 & Transporte & Segmento \\
\hline Camada 3 & Rede & Datagrama \\
\hline Camada 2 & Enlace & Quadro \\
\hline Camada 1 & Física & \\
\hline
\end{tabular}

Figura 2.1: Pilha de protocolos da Internet.

Uma mensagem gerada na camada de aplicação é passada para a camada de transporte, em que são anexadas as informações de cabeçalho da camada de transporte, constituindo o segmento de camada de transporte. A camada de transporte, por sua vez, passa o segmento para a camada de rede, que adiciona informações de cabeçalho da camada de rede, encapsulando o segmento, e construindo um datagrama de camada de rede. Este é então passado para a camada de enlace, que adiciona suas informações e cria um quadro da camada de enlace. 


\subsubsection{Camada de Aplicação}

A camada de aplicação é responsável pelo suporte as aplicações de rede e seus protocolos. Geralmente, um protocolo de aplicação possui um lado cliente e um lado servidor.

A camada de aplicação inclui protocolos como HTTP (Hypertext Transfer Protocol), para prover requisição e transferência de arquivos pela Web, SMTP (Simple Mail Transfer Protocol), para oferecer transferência de mensagens de correio eletrônico, FTP (File Transfer Protocol), para permitir transferência de arquivos entre dois sistemas finais, TELNET, utilizado para efetuar login remoto e, DNS (Domain Name Server), usado para mapear os nomes dos hosts em endereços de rede.

\subsubsection{Camada de Transporte}

A camada de transporte oferece o serviço de transporte das mensagens da camada de aplicação entre os lados do cliente e do servidor. Existem dois tipos de protocolos de transporte na Internet: o TCP (Transmission Control Protocol) e o UDP (User Datagram Protocol).

O TCP oferece serviços orientados à conexão, ou seja, ocorre uma troca de informações de controle da camada de transporte entre o cliente e o servidor antes que as mensagens da camada de aplicação comecem a ser transmitidas. Alguns destes serviços orientados à conexão oferecidos pelo TCP incluem a divisão das mensagens em segmentos menores e remontagem no destino, entrega garantida de mensagens, sem erros e na ordem correta (pois os segmentos de mensagens recebidos são reorganizados na entrada), reenvio de todas as mensagens não recebidas, controle de fluxos (ajuste das velocidades do remetente e transmissor), e controle de congestionamento quando a rede está congestionada.

O UDP fornece um serviço não orientado à conexão, oferecendo um serviço de transferência de dados não confiável e usado em aplicações em que a velocidade de transmissão é mais importante que a entegra precisa, como por exemplo, transmissão de áudio de vídeo. O UDP não inclui um mecanismo de controle de congestionamento e, assim como o TCP, não oferece garantias em relação a atrasos.

\subsubsection{Camada de Rede}

A camada de rede é a responsável por movimentar datagramas de uma máquina de origem para uma máquina de destino. O protocolo utilizado na camada de transporte (TCP ou UDP) transmite um segmento e um endereço de destino à camada de rede, na máquina de origem, e 
então, a camada de origem entrega o segmento à camada de transporte na máquina de destino.

A camada de rede da Internet trabalha com dois protocolos, o IP e um protocolo de roteamento a escolha do administrador. O IP define os campos no datagrama e a maneira como os sistemas finais e os roteadores atuam nesses campos. Todos os componentes da Internet que tem uma camada de rede usam esse protocolo. O protocolo de roteamento determina as rotas que os datagramas seguem entre a origem e o destino. A Internet possui vários protocolos de roteamento, como o RIP (Routing Information Protocol) [Hedrick 1988; Malkin 1994] e o OSPF (Open Shortest Path First) [Moy 1997].

Apesar da camada de rede executar o IP e diversos protocolos de roteamento, ela é, geralmente, chamada de camada IP, demonstrando o fato de que o IP é o componente essencial que mantém a integridade da Internet. Atualmente, estão sendo usadas duas versões do protocolo IP: o IPv4 e o IPv6 [Kurose and Ross 2010]. A necessidade primária para o desenvolvimento de um sucessor para o IPv4 foi a maior capacidade de endereçamento.

Os protocolos TCP e IP são os mais importantes da Internet, chamados em conjunto de TCP/IP. Esses protocolos destacam-se por funcionar em um grande número de arquiteturas de rede diferentes, como cabos coaxiais, fibras óticas e redes sem fio, e por permitir que as aplicações sejam escritas em um alto grau de abstração utilizando a API (Application Programming Interface) de sockets, omitindo a maneira como a comunicação realmente ocorre.

Como principais características que distinguem o TCP/IP dos demais protocolos, podem ser citadas: o uso de padrões abertos, estando disponível gratuitamente e sendo independente de plataforma; independência da tecnologia de rede, pois usa comutação de pacotes para realizar a comunicação e funciona sobre diversos protocolos das camadas física e de enlace; são protocolos padronizados não apenas em nível de rede e de transporte, como também em nível de aplicação; interconexão total, permitindo que cada dispositivo conectado a uma rede TCP/IP receba um endereço único, se comunique e seja acessível de qualquer ponto da rede; e, confirmações fim a fim entre a origem e o destino de uma comunicação, e não somente entre pares de máquinas ao longo do percurso, o que torna a entrega de dados mais confiável [Hunt 2002] [Comer 2006].

\subsubsection{Camada de Enlace}

A camada de rede roteia um datagrama usando vários roteadores de pacotes entre a origem e o destino. Para transmitir um pacote de um nó ao nó seguinte na rota, a camada de rede depende dos serviços da camada de enlace, que é responsável por essa entrega ao longo dos nós da rota. 
Os serviços prestados pela camada de enlace dependem do protocolo utilizado, alguns exemplos são Ethernet, PPP (Point-to-Point Protocol), ATM (Asynchronous Transfer Mode) e a rede Frame Relay. Como os datagramas geralmente trafegam por diversos enlaces entre a origem e o destino, eles podem ser manuseados por diferentes protocolos dessa camada ao longo da rota e, a camada de rede receberá um serviço diferente de cada um dos vários protocolos.

\subsubsection{Camada Física}

A tarefa da camada de enlace é movimentar quadros de um nó da rede até o nó seguinte da rota e o da camada física é movimentar os bits que pertencem a esses quadros. Os protocolos desta camada dependem do enlace e do meio de transmissão do enlace. Por exemplo, a Ethernet possui um protocolo para par de fios trançado, um para cabo coaxial, um para fibra ótica e, em cada um desses casos, os bits são movimentados de maneira diferente pelo enlace.

Uma camada de protocolo pode ser implementada em software, hardware ou em ambos. Os protocolos da camada de aplicação e de transporte são implementados quase sempre em software nos sistemas finais. Como a camada física e a de enlace de dados são responsáveis por manipular a comunicação por um enlace específico, geralmente são implementadas em uma placa de interface de rede associadas a um determinado enlace. A camada de rede normalmente é uma implementação mista de hardware e software.

\subsection{World Wide Web (WWW)}

A WWW é formada, basicamente, por documentos denominados páginas Web, desenvolvidas geralmente em HTML (Hypertext Markup Language) [W3C 1999]. As tags da HTML descrevem a estrutura da página, fornecem informações sobre sua formatação e estabelece links com outros documentos ou páginas relacionadas. A HTML constitui um padrão de grande portabilidade.

Uma página Web é composta de objetos, ou seja, arquivos, como de imagem JPEG ou de texto HTML. A maioria das páginas Web é formada por um arquivo-base HTML e vários objetos relacionados por meio de suas URLs. Uma URL (Uniform Resource Locators) é constituída de (Figura 2.2):

- Protocolo - informa o nome do protocolo empregado para o transporte dos dados; 
- Nome do Servidor - apresenta o endereço IP ou o nome do hospedeiro do servidor no qual o objeto requisitado está localizado;

- Número da Porta - informa a porta na qual o processo servidor recebe as conexões. O valor padrão para o HTTP é 80, e para o FTP é 21;

- Localização do Recurso - informa o diretório no qual o arquivo está armazenado e o nome do arquivo.

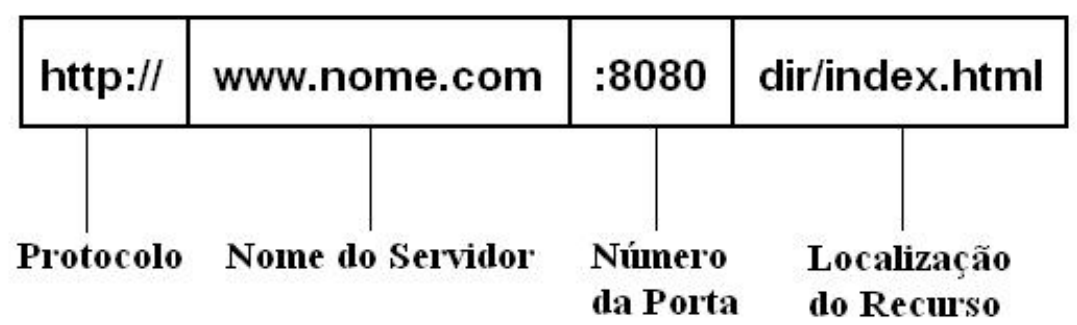

Figura 2.2: Estrutura de uma URL [Teixeira 2004].

O funcionamento da $W e b$ é baseado no paradigma cliente-servidor, em que há uma estrutura de interligação entre os documentos. Esta estrutura permite que um documento referencie outro distribuído geograficamente, ou seja, em outras máquinas na Internet. A Web é uma grande plataforma cliente-servidor, evidenciando a viabilidade deste paradigma em larga escala, numa rede mundial.

Um servidor Web é um processo que fica permanentemente aguardando por requisições vindas dos clientes. Ao chegar uma requisição, ele a interpreta e, caso seja válida, retorna ao cliente o objeto solicitado. Este objeto pode estar fisicamente armazenado no sistema de arquivos do servidor $W e b$, disponível para leitura, ou ser gerado dinamicamente por um aplicativo executado no servidor Web ou no próprio cliente, no momento em que o objeto é requisitado. Assim, as páginas Web podem ser classificadas como estáticas, ou dinâmicas, de acordo com a forma em que são geradas.

As páginas estáticas apresentam textos, imagens, e alguns recursos multimídia, como áudio e vídeo. Essas páginas são desenvolvidas em HTML e seu maior recurso são os links para outras páginas.

As páginas dinâmicas são geradas em tempo de processamento da requisição. Estas páginas possuem recursos como controle de formulários e janelas e, para sua geração são necessárias outras linguagens de programação além do HTML. Algumas tecnologias utilizadas para gerar 
páginas dinâmicas no lado cliente são: Java, ActiveX e Dynamic HTML. Esses recursos são executados diretamente pelo browser e existe a vantagem de se reduzir o tempo de resposta e o uso excessivo dos recursos de rede [Menascé and Almeida 2003]. Algumas tecnologias de criação de páginas dinâmicas no lado servidor são ASP (Active Server Pages), PHP (Hypertext Preprocessor) e JSP (Java Server Pages). A geração de páginas dinâmicas pelo servidor pode acarretar um alto consumo do processador do servidor $W e b$, caso as aplicações sejam complexas, causando sobrecarga.

Para a comunicação entre os clientes e servidores Web é utilizado o protocolo HTTP, que funciona sobre o protocolo TCP.

\subsection{Protocolo HTTP}

O HTTP é o protocolo da camada de aplicação que define como as mensagens trocadas entre clientes e servidores $W e b$ são formatadas e transmitidas, ou seja, como os clientes $W e b$ - browsers ou navegadores - solicitam páginas aos servidores, e como os servidores transferem essas páginas aos clientes.

Quando uma página Web é solicitada, o browser envia ao servidor mensagens de requisição HTTP para os objetos da página e o servidor, por sua vez, responde com mensagens de resposta HTTP que contém os objetos.

O HTTP é considerado stateless [Orfali et al. 1999], ou protocolo sem estado, pois o servidor não guarda informações de estado dos clientes. Se um cliente solicita um mesmo objeto duas vezes em um pequeno intervalo de tempo, o servidor envia novamente o objeto, e também, em caso de falhas durante a comunicação, é responsabilidade do cliente enviar novamente a requisição.

Para solucionar essa deficiência, uma extensão do protocolo HTTP faz uso de cookies, permitindo os servidores definir informações armazenadas pelos browsers. Cookies são blocos de informações que servidores podem enviar para os browsers em campos especiais do protocolo HTTP, junto com a resposta. Eles permitem que os servidores identifiquem os usuários e as suas requisições que já foram atendidas.

Os browsers e os servidores Web implementavam a versão HTTP/1.0, definida no RFC 1945 [Berners-Lee et al. 1996] e, a partir de 1999, foi lançada a versão HTTP/1.1, definida no RFC 2616 [Fielding et al. 1999], compatível com a versão 1.0. O HTTP/1.0 usa conexões não persistentes, e o modo padrão do HTTP/1.1 usa conexões persistentes. O esquema de troca de mensagens realizado entre cliente e servidor $W e b$, para os protocolos $\mathrm{HTTP} / 1.0$ e HTTP/1.1, 
é mostrado na Figura 2.3, e discutido na Seção 2.4.1.

HTTP/1.0 possui uma série de conexôes, uma para cada Requisição/Resposta.

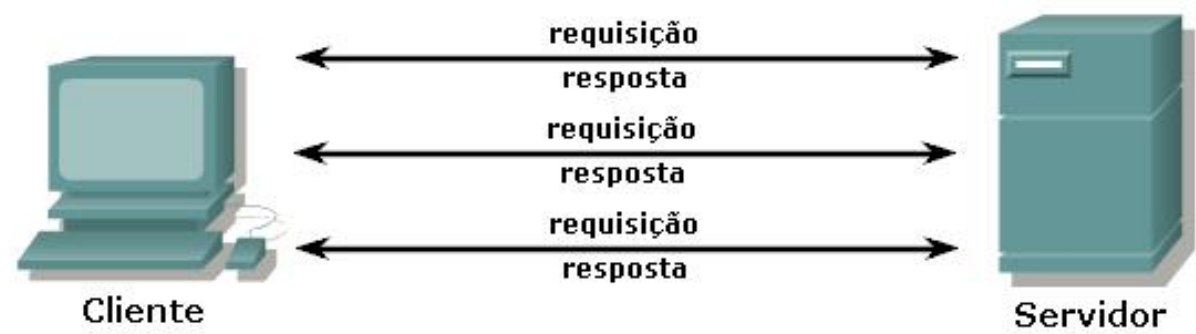

HTTP/1.1 possui várias sessôes ativas utilizando uma única conexão.

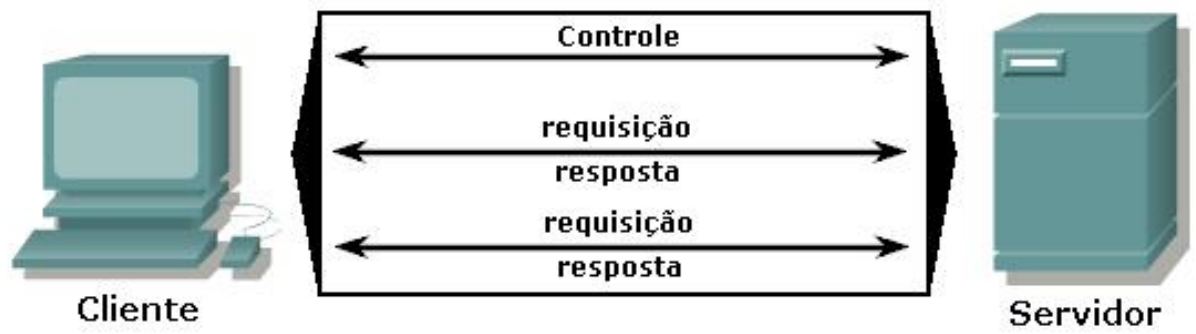

Figura 2.3: Funcionamento do protocolo HTTP [Silva 2006].

\subsubsection{Conexões Não Persistentes e Conexões Persistentes}

Como discutido anteriormente, uma página $W e b$ é constituída de um arquivo-base HTML e outros diversos objetos. No caso de conexões não persistentes, para cada requisição de objeto feita ao servidor, uma conexão TCP é aberta e cada conexão é fechada depois que o servidor envia o objeto, não persistindo para outros objetos. Assim, cada conexão TCP transporta exatamente uma mensagem de requisição HTTP e uma mensagem de resposta HTTP. As conexões TCP podem ocorrer em série ou pode haver um grau de paralelismo entre conexões TCP, controlado pelos navegadores. Nos modos padrão, a maioria dos navegadores abre de cinco a dez conexões TCP paralelas e, cada uma delas manipula uma transação requisição/resposta [Kurose and Ross 2010].

Como para cada conexão devem ser alocados buffers e variáveis do TCP no cliente e no servidor, as conexões não persistentes podem sobrecarregar o servidor $W e b$, pois o número de clientes atendidos ao mesmo tempo por um servidor pode ser grande [Kurose and Ross 2010]. 
Outra desvantagem é que para cada objeto transmitido há um atraso de dois RTTs (RoundTrip Time): um RTT para estabelecer a conexão TCP e outro para solicitar e receber o objeto. Além disso, o mecanismo de controle de congestionamento do TCP faz com que as conexões iniciem sua transmissão dos dados a uma velocidade relativamente baixa, para prevenir um possível congestionamento da rede. Essa fase de partida lenta do TCP faz com que cada objeto suporte esse início vagaroso, no caso das conexões não persistentes.

Nas conexões persistentes, a conexão TCP aberta é mantida pelo servidor após ter enviado uma resposta. Assim, as requisições e respostas seguintes podem ser enviadas pela mesma conexão. Quando a conexão não é usada durante um determinado intervalo de tempo, o servidor $W e b$ a fecha.

As conexões persistentes podem ser em série ou com paralelismo. Nas conexões sem paralelismo, o cliente envia uma nova requisição somente quando a resposta à requisição anterior foi recebida. Já nas conexões com paralelismo, o cliente $W e b$ envia uma requisição assim que ele encontra uma referência para algum objeto.

\subsubsection{Mensagens HTTP}

O protocolo HTTP define dois tipos de mensagem: de requisição e de resposta.

A mensagem de requisição, definida pelo protocolo HTTP, é formada tipicamente pelos seguintes campos:

- Linha de Requisição - linha que informa a ação a ser executada no servidor, ou seja, o método invocado, a localização do objeto no servidor e a versão do protocolo HTTP utilizada;

- Linhas de Cabeçalho - uma ou mais linhas de cabeçalho que podem ser usadas pelo cliente, para enviar informações ao servidor, por exemplo, os tipos de dados que ele é capaz de aceitar;

- Corpo da Mensagem - é usado quando dados adicionais do cliente devem ser enviados ao servidor. Este campo é opcional.

Um exemplo de uma mensagem de requisição é mostrado na Figura 2.4, em que o cliente solicita (GET) o arquivo /index.html localizado no diretório /dir do servidor www.nome.com usando o protocolo HTTP/1.1. O campo Connection é responsável pelas conexões persistentes, neste caso, a conexão será fechada, mesmo sendo um cliente HTTP/1.1, pois este campo está 
definido como close. O campo Accept informa que o cliente é capaz de receber textos em formato HTML (text/html) e imagens em formato JPEG (image/jpeg). O tipo de navegador do cliente é especificado no campo User-agent (Mozzila, versão 4.0).

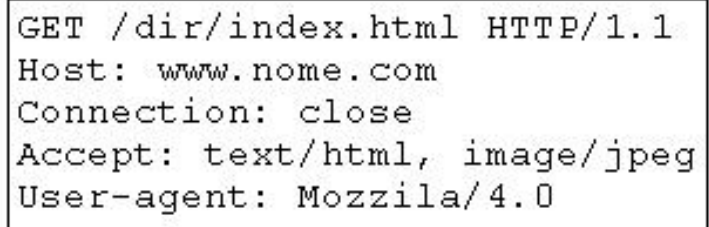

Figura 2.4: Exemplo de uma mensagem de requisição HTTP.

O cliente pode enviar comandos ao servidor invocando um conjunto de métodos definidos pelo protocolo HTTP. Na versão HTTP/1.0 estão definidos os métodos GET, HEAD e POST. Na versão HTTP 1.1 são acrescentados os métodos OPTIONS, PUT, DELETE, TRACE e CONNECT. Um resumo desses métodos pode ser visto na Tabela 2.1.

Tabela 2.1: Métodos definidos pelo protocolo HTTP/1.1.

\begin{tabular}{|c|c|}
\hline Método & Função \\
\hline GET & $\begin{array}{c}\text { Realiza uma requisição do objeto especificado pela URL, } \\
\text { contida na requisição. }\end{array}$ \\
\hline POST & $\begin{array}{l}\text { Envia informações adicionais do cliente para o } \\
\text { servidor } W e b \text { no corpo da mensagem, geralmente dados } \\
\text { digitados em formulários HTML. }\end{array}$ \\
\hline HEAD & $\begin{array}{c}\text { Utilizado para obter informações a respeito de } \\
\text { um objeto, sem que seu conteúdo seja retornado ao cliente. } \\
\text { Testa a validade de links, acessibilidade e a data da } \\
\text { última atualização. }\end{array}$ \\
\hline OPTIONS & $\begin{array}{c}\text { Permite ao cliente obter as opções de comunicação } \\
\text { disponíveis e/ou requisitos associados ao recurso solicitado, } \\
\text { sem necessariamente, iniciar sua recuperação. }\end{array}$ \\
\hline$\overline{\mathrm{PUT}}$ & Cria ou modifica um recurso no servidor $W e b$. \\
\hline DELETE & $\begin{array}{c}\text { Solicita que o objeto identificado na URL seja apagado } \\
\text { no servidor } W e b .\end{array}$ \\
\hline TRACE & $\begin{array}{c}\text { Usado para enviar mensagem de teste ao } \\
\text { servidor } W e b .\end{array}$ \\
\hline CONNECT & $\begin{array}{l}\text { Reservado para comunicação com servidores } \\
\text { proxy. }\end{array}$ \\
\hline
\end{tabular}


A mensagem de resposta HTTP contém uma linha de status, linhas de cabeçalho uma linha em branco, e um corpo de mensagem opcional, como descrito a seguir:

- Linha de Status - contém três campos: o da versão do protocolo utilizado, uma codificação para o status e uma mensagem de estado que descreve o código correspondente;

- Linhas de Cabeçalho - contém vários campos com informações sobre as características do servidor e do objeto retornado ao cliente;

- Corpo da Mensagem - contém o objeto solicitado pelo cliente, antecedido por uma linha em branco.

Na Figura 2.5 é apresentado um exemplo de mensagem de resposta. A resposta do servidor mostra que ele está usando o HTTP/1.1 e que a requisição foi bem-sucedida, indicada pelo código 200 e pela mensagem de estado OK. A linha Connection, com o valor close, diz que a conexão TCP será fechada após o envio da mensagem. Os três campos seguintes informam a data e o horário da resposta, o tipo de servidor Web (Apache/ 1.3.31) e a última atualização do arquivo. O campo Content-Type mostra que o objeto retornado é um documento HTML, cujo tamanho é 3351 bytes, indicado pelo campo Content-Length. Após a linha em branco formada por um carriage return e um line feed, encontra-se o objeto, formado por (dado dado dado ...).

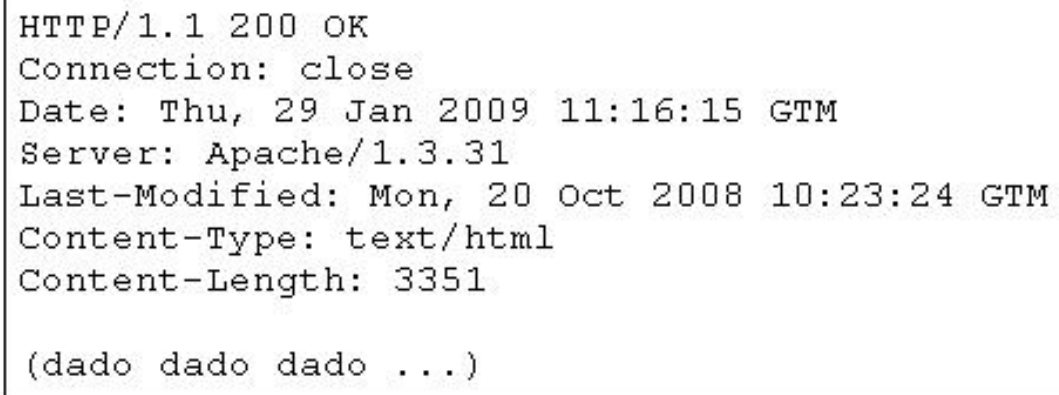

Figura 2.5: Exemplo de uma mensagem de resposta HTTP.

Os códigos de status, retornado pelo servidor Web para informar o resultado da execução realizada, apresentam-se divididos em classes, na Tabela 2.2 .

\subsection{Considerações Finais}

Este capítulo abordou inicialmente a estrutura da Internet, apresentando as camadas da pilha de protocolos que compõem a sua infra-estrutura, responsáveis pela comunicação. 
Tabela 2.2: Classes de códigos de status das respostas HTTP.

\begin{tabular}{||l||c|}
\hline \hline Classe & Descrição \\
\hline \hline $1 \mathrm{xx}$ & Finalidade informativa \\
\hline $2 \mathrm{xx}$ & Sucesso \\
\hline $3 \mathrm{xx}$ & Redirecionamento \\
\hline $4 \mathrm{xx}$ & Erro do cliente \\
\hline $5 \mathrm{xx}$ & Erro do servidor \\
\hline \hline
\end{tabular}

Apresentou-se uma visão geral da $W e b$, que tem seu funcionamento baseado no paradigma cliente-servidor, discutindo-se também o funcionamento do protocolo de aplicação mais importante para acesso aos servidores Web, o HTTP. O HTTP define como as mensagens trocadas entre os clientes e servidores, na camada de aplicação, são formatadas e transmitidas. Apresentou-se os formatos dessas mensagens HTTP e, discutiu-se sobre a sobrecarga que as conexões não persistentes podem causar nos servidores Web devido à alocação de buffers e variáveis do TCP para a transmissão de cada objeto, além do atraso para estabelecer a conexão e solicitar o objeto, multiplicado por cada objeto requisitado.

Todos os tópicos abordados neste capítulo são importantes para o trabalho a ser desenvolvido, uma vez que será tratado o principal serviço da Internet atualmente, a Web, mais especificamente, os servidores $W e b$, e a qualidade de serviço inerente a eles.

Assim, no próximo capítulo serão abordadas as limitações do serviço de melhor esforço adotado na Internet, que tem sido ineficiente para as atuais aplicações que requerem melhores serviços. As arquiteturas de Serviços Integrados (IntServ) e Serviços Diferenciados (DiffServ), que foram propostas como meios de fornecimento de qualidade de serviço em nível de rede, serão também discutidas.

Discute-se ainda, a necessidade da introdução de qualidade de serviço na camada de aplicação, algumas arquiteturas para implementação de servidores $W e b$, o conceito de sessão, um dos elementos-chave deste trabalho e, alguns modelos de servidores $W e b$ com provisão de serviços diferenciados. 


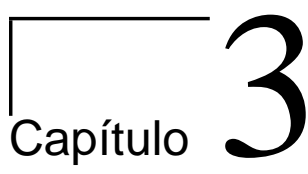

\section{Qualidade de Serviço na Internet}

\subsection{Considerações Iniciais}

No Capítulo 2, foram abordadas uma visão geral da pilha de protocolos da Internet, e da $W e b$, o funcionamento do protocolo de aplicação mais importante para acesso aos servidores $W e b$, o HTTP e, discutido sobre conexões persistentes e não persistentes. Este capítulo aborda o conceito de Qualidade de Serviço (Quality of Service - QoS), a QoS na Internet na forma de Serviços Integrados e Serviços Diferenciados, a QoS em nível de aplicação, a arquitetura de implementação dos servidores $W e b$ e o conceito de sessões.

Durante a exposição do protocolo HTTP, no Capítulo 2, comentou-se que este é um protocolo sem estado (stateless) [Orfali et al. 1999]. Isto significa que, o servidor não guarda informações sobre o estado dos clientes após enviar uma resposta contendo o objeto solicitado.

A utilização de um protocolo stateless foi apropriada no surgimento da Web, mas atualmente, ela adquiriu novas funcionalidades e, muitas vezes, o modelo se torna inadequado pois não guarda nenhuma informação sobre os clientes. Este é o caso de alguns servidores Web, como os que só permitem sua utilização após o registro de clientes. Assim, o servidor deve ser capaz de distinguir as requisições vindas de clientes registrados daquelas vindas de clientes que não são registrados. Para a utilização desse tipo de procedimento, necessita-se considerar o uso de sessões.

Assim, na Seção 3.6, será conceituado e discutido o uso de sessões pelos servidores $W e b$, apresentando-se alguns trabalhos relacionados encontrados na literatura e, ao final deste capítulo, aborda-se alguns modelos de servidores $W e b$ com diferenciação de serviços. 


\subsection{Qualidade de Serviço (Quality of Service - QoS)}

QoS refere-se a capacidade dos elementos da rede (roteadores e switchs) de fornecer uma medida de atraso e garantia de entrega de banda, mantendo os acordos de tráfego [Stardust 1999b], ou seja, fornecer um melhor serviço para determinados tráfegos de acordo com suas necessidades. A garantia de QoS está relacionada com a provisão de baixos atrasos de entrega e perdas de pacotes para determinadas aplicações ou tráfego [Zhao et al. 2000].

A QoS pode ser descrita de forma relativa ou absoluta. Na QoS absoluta são dadas garantias a cada fluxo, reservando os recursos ao longo do percurso para que esse fluxo possa ter suas exigências de QoS garantidas. A especificação em termos absolutos considera métricas a serem cumpridas, normalmente relacionadas a atrasos ou perda de pacotes, ou seja, todas as classes de serviço devem cumprir o contrato estipulado previamente, ao invés de priorizar uma classe em relação às demais. Caso a rede não seja capaz de garantir um serviço com a característica desejada, o fluxo não terá acesso ao meio de comunicação.

Na QoS relativa, os fluxos são divididos em diferentes classes de serviço e, a essas classes são dados tratamentos diferenciados de acordo com as suas prioridades. Neste caso, a rede garante que uma aplicação em uma classe de prioridade mais alta, sempre receberá um serviço melhor que o de qualquer classe inferior. No entanto, garantias em termos de métricas não são possíveis para as aplicações, pois a QoS resultante depende da carga na rede em determinado instante, em cada classe [Vasiliou 2000].

É possível identificar dois aspectos importantes dentro do tema de QoS: garantia de desempenho e diferenciação de serviços [Zhao et al. 2000]. O primeiro se relaciona com o gerenciamento de largura de banda, perda de pacotes, atraso e variação do atraso. A largura de banda é o recurso mais importante e a sua disponibilidade e forma de alocação, afetam as outras características. A diferenciação de serviços consiste em fornecer diferentes níveis de QoS para diferentes fluxos segundo seus requisitos. A diferenciação de serviços, geralmente, está relacionada à QoS relativa pois garante apenas que a classe de mais alta prioridade receba um serviço melhor que qualquer classe de mais baixa prioridade [Peixoto et al. 2008].

O protocolo IP que oferece suporte a Internet fornece um serviço de melhor esforço para todos os datagramas que transporta, ou seja, a Internet faz seu melhor esforço para transportar os dados o mais rápido possível. No entanto, o serviço de melhor esforço não oferece garantias quanto aos atrasos. Dessa forma, desenvolver aplicações de sucesso na Internet que dependam da entrega de dados com garantias de temporização rígidas, é um problema desafiador, especialmente quando há congestionamentos. 
Uma possibilidade para que a Internet atenda melhor as aplicações com limitações rígidas de temporização é, adicionar mais largura de banda, ao invés de realizar modificações no serviço de melhor esforço e em seus protocolos. Porém, adicionar largura de banda pode ser dispendioso, uma vez que a Internet é uma grande rede formada por redes, compreendendo diversas tecnologias e, portanto, não sendo tão simples incrementar a capacidade de todos os seus canais de comunicação. Além disso, a quantidade de largura de banda disponibilizada pode não ser importante, uma vez que a tendência é que, em pouco tempo, tal quantidade seja completamente esgotada [Kurose and Ross 2010].

Outra possibilidade considera que devem ser feitas modificações na Internet para que as aplicações possam reservar explicitamente largura de banda fim a fim. Mas, para permitir que aplicações façam essas reservas e exigir que a rede cumpra tais reservas, são necessárias grandes mudanças, exigindo novos e complexos softwares nos sistemas finais e intermediários e, novos tipos de serviços [Kurose and Ross 2010]. Essa idéia é denominada Serviços Integrados (IntServ) [Braden et al. 1994].

Uma abordagem intermediária é a denominada arquitetura de Serviços Diferenciados (DiffServ) [Blake et al. 1998]. Esse modelo introduz mudanças relativamente pequenas na rede e na camada de transporte.

\subsubsection{Serviços Integrados}

A arquitetura IntServ definida no RFC 1633 [Braden et al. 1994], apresenta duas características fundamentais [Kurose and Ross 2010]:

- Recursos Reservados - o roteador deve ter conhecimento da quantidade de seus recursos que já estão alocados para aplicações em andamento;

- Estabelecimento de Chamada - uma aplicação que exige garantias de QoS deve primeiramente estar capacitada a reservar os recursos suficientes em cada roteador da rede ao longo do seu percurso, para garantir que suas exigências de QoS fim a fim sejam satisfeitas. Esse processo exige a participação de cada roteador do percurso e cada um deles deve determinar se tem recursos suficientes para cumprir as exigências de QoS desta aplicação, sem infringir as garantias de QoS dadas as aplicações já em andamento.

A arquitetura IntServ define duas grandes classes de serviços: serviço garantido e serviço de carga controlada. Cada uma dessas classes fornece um modelo diferente de garantia de QoS: 
- Serviço de Qualidade Garantida - usado por aplicações intolerantes, fornece limites rígidos para atrasos fim a fim, e garante a disponibilidade de largura de banda. Sua especificação está definida no RFC 2212 [Shenker et al. 1997];

- Serviço de Rede de Carga Controlada - recomendado para aplicações que toleram variações no atraso fim a fim, pois não fornece garantias rígidas de atraso máximo, ao contrário disto, certifica que a maior parte dos pacotes de uma aplicação atravessará uma Internet com pouco tráfego. Caso ela esteja sobrecarregada, a largura de banda será compartilhada entre múltiplas aplicações, garantindo um serviço de melhor esforço. Esta classe de serviço está especificada no RFC 2211 [Wroclawski 1997].

A arquitetura IntServ exige um protocolo de sinalização para reservar recursos dentro da rede. O RSVP (Resource Reservation Protocol), definido no RFC 2205 [Braden et al. 1997], é um protocolo de controle e sinalização que atua na camada de rede, sendo responsável por reservar recursos na sub-rede de comunicação. O RSVP não é um protocolo de roteamento, assim, ele depende de um protocolo de roteamento subjacente para determinar as rotas dos fluxos. Cada roteador ao longo do percurso precisa dar suporte a RSVP para que se possa garantir QoS. Com isso, percebe-se que o RSVP introduz uma complexidade significativa no núcleo da Internet, o que representa uma ruptura com o seu modelo tradicional de serviços, que sempre procurou manter a rede simples e levar a complexidade para os sistemas finais [Stardust 1999a].

\subsubsection{Serviços Diferenciados}

Uma das desvantagens da arquitetura IntServ é a necessidade de roteadores para reservar recursos e manter o estado de fluxo para cada fluxo, o que gera uma possível falta de escalabilidade. Outra desvantagem é que ele é um modelo de serviços inflexível, ou seja, o modelo IntServ atende a um número de classes de serviços pré-estabelecidas e, esse grupo de classes específicas não comporta definições mais qualitativas para as diferenças entre as classes. A arquitetura de Serviços Diferenciados (DiffServ), definida no RFC 2475 [Blake et al. 1998] oferece uma abordagem que minimiza os problemas discutidos.

A arquitetura DiffServ tem o objetivo de fornecer diferenciação de serviços escalável e flexível, isto é, a capacidade de tratar diferentes classes de tráfego de maneiras distintas dentro da Internet. Essa arquitetura consiste em dois grupos funcionais [Kurose and Ross 2010]:

Funções de Borda: classificação de pacotes e condicionamento de tráfego. Na borda 
de entrada da rede, os pacotes que chegam são marcados, ou seja, o campo DS (Differentiated Service) do cabeçalho do pacote é marcado. A marca que um pacote recebe identifica a classe de tráfego à qual ele pertence, e dessa forma, diferentes classes de tráfego receberão serviços diferenciados dentro do núcleo da rede.

Função Central: envio. Quando um pacote marcado com DS chega a um roteador habilitado com DiffServ, ele é repassado para o próximo roteador de acordo com o tratamento associado à classe do pacote. Esse tratamento influencia a maneira pela qual os buffers e a largura de banda de um roteador são compartilhados entre as classes de tráfego concorrentes. O comportamento da transmissão do pacote se baseia apenas nas marcas dos pacotes, assim, não há necessidade de manter o estado do roteador para pares origemdestino individuais, um fator importante para manter a escalabilidade e para manter a complexidade na fronteira da rede (princípio básico do projeto da Internet).

O campo DS do cabeçalho do pacote IPv4 é a substituição do campo ToS (Type of Service), e no IPv6 é a substituição do campo Traffic Class.

A arquitetura de serviços diferenciados define dois tratamentos dados aos pacotes no interior da rede [Kurose and Ross 2010]:

- Repasse Acelerado - esse serviço especifica que a taxa de partida de uma classe de tráfego deve ser maior ou igual a uma taxa configurada. Assim, é fornecida a uma classe uma abstração simples de um enlace com largura de banda de enlace mínima garantida, ou seja, em qualquer instante de tempo, é garantido que a classe receba largura de banda suficiente para que a taxa de saída do tráfego seja maior ou igual a essa taxa configurada. Nesse serviço, independentemente da intensidade do tráfego e mesmo que outras classes estejam sobrecarregando os recursos do roteador e do enlace, recursos suficientes deverão ser mantidos disponíveis para a classe, e isto sugere algum tipo de isolamento entre as classes de tráfego;

- Envio Assegurado - esse serviço divide o tráfego em quatro classes e garante, a cada uma dessas classes, o fornecimento de uma quantidade mínima de largura de banda e de buffer. Dentro de cada classe, os pacotes são divididos em três categorias de descarte preferencial e assim, quando um congestionamento acontece dentro de uma classe, o roteador descarta pacotes de acordo em seus valores de descarte preferencial. 


\subsection{QoS em Nível de Aplicação}

O serviço oferecido na Internet baseia-se no modelo de melhor esforço (Best Effort), ou seja, a rede busca transportar os dados que devem ser transmitidos, no menor tempo possível, preferencialmente, sem erros ou inconsistências. Entretanto, não são dadas às aplicações garantias de que isso realmente ocorrerá [Comer 2006].

Uma das conseqüências da adoção desse modelo é o fato de que todo o tráfego é tratado de maneira uniforme, sem nenhum tipo de diferenciação ou priorização [Teixeira 2004]. Assim, em uma situação de congestionamento, os pacotes presentes na rede são descartados sem diferenciação. Contudo, verifica-se que nem todos os tipos de tráfego e transações são equivalentes ou têm a mesma prioridade [Dovrolis and Ramanathan 1999].

O grupo IETF (Internet Engineering Task Force) disponibiliza várias especificações, para superar o serviço de melhor esforço e prover QoS na camada de rede, com destaque para as arquiteturas de Serviços Integrados e Serviços Diferenciados, discutidos nas Seções 3.2.1 e 3.2.2, respectivamente.

Como essas duas arquiteturas visam a oferecer melhores serviços em nível de rede, a garantia de qualidade de serviço pode não ter sucesso, pois, em última instância, são os servidores Web os responsáveis pelo atendimento das solicitações dos usuários [Teixeira et al. 2005].

Atualmente, grande parte dos servidores $W e b$ trata as requisições igualmente, segundo a disciplina FCFS (First Come First Served) [Tanembaum 2007]. Este tratamento uniforme pode inutilizar os esforços desprendidos em nível de rede para o oferecimento de QoS. Serviços Diferenciados têm se mostrado uma solução eficiente não só em nível de rede, como também em nível de aplicação, como nos servidores Web. Cardellini et al. [Cardellini et al. 2001] apresentam um novo conceito em um trabalho desenvolvido nessa área, o de "Quality of Web Services" (QoWS), inspirado em Princípios de Garantia de QoS em nível de rede, definidos em [Kurose and Ross 2010]. Os princípios são:

1. Classificação. Distingue as diferentes classes de serviço.

2. Isolamento. Protege uma classe em relação às demais. Por exemplo, alocando uma parte de recursos a cada classe (entretanto, isso produziria o uso ineficiente dos recursos, caso a classe não utilizasse toda a parte alocada a ela).

3. Alta Utilização dos Recursos. Mesmo fornecendo isolamento, é necessário que os recursos sejam utilizados de maneira eficiente. 
4. Controle de Admissão. Declarada a necessidade de sua classe, a tarefa pode ser bloqueada, caso essa necessidade não possa ser atendida.

O Isolamento é obtido por meio de algoritmos de escalonamento e/ou particionamento que visam oferecer a diferenciação de serviços, baseando-se principalmente nas classes das tarefas.

O Controle de Admissão previne a sobrecarga do sistema e faz com que os acordos de serviços sejam respeitados, baseando-se nas informações de carga do próprio sistema e nos contratos firmados com os clientes.

\subsection{Arquitetura de Servidores $W e b$}

Em uma visão de alto nível, pode-se considerar a $W e b$ formada por três componentes principais: os browsers, a rede e os servidores. São os servidores que atendem as requisições dos usuários, mantendo-se em um laço infinito, em permanente espera por requisições.

Alguns atrasos que podem estar presentes, como a espera pela transmissão dos dados na rede, o acesso ao disco do servidor e o escalonamento dos processos pelo sistema operacional, em caso de sobrecarga, levam o servidor $W e b$ a se tornar o gargalo do sistema.

Segundo Menascé [Menascé 2003], a arquitetura de um servidor Web pode ser definida de acordo com o modelo de processamento e o comportamento do tamanho de seu pool. Um pool é constituído de um processo dispatcher e um número de processos works. O modelo de processamento define se processos/threads serão usados no atendimento das requisições e, o comportamento do tamanho do pool, define como os processos ou threads processam a carga presente no servidor.

De acordo com esses critérios, algumas arquiteturas discutidas em [Teixeira 2004], visando atender o maior número de requisições e melhorar o nível de concorrência, são apresentadas a seguir.

\subsubsection{Organização dos Servidores $W e b$}

\section{Servidor Iterativo}

Este modelo de servidor $W e b$ propõe que as requisições vindas dos clientes sejam aguardadas e tratadas, uma por vez, conforme sua ordem de chegada. Nenhum tipo de concorrência é estabelecido entre elas e na prática este modelo seria muito ineficiente, sendo usado apenas para fins didáticos. 


\section{Processo por Requisição}

Este é um dos modelos mais comuns dentre os usados na construção de servidores Web concorrentes. Neste modelo existe um processo pai que aguarda por requisições em uma porta pré-definida. Sempre que uma nova requisição chega ao servidor, uma cópia deste processo, chamado processo filho, é criada para atender a requisição, e o processo pai retorna ao laço infinito de espera. Assim que o processo filho atende a requisição, ele deixa de existir.

Com isso, em determinados instantes, poderão existir várias cópias do servidor executando concorrentemente, limitadas apenas pela capacidade da máquina. A desvantagem deste modelo é que a criação de um novo processo tem um custo computacional elevado, e o desempenho pode ser degradado.

\section{Pool de Processos}

Este modelo visa aproveitar a simplicidade da abordagem anterior, e eliminar a sua desvantagem. Para isso, é criado um processo dispatcher, responsável por gerenciar as requisições, e um número de processos denominados workes. Esse conjunto de processos constitui o pool de processos [Hu et al. 1997].

O processo dispatcher aguarda as solicitações dos clientes e, ao receber uma requisição, transfere o pedido para um processo work ocioso. Após a atribuição, o dispatcher retorna ao laço de espera. Os processos works não encerram sua execução após atender uma requisição, eles permanecem esperando até serem convocados novamente.

Com este modelo, o objetivo de eliminar a sobrecarga na criação de novos processos é alcançado, porém, o dispatcher pode se tornar o gargalo do sistema caso o número de requisições seja superior à quantidade de solicitações que ele possa tratar, ou seja, o número de processos no pool não tenha sido definido adequadamente. Neste caso, o desempenho do servidor está relacionado ao poder de processamento do dispatcher. Assim, ele deve ser robusto para não comprometer o sistema como um todo.

Caso o número de processos do pool seja inadequado, uma solução é que o servidor crie novos processos, recaindo então, no problema da abordagem anterior.

\section{Thread por Requisição}

Uma outra abordagem é criar threads para atender cada nova requisição que chega, diminuindo a sobrecarga no servidor causada pela criação de novos processos. As threads consomem menos recursos de máquina que um processo, compartilham o mesmo espaço de endereçamento, 
código e dados, e ainda, como elas se encontram dentro de um mesmo processo, a troca de contexto entre elas é mais rápida [Menascé 2003].

Outra vantagem no uso de threads em servidores Web é permitir que as requisições sejam executadas concorrentemente, o que resulta numa utilização mais eficiente dos recursos da máquina, além de aumentar o desempenho.

Essa abordagem, contudo, é menos estável que as baseadas em processos [Menascé 2003]. Como as threads compartilham um mesmo endereço de memória, caso ocorra algum problema com uma thread, todas as outras podem ser afetadas, deixando o servidor Web inoperante. Além disso, essa abordagem é muito mais complexa se comparada à proposta de processos. Outro fator negativo é o uso de bibliotecas específicas para um dado sistema operacional, comprometendo a portabilidade [Yeager and Mcgrath 1996].

\section{Pool de Threads}

Outra alternativa possível é a utilização do modelo de pool de threads. Elas são criadas quando o servidor Web é iniciado e elimina a sobrecarga de criação de uma nova thread para tratar cada requisição que chega, como no caso da utilização do pool de processos.

\subsection{Servidor Web com suporte a QoS}

Chen \& Mohapatra [Chen and Mohapatra 1999] propõem um modelo de servidor Web distribuído baseado em rede de filas (Figura 3.1). Este modelo consiste de quatro componentes lógicos: um iniciador $S_{I}$ responsável pelo controle de admissão, um escalonador $\mathrm{Q}, \mathrm{N}$ servidores de tarefas $S_{T}(\mathrm{t}=1, \ldots, \mathrm{N})$ e um canal de comunicação de $N_{S}$. As requisições que chegam ao sistema são inseridas na fila, aguardando pela admissão do $S_{I}$. As requisições são rejeitadas pelo iniciador quando a taxa de acesso é superior à capacidade do sistema. sf fornece informações de carga do sistema para o iniciador. As requisições admitidas são então, associadas a uma tarefa e, para cada tarefa, é dada uma prioridade pelo escalonador Q. As tarefas são escalonadas e processadas pelos servidores de tarefa $S_{T}$, de acordo com suas prioridades. Q escalona tarefas de diferentes prioridades para assegurar que o sistema trabalhe em condições aceitávies de carga. nf fornece um histórico de carga da rede para o escalonador. As respostas são enviadas através do canal de comunicação $N_{S}$, para os clientes.

Montez [Montez 2002] defende a utilização do modelo relativo proporcional, para prover diferenciação de serviços às aplicações, pois, este modelo mantém valores proporcionais de QoS 


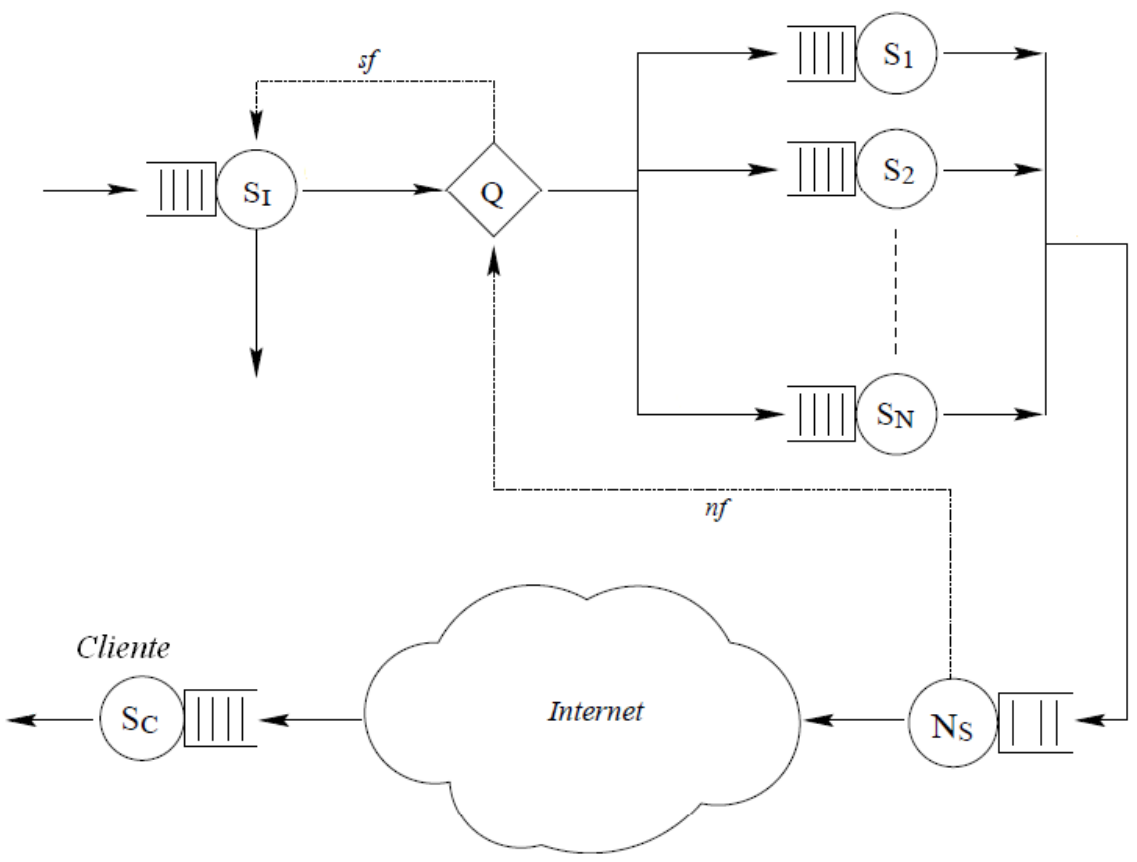

Figura 3.1: Modelo de um servidor Web distribuído [Chen and Mohapatra 1999].

entre as classes de serviços, independente da alteração na carga. Nesse trabalho é proposta uma nova heurística que procura manter a diferenciação de serviços proporcional em servidores Web, chamada Proportional Cumulative Value Attribution (PCV). Essa heurística possui duas políticas que, ordenam as requisições conforme suas prioridades e selecionam versões diferentes de páginas Web para atender as requisições. Além disso, em situações de sobrecarga, a heurística reduz a carga selecionando algumas execuções e distribui as perdas de deadline, priorizando determinadas classes, pois, existem algumas aplicações, de controle e de multimídia, por exemplo, que toleram a perda de deadline ou descartes de algumas ativações, desde que estas ocorram esparsadamente.

Elnikety et al. [Elnikety et al. 2004] apresenta um método para controle de admissão e escalonamento de requisições para sites de e-commerce, que mantém comportamento estável durante a sobrecarga e melhora o tempo de resposta. Além disso, não exige modificações no sistema operacional, servidor Web, servidor de aplicações ou banco de dados. É um método externo, que pode ser implementado em um proxy.

Teixeira [Teixeira 2004] propõe um modelo, chamado SWDS (Servidor Web com Diferenciação de Serviços), modelado através de Rede de Filas e composto pelos seguintes elementos (Figura 3.2):

Classificador - responsável por receber as requisições que chegam ao sistema e dividí-las em 
classes de serviço.

Controle de Admissão - recebe as requisições classificadas e coordena a sua aceitação pelo servidor, utilizando as políticas de atendimento e as informações da carga de trabalho do sistema. Caso o servidor esteja sobrecarregado, a requisição poderá ser descartada, ou ter suas exigências de QoS relaxadas, ou seja, poderá ser aceita em uma classe de prioridade inferior (negociação).

Cluster de processos ou servidores $\boldsymbol{W} \boldsymbol{e} \boldsymbol{b}$ - as requisições admitidas são enviadas a um dos nós do cluster e atendidas conforme a política de escalonamento pré-estabelecida, então as requisições são processadas e seus resultados são enviados de volta para os clientes que as realizaram. Cada nó é considerado um servidor $W e b$, composto de CPU, disco e interface de rede e com múltiplas filas de prioridade para as diferentes classes de serviço.

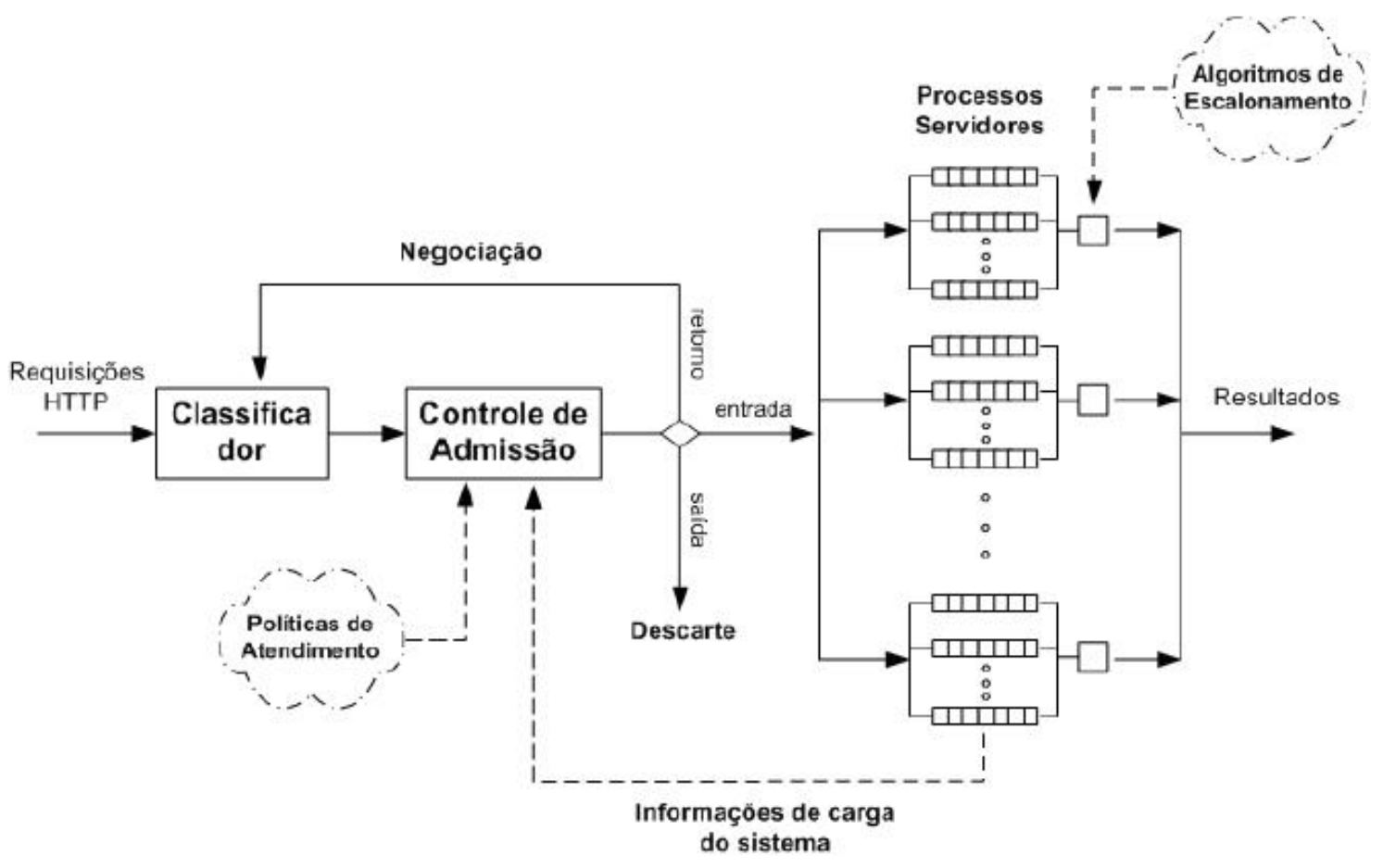

Figura 3.2: Servidor Web com Diferenciação de Serviços (SWDS) [Teixeira 2004].

Suchacka [Suchacka 2005] discute a respeito da Qualidade de Serviço da Web (QoWS), realizando uma análise crítica da literatura sobre algoritmos de escalonamento para servidores Web de e-commerce. 
Serra et al. [Serra et al. 2005] apresenta um mecanismo de controle de admissão e balanceamento de carga, desenvolvido para prover uma melhor QoS em clusters de servidores Web. O mecanismo possui três funções principais: balancear a carga imposta aos servidores, proporcionar diferenciação de serviços e utilizar os recursos disponíveis de maneira eficaz. Para que a última função seja garantida, os recursos alocados para as diferentes classes de serviços (com seus respectivos contratos de QoS), são divididos dinamicamente, em três estados: compartilhados, exclusivos ou saturados.

Quando está no estado compartilhado, o cluster da classe em questão possui recursos disponíveis que podem ser utilizados por outras classes durante um intervalo de tempo, sem afetar o contrato estabelecido. Quando passa para o modo exclusivo, significa que a carga está alta, e aceitar requisições de outras classes pode comprometer o contrato com a classe nativa do cluster, ou seja, o sistema pode recusar requisições da classe nativa por estar atendendo outras sessões de outras classes. No estado saturado, nenhuma nova requisição é aceita, pois os recursos não serão suficientes para garantir QoS.

Ye et al. [Ye et al. 2005] apresentam dois modelos para servidores Web. O primeiro é sequencial e apresenta suporte a QoS (Figura 3.3(a)). O segundo modelo refere-se ao DiffServ básico, em que as requisições são classificadas em diferentes níveis de prioridade e colocadas em diferentes filas (Figura 3.3(b)). Assim, as requisições de alta prioridade são sempre processadas pelo servidor antes daquelas que possuem menor prioridade. Os autores sugerem um servidor $W e b$ composto por esses dois modelos apresentados na Figura 3.3. Quando uma nova requisição chega ao servidor, é dada a ela uma prioridade, e esta é inserida em sua fila correspondente. Entretanto, antes na nova requisição ser inserida na fila, o controle de admissão é acionado, decidindo por sua aceitação ou não.

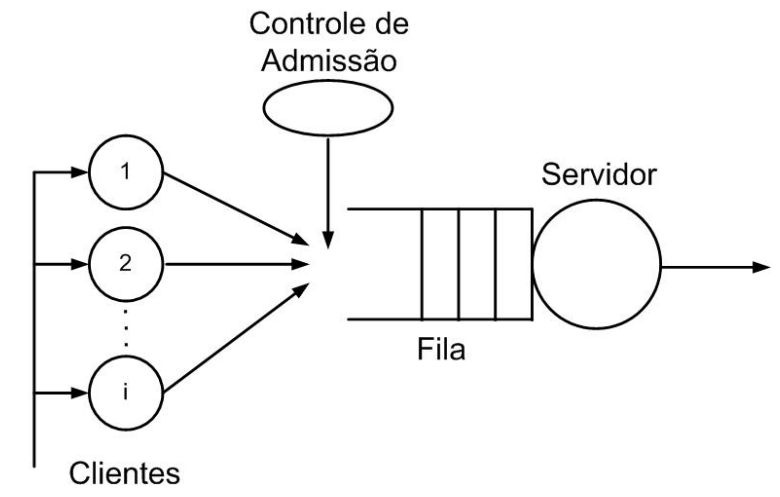

(a) Modelo de um servidor Web com QoS seqüencial.

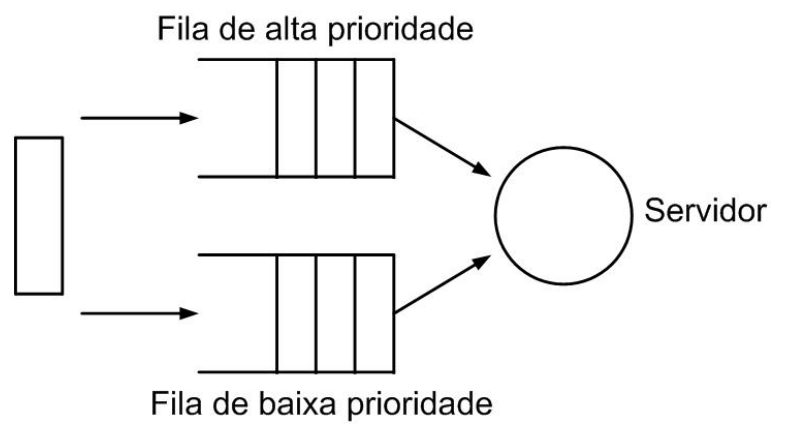

(b) Modelo DiffServ básico.

Figura 3.3: Modelos de servidores Web [Ye et al. 2005]. 
Shan et al. [Shan et al. 2005] discutem um protótipo de servidor Web baseado em QoS, chamado QoS Apache, e apresentam resultados de testes de desempenho, comparando-o com o servidor Apache convencional. Para gerar a carga de trabalho e realizar os testes é usado o Httperf [Httperf 2009], um benchmark que gera cargas baseada em traces e híbrida. Na Figura 3.4 é apresentado o modelo QoS Apache.

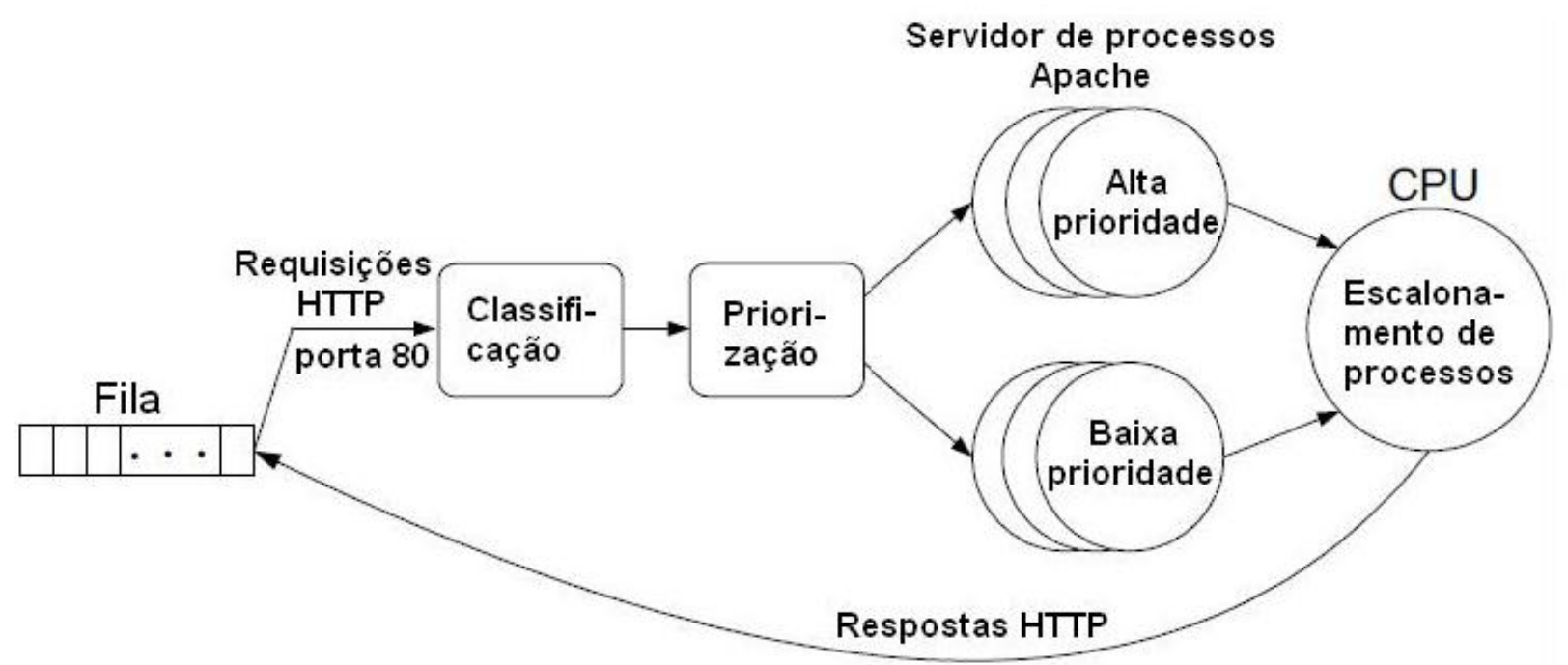

Figura 3.4: QoS Apache [Shan et al. 2005].

No QoS Apache as requisições são classificadas em múltiplas categorias, e são concedidos diferentes níveis de prioridade. Shan et al. consideram duas classes de requisições e dois níveis de prioridade em seu trabalho. A chave está na habilidade de identificar e classificar as requisições de cada classe. Depois da classificação, as requisições são priorizadas em alta prioridade ou baixa prioridade. Os processos de prioridade alta podem adquirir mais recursos de CPU do sistema que os de baixa prioridade. Assim, o servidor Web Apache modificado pode prover QoS diferenciado para tipos diferentes de requisições.

Sabo [Sabo 2006] propõe um modelo de Servidor Web para E-Commerce (SWE-C) que possui dois componentes, um escalonador e um cluster de servidores Web. O escalonador admite as requisições que chegam e as atribui a um dos nós do cluster, segundo o algoritmo de balanceamento de carga vigente. Os nós servidores são modelados com um recurso que represente o consumo de CPU e um que represente o consumo de I/O (Entrada/Saída). Após serem admitidas, as requisições são colocadas na fila da CPU escolhida e atendidas conforme a disciplina de fila. A seguir, as requisições passam por uma fila de I/O, que usa a disciplina FIFO, conforme mostrado na Figura 3.5. Para validação desse sistema foram realizadas simulações 
com vários algoritmos de escalonamento e disciplinas de atendimento para filas, inclusive aquela proposta pelo autor, que usa um mecanismo de prioridades orientado ao consumo de CPU. Empregou-se uma carga sintética gerada a partir de um modelo criado com os principais tipos de requisições que distinguem um site de e-commerce. A criação desse modelo de carga se deu baseando-se em estudos realizados em trabalhos relacionados.

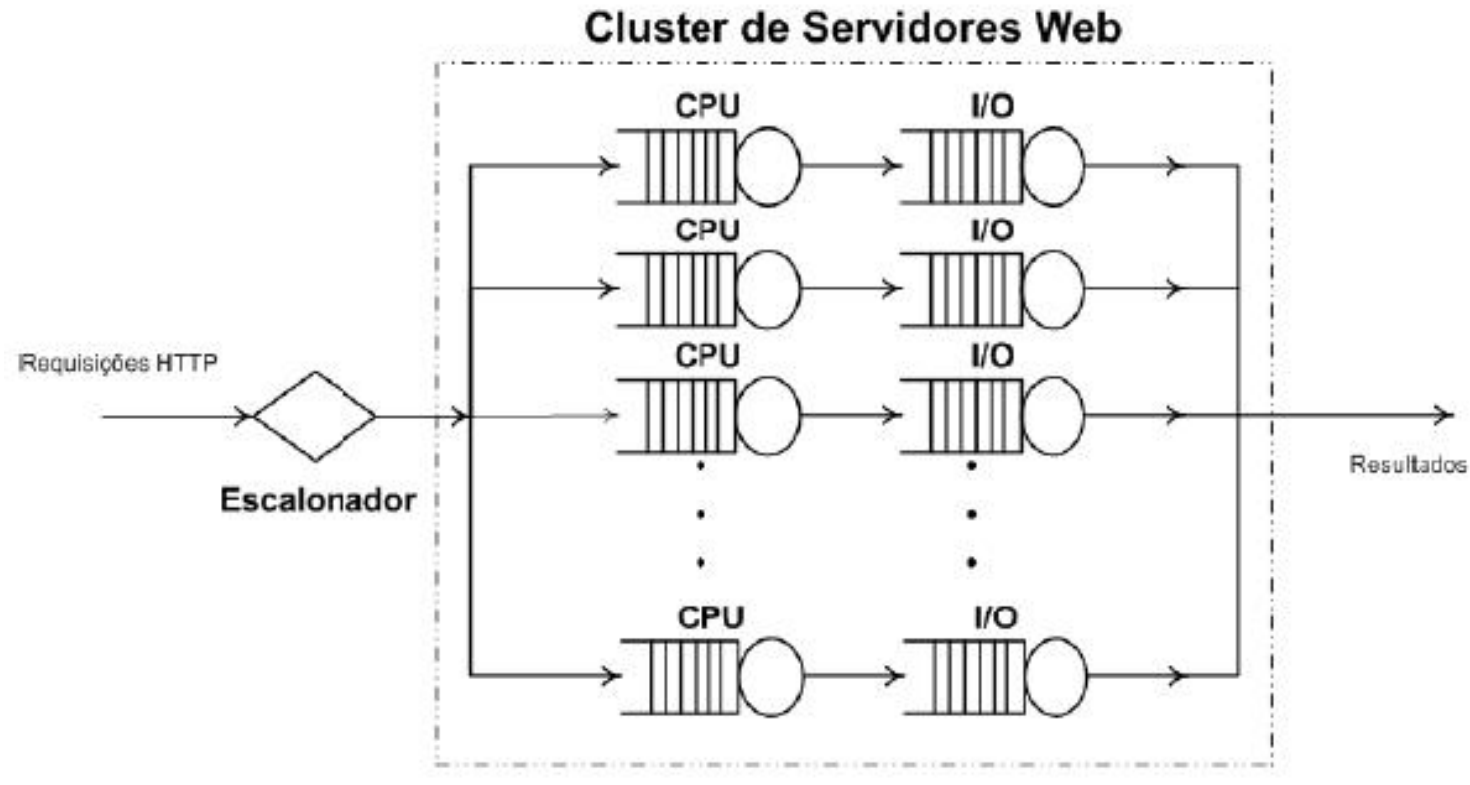

Figura 3.5: Modelo de Servidor Web para E-Commerce (SWE-C) [Sabo 2006].

Suchacka [Suchacka 2006] discute os problemas relacionados com a eficiência dos novos mecanismos de Qualidade de Serviço da Web (QoWS), para servidores Web, verificados através de simulação. Problemas como caracterização precisa de tráfego $W e b$, modelagem de requisições de clientes e modelagem de servidores $W e b$ também são tratados. Também é mostrado como utilizar os dados gravados em um arquivo de log do servidor Web para gerar dados de entrada para o simulador de servidor $W e b$ e, apresenta os resultados da sua utilização para testar duas políticas de escalonamento: a FIFO - First In First Out (primeiro a chegar, primeiro a sair) e uma política que escalona as requisições de acordo com o menor tamanho do arquivo solicitado.

Em [Messias 2007] foi desenvolvido um protótipo de servidores Web com diferenciação de serviços, baseado no modelo SWDS, em ambiente real, visando fornecer QoS relativa. Para mapear o modelo de Teixeira (2004) para o protótipo foi considerada uma arquitetura de cluster de servidores Web, e uma máquina foi utilizada com Front-End, responsável por receber as requisições dos clientes e repassá-las a um servidor que as atenderá, o Back-End. Para implementação do Front-End foi utilizado servidor Web Apache configurado como proxy re- 
verso. O cluster é composto por servidores Web Apache padrão, e cada nó possui programas responsáveis pelo monitoramento de carga e envio dessas informações para o Front-End.

Guiesi Júnior [Guiesi Júnior 2008] implementa um modelo de servidor Web que divide o seu funcionamento em quatro módulos, sendo que cada um é responsável por uma etapa do processamento da requisição. O módulo 1 é responsável pelo atendimento da requisição, o módulo 2 pela transferência do arquivo para a memória principal, o módulo 3 pelo processamento de requisições dinâmicas, e finalmente, o módulo 4, pelo envio do arquivo ao cliente. Estes módulos são interligados e alimentados por uma carga gerada pelo gerador de cargas sintéticas W4Gen. Esta carga passa sempre pelos módulos 1, 2 e 4; o módulo 3 é utilizado somente quando se atende requisições dinâmicas.

Peixoto et al. [Peixoto et al. 2008] apresentam um trabalho que tem por objetivo fornecer QoS absoluta para um array de servidores $W e b$ heterogêneos através de uma arquitetura ortogonal de escalonamento, diferentemente da maioria das abordagens atuais que visam fornecer QoS relativa através de diferenciação de serviços. Nessa arquitetura ortogonal, dois tipos de escalonamento são utilizados, o escalonamento das requisições em fila (horizontalmente) e, o escalonamento de recursos (verticalmente). Assim, dois escalonadores são combinados ortogonalmente, para selecionar a ordem de execução de uma requisição e um recurso. No trabalho realizado tem-se a comparação de algumas combinações entre as políticas de fila EDF (Earliest Deadline First) e EBS (Exigency-Based Scheduling), e as políticas de recursos MQ (Multiple Queue), SQ (Single Queue) e DSQ (Dynamic Single Queue).

\subsection{Sessões em Servidores $W e b$}

Uma sessão de usuário consiste de uma sequência de requisições, relacionadas, pertencentes a um mesmo cliente [Arlitt 2000; Chen and Mohapatra 2002; Cherkasova and Phaal 2002; Wang et al. 2004].

Uma sessão é um período de trabalho contínuo de um usuário [Zilber et al. 2005], sendo que o usuário pode não estar totalmente ativo durante todo o tempo da sessão. O tempo decorrido entre a resposta de uma requisição de um usuário e sua próxima requisição é denominado de tempo de pensar.

O tempo de pensar dentro de uma mesma sessão pode apresentar uma variação significativa. Quando um usuário realiza uma requisição de uma página HTML que contém vários objetos relacionados, o tempo de pensar é curto. Mas quando o usuário recebe todos os objetos que compõem a página, o tempo de pensar pode ser longo, antes que ele realize a próxima requisição. 
As sessões podem ser finalizadas explicitamente ou abortadas caso um valor definido como tempo limite, denominado timeout, seja alcançado. As requisições pertencem a uma mesma sessão se há um tempo de pensar curto entre elas, ou seja, se o tempo de pensar não ultrapassar o valor de timeout. Não há uma definição formal para sessão, bem como não há um tempo de pensar amplamente aceito, para limitar uma sessão [Zilber et al. 2005].

No contexto de e-commerce, um usuário pode colocar vários itens em seu "carrinho de compras". A forma como o servidor mantém e gerencia esses itens de compra de um usuário específico, é realizada por meio de sessão.

Uma forma de identificar os usuários de um servidor é por meio de seus endereços IP [Tanembaum 2002]. Alguns autores, como por exemplo Arlitt [Arlitt 2000], consideram uma sessão como todas as requisições vindas de um determinado endereço IP dentro de certo intervalo de tempo. O problema desta abordagem é que endereços IP identificam máquinas, e não usuários. Assim, quando vários usuários compartilham computadores, ou quando os IPs usam NAT (Network Address Translation) [Srisuresh and Egevang 2001], as requisições enviadas por vários usuários diferentes são consideradas pelo servidor $W e b$ como vindas de um único usuário, representado pelo endereço IP. Uma solução para esse problema é o uso de cookies, definidos no RFC 2109 [Kristol and Montulli 1997], que tem por objetivo manter a persistência de sessões HTTP, e é usado para que os servidores $W e b$ obtenham informações dos clientes.

Cherkasova \& Phaal [Cherkasova and Phaal 2002] apresentam um modelo de Rede de Filas para servidor $W e b$, solucionado por meio de simulação. Esse modelo consiste de um gerador de sessões, $\mathrm{N}$ clientes e um servidor Web. As requisições da nova sessão, produzida pelo gerador de sessões, são enviadas para o servidor Web. Caso o servidor esteja ocupado, as requisições são armazenada na fila de espera, que suporta até 1024 requisições. Cada um dos $\mathrm{N}$ clientes inicia uma nova sessão somente após o término da sessão anterior. As sessões são geradas com diferentes tamanhos, e o tempo de pensar entre as requisições de uma mesma sessão também possui diferentes valores.

Gijsen et al. [Gijsen et al. 2004] consideram, para cada sessão gerada, um número fixo de requisições, com um tempo de pensar que varia uniformemente. Após o recebimento da última requisição da sessão, o cliente espera por um intervalo de tempo, configurado com um valor maior que o timeout, antes de enviar as requisições da próxima sessão.

Em [Mourão et al. 2007], é apresentada a introdução da característica de reconhecimento de sessões no modelo de servidor Web com diferenciação de serviços (SWDS) [Teixeira 2004; Teixeira et al. 2005]. Um controle de admissão (Controle de Admissão de Sessões - CAS) foi criado e adicionado ao SWDS para fornecer garantias de finalização das sessões. Nesse trabalho, 
são utilizados logs de acesso a servidores Web reais, coletados durante a Copa do Mundo de 1998, na França, ao invés de um gerador de cargas sintético. Um campo do registro do log chamado clientID, que apresenta o mapeamento do endereço IP do cliente, é usado na sua identificação e no controle das sessões. Assim, todas as requisições vindas do mesmo clientID pertencem a mesma sessão, desde que o tempo entre as suas chegadas não ultrapasse o timeout, configurado em 100 segundos.

Em [Barbato 2007], foi também inserida a capacidade de reconhecimento de sessões HTTP no modelo de servidor Web com diferenciação de serviços, proposto por Teixeira [Teixeira 2004; Teixeira et al. 2005]. Nesse trabalho também são utilizados logs de acesso coletados durante a Copa do Mundo de 1998, na França. Cada registro do log contém vários campos, e para a identificação das sessões são utilizados os campos clientID e timestamp. O campos clientID é um mapeamento do endereço IP do cliente, assim como em [Mourão et al. 2007] e o valor do timestamp é usado no cálculo do tempo de chegada da requisição HTTP ao sistema.

Wolfram et al. [Wolfram et al. 2009] investigam características de sessões baseando-se em logs de três ambientes de pesquisa Web: site acadêmico, engine de busca e portal de informações de saúde. O conjunto de dados do ambiente acadêmico foi obtido da University of TennesseeKnoxville, sendo este um conjunto completo compreendendo dois anos (os anos de 2003 e 2004). Para análise das características das sessões de engine de busca, utilizou-se dois conjuntos de dados, cada um representando um dia, em 1999 e 2001. Para o último ambiente, utilizou-se um conjunto de dados completo coletado no período de um ano, em 2005. Características das sessões como tamanho da sessão, média do número de páginas visitadas durante uma sessão, número de buscas utilizando operadores booleanos dentro de uma sessão e média do número de palavras reconhecidas e não reconhecidas em uma sessão, são analisadas. É observado que existem padrões nos três ambientes estudados, e que, com base nas características da sessão de busca, os comportamentos de busca podem ser agrupados em grupos distintos.

Meiss et al. [Meiss et al. 2009] examinaram as propriedades de requisições geradas por milhares de estudantes no período de dois meses e, demonstram que os fluxos de cliques de usuários não podem ser segmentados dentro de sessões usando timeout. Assim, segundo os autores, a navegação hipertexto não deve ser modelada utilizando estatísticas de sessões individuais. É proposta então, uma definição estritamente lógica de sessões baseado na atividade de navegação, revelada por indicadores URLs; assim, um usuário pode ter várias sessões ativas em seu fluxo de cliques a qualquer momento. É demonstrado também que aplicar um timeout nessas sessões lógicas afeta suas estatísticas em menor medida que a sua aplicação em um mecanismo baseados puramente baseado em timeout. 
Fang and Huang [Fang and Huang 2010] sugerem que, tradicionalmente, existem quatro aritméticas para identificar uma sessão. Na primeira delas é dado ao tempo de acesso do usuário à todo o site, um limite superior. Caso esse limite seja excedido, inicia-se uma nova sessão. Na segunda, também é dado ao tempo de acesso do usuário um limite superior. Se o intervalo entre duas requisições sucessivas não ultrapassar esse limite, as requisições pertencem a mesma sessão. No terceiro caso, as sessões são classificadas de acordo com o histórico de acesso do usuário. E na última aritmética, a página acessada pelo usuário anteriormente não pertence à sessão; assim, se o usuário avançar para acessar a próxima página e clicar no botão para retroceder, significa que a sessão terminou, e uma nova irá começar.

Fang and Huang [Fang and Huang 2010] propõem também um método de identificação da sessão baseado no tempo máximo de acesso e reconstrução de sessões, composto por duas etapas. Em primeiro lugar identifica-se a sessão, com base no tempo limite de acesso à página. Em segundo lugar, o conjunto da sessão é aperfeiçoado com um método chamado reconstrução de sessões, para que o conjunto da sessão esteja mais próximo da sessão real.

\subsection{Considerações Finais}

Neste capítulo, as limitações do serviço de melhor esforço adotado na Internet foram apresentadas. Discutiu-se a importância de se prover qualidade de serviço não só em nível de rede, como também em nível de aplicação, para que garantias de QoS sejam efetivamente dadas aos usuários finais e os esforços na camada de rede não sejam desperdiçados. Algumas arquiteturas para implementação de servidores $W e b$ foram apresentadas, bem como discutido o conceito de sessão, seu uso e sua importância no atual contexto da Web. E foram apresentados alguns trabalhos encontrados na literatura relacionados a sessões.

E finalmente, foram apresentados alguns modelos de servidores $W e b$ com suporte a QoS encontrados na literatura. Esses modelos utilizam-se de controle de admissão e/ou algoritmos de escalonamento para garantir que o sistema não seja sobrecarregado causando negação do serviço, e não trate todas as classes de requisições uniformemente, possibilitando então, alguma qualidade de serviço aos usuários finais.

No próximo capítulo aborda-se os conceitos relacionados a controle de admissão, escalonamento e particionamento de recursos, apresentando alguns algoritmos baseados em sessão encontrados na literatura. 
${ }_{\text {Capiuto }} 4$

\section{Políticas de Controle de Admissão e Diferenciação de Serviços}

\subsection{Considerações Iniciais}

No Capítulo 3, discutiu-se a importância da QoS na camada de aplicação, para servidores $W e b$, apresentando-se os quatro princípios para fornecimento de QoS em nível de rede também utilizados em nível de aplicação. São eles: Classificação, Isolamento, Alta Utilização dos Recursos e Controle de Admissão.

O emprego do Controle de Admissão necessita de alguma política, para tomada de decisão se uma determinada requisição deve ou não ser admitida.

Assim como o Controle de Admissão, o Isolamento, que tem por objetivo proteger uma classe em relação às outras, também é um importante requisito que compõe os quatros princípios para a garantia de QoS. Cardellini et al. [Cardellini et al. 2001] afirmam que esse é um dos mais importantes princípios emprestados da teoria de QoS. O Isolamento pode ser alcançado por meio de políticas de escalonamento e/ou políticas de particionamento de recursos [Andreolini et al. 2004].

Na Seção 4.2 discute-se a utilização de controle de admissão, como as políticas podem ser definidas e, apresentam-se algumas políticas para servidores Web, baseadas em sessão e em requisições individuais. Na Seção 4.3 são discutidas, com mais detalhes, as políticas de escalonamento e as políticas de particionamento de recursos para diferenciação de serviços em servidores $W e b$, idéia adotada por muitos pesquisadores da área para fornecimento de QoS. 


\subsection{Controle de Admissão}

Como o tráfego da Internet apresenta alguma instabilidade, torna-se difícil prever a carga de um sistema $W e b$. Caso os servidores $W e b$ fiquem sobrecarregados, o tempo médio de resposta das requisições pode ficar muito maior que o esperado, causando o efeito de negação de serviço (Denial of Service - DoS) [Chen et al. 2001].

Aumentar a capacidade dos servidores Web é uma alternativa para evitar a sua sobrecarga. Porém, alocar mais recursos para acomodar todo o tráfego, além de não ser uma solução com melhor custo-benefício, pode não ser efetiva [Zhu et al. 2001]. As situações de saturação podem ocorrer esporadicamente, fazendo com que os novos recursos fiquem ociosos grande parte do tempo.

Sob condições de sobrecarga dos servidores $W e b$, situação na qual o volume das requisições excede a capacidade do sistema, algumas dessas requisições podem ser rejeitadas, ao invés de todas elas serem submetidas a inaceitáveis tempos de resposta [Welsh and Culler 2003]. Decidir quando e quais requisições serão rejeitadas é a tarefa do Controle de Admissão.

Em momentos de sobrecarga, a QoS pode ser garantida mantendo o sistema dentro de certos limites (thresholds) e, o controle de admissão possibilita conservar o sistema dentro desses limites [Chen and Mohapatra 1999].

Existem diversos algoritmos que se propõem a fazer este controle, e estes podem ser dividios em duas categorias: os baseados em modelos e os baseados em medidas [Mognatto Júnior 2009].

Os algoritmos baseados em modelos aceitam novas requisições baseando-se em modelos de tráfego previamente definidos. Portanto, a eficiência desses algoritmos está relacionada à precisão dos modelos e, devido à dificuldade de se obter o tráfego característico de certas aplicações, o desempenho desses algoritmos pode ser prejudicado.

Os algoritmos baseados em medidas utilizam medidas feitas no sistema para a tomada de decisão. Existem várias técnicas para fazer a medida, entre elas estão [Mognatto Júnior 2009]:

Janelas de tempo - Nesta técnica uma amostra é medida no sistema a cada intervalo de tempo S. A carga de trabalho do sitema é definida como o maior valor das amostras em um intervalo de tempo T. Quando é realizada uma nova admissão, a janela é reiniciada, e caso o valor medido naquele momento seja maior que o valor definido anteriormente, o valor da carga do sistema é atualizado.

Amostra de pontos - Esta técnica faz medidas a cada intervalo de tempo S, e torna o valor da amostra, a carga média do sistema. 
Média móvel exponencial com peso - Esta técnica também toma amostras a cada intervalo S, mas a carga média avg' é atualizada como uma função da amostra instantânea $q$ e da carga média anterior avg:

$$
a v g^{\prime}=(1-w q) * a v g+w q * q
$$

em que $w q$ é parâmetro que determina quão rápido a média irá se adaptar às novas medidas e, $0<w q<1$.

O controle de admissão é fundamental para que os servidores Web não excedam a sua capacidade em caso de um grande volume de carga, por meio da rejeição de algumas requisições, e honrem os acordos de nível de serviço (SLA) firmado com seus clientes.

\subsubsection{Algoritmos para Controle de Admissão}

Barbato [Barbato 2007] propõe uma definição hierárquica das políticas do controle de admissão, para o descarte de requisições ou sessões (Figura 4.1).

O controle de admissão pode avaliar as requisições individualmente ou reconhecer as sessões, como mostra o primeiro nível da hierarquia, na Figura 4.1. No caso em que o controle de admissão trata as requisições individualmente, são avaliadas as condições correntes do sistema para verificar se ele é capaz de atendê-la. No caso em que são tratadas as sessões, o controle de admissão aceita uma nova sessão, somente se o sistema tiver condições de atender todas as futuras requisições desta sessão.

No segundo nível da hierarquia (Figura 4.1), o controle de admissão decide se aceita ou rejeita uma nova requisição ou sessão, baseado-se em informações de carga do sistema, ou seja, se este está sobrecarregado ou é capaz de atendê-la. Além de informações de carga, o controle de admissão pode considerar a classe da requisição ou da sessão.

No caso do controle de admissão que trata sessões, o estágio da sessão também pode ser considerado. Quando o controle de admissão é capaz de reconhecer sessões, ele possui informações de quantas sessões estão ativas no sistema em determinado instante. Assim, o controle de admissão pode analisar se essas sessões estão no início, no meio, ou próximas de serem finalizadas, podendo então, aprimorar o controle sobre o sistema.

Quando o controle de admissão considera, além da carga do sistema, a classe da requisição/sessão, tem-se o terceiro nível da hierarquia. Nessas condições o algoritmo de controle de admissão pode ser: baseado na prioridade ou baseado no SLA de cada classe. 

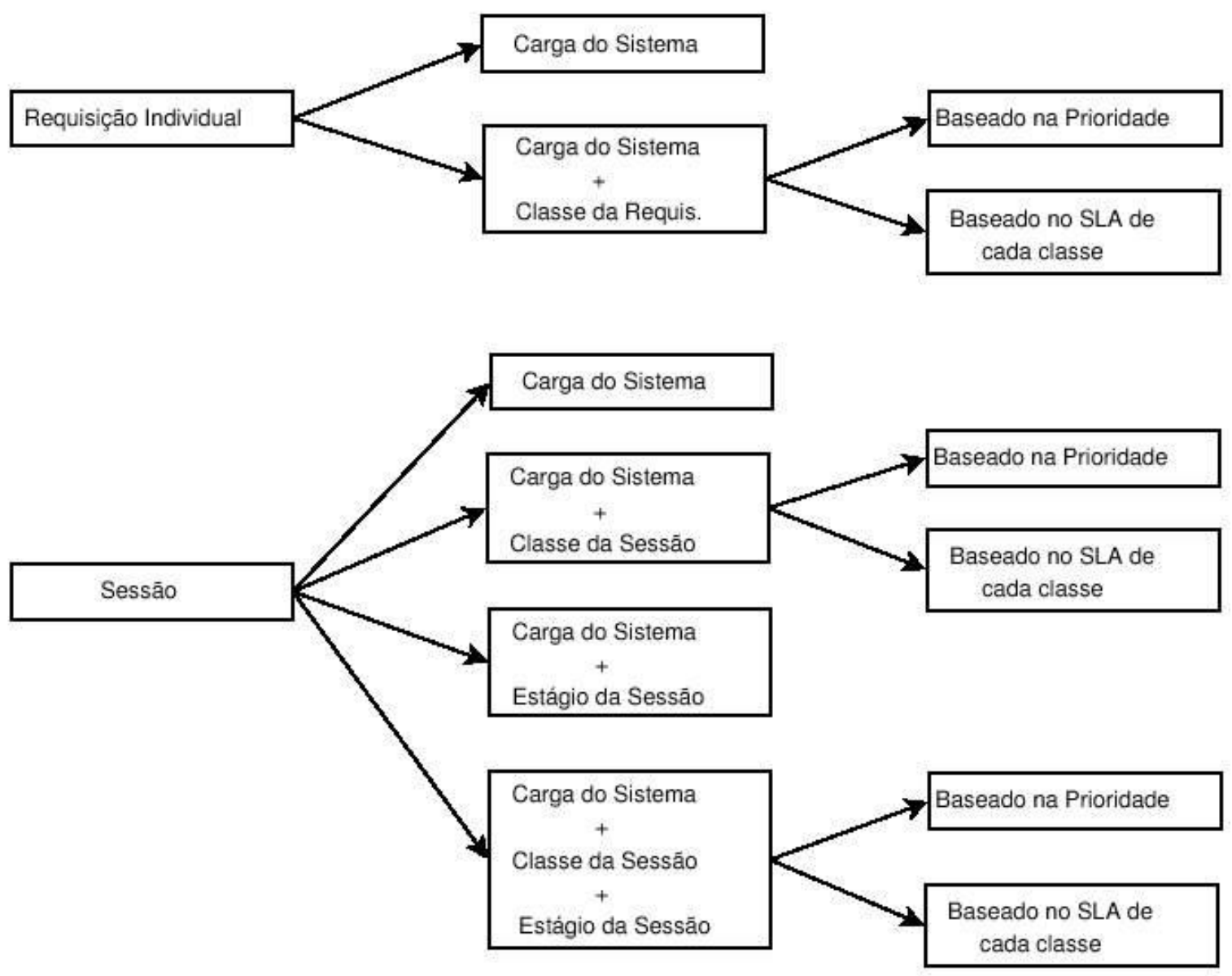

Figura 4.1: Classificação das políticas de Controle de Admissão [Barbato 2007].

Se o algoritmo for baseado na prioridade, ele sempre prioriza as requisições/sessões das classes mais altas. Assim, as restrições de admissão são feitas somente a requisições ou sessões das classes inferiores. Dessa forma, as requisições/sessões das classes favorecidas são descartadas somente em condições críticas do sistema.

Se o algoritmo de controle de admissão for baseado no SLA de cada classe, as requisições/sessões de todas as classes são submetidas a restrições de admissão. Neste caso, os acordos de nível de serviço (SLA) são estabelecidos para todas as classes e, se a aceitação de uma nova requisição/sessão infringir algum desses acordos, essa requisição/sessão será descartada, mesmo que ela pertença a uma classe superior àquela transgredida.

Os acordos de serviço devem ser definidos baseando-se em medições feitas no sistema. Essas medições têm como objetivo apontar as limitações do sistema e, conseqüentemente, quais serão os possíveis acordos de nível de serviço oferecidos pelo sistema aos seus clientes. As várias configurações do sistema, como por exemplo, a política de escalonamento e/ou particionamento 
e a política de controle de admissão adotada, estabelecem a forma como esses acordos podem ser alcançados.

O descarte das requisições/sessões pode ainda ser substituído por uma negociação, e assim, a requisição/sessão a ser descartada pode ter suas exigências de qualidade de serviço relaxadas, e ela pode ser aceita em uma classe de prioridade inferior.

\subsubsection{Mecanismos para Controle de Admissão}

Para evitar a saturação do sistema, deve existir algum algoritmo que gerencia a admissão ou descarte de requisições ou sessões, usando informações de carga do sistema.

Os algoritmos de controle de admissão existentes podem ser diferentes quanto a métrica para verificação da carga do sistema. No trabalho de Barbato [Barbato 2007], foi utilizado dois mecanismos de controle de admissão:

Mecanismo que limita o tamanho da fila - Um dos mais simples e utilizados pelos servidores Web. Este mecanismo descarta requisições/sessões quando o tamanho da fila do servidor alcança um limite pré-estabelecido.

Mecanismo que limita a utilização média do cluster - Este mecanismo foi proposto por Teixeira et al. [Teixeira et al. 2005] e tem como métrica a utilização média do cluster de servidores $W e b$, obtida por meio de uma média ponderada exponencialmente. Quando uma requisição chega ao sistema, a utilização atual do cluster é medida. Usando este valor atual e os valores anteriores da utilização dos servidores (histórico), encontra-se a média ponderada exponencialmente. Se a utilização média estiver acima do limite pré-estabelecido, requisições deverão ser descartadas.

Após definir a métrica de verificação da carga do sistema, é preciso decidir qual tarefa deve ser descartada quando a carga do sistema estiver no seu limite. Para esta decisão é que utilizase os algoritmos de controle de admissão que, a partir das informações de carga, elegem a tarefa a ser rejeitada para que o servidor não sature. A seguir, serão apresentadas vários algoritmos de controle de admissão retiradas na literatura.

\subsubsection{Trabalhos Relacionados}

Diversos trabalhos encontrados na literatura discutem como são feitas as políticas de controle de admissão, e em que são baseadas as decisões para a rejeição das tarefas. Alguns desses trabalhos são apresentados a seguir. 
Floyd and Jacobson [Floyd and Jacobson 1993] apresentam o Random Early Detection (RED), um algoritmo para evitar o congestionamento em redes de comutação de pacotes, realizando um controle de admissão desses pacotes. O gateway detecta o congestionamento calculando o tamanho médio da fila. Quando o tamanho médio da fila encontra-se entre dois limites pré-definidos, o gateway marca cada um dos pacotes que chegam com uma certa probabilidade de descarte, em que essa probabilidade exata é uma função do tamanho médio da fila. Este algoritmo pode ser utilizado também na camada de aplicação, para descarte de requisições, ao invés de pacotes [Pykosz 2006; Barbosa 2007; Almeida and Santana 2010].

Cherkasova and Phaal [Cherkasova and Phaal 1999] propõem o Controle de Admissão Baseado em Sessão (Session Based Admission Control - SBAC) para servidores com carga de trabalho baseada em sessões. O controle de admissão aceita uma nova sessão somente quando o servidor pode processar todas as futuras requisições desta sessão, ou seja, quando é garantido que a sessão será completada com sucesso pelo servidor. Se o servidor estiver próximo de sua capacidade limite, a nova sessão será rejeitada. Nesse trabalho, os autores mostram que o throughput, medido como o número de sessões completadas com sucesso, nesse tipo de sistema, é maior quando o controle de admissão trata sessões, ao invés de descartar as requisições individualmente, de forma independente de sessões.

No modelo de servidor Web proposto por Chen and Mohapatra [Chen and Mohapatra 1999], mostrado na Figura 3.1, a admissão das requisições é feita antes da classificação das mesmas. Quando as requisições chegam ao sistema, elas são colocadas na fila aguardando para serem admitidas. Se a taxa de acesso exceder a capacidade do sistema, as novas requisições são rejeitadas. Somente após sua aceitação, o escalonador atribui à requisição certa prioridade e assim, o controle de admissão não considera a classe das requisições para realizar o descarte.

No trabalho de Kanodia and Knightly [Kanodia and Knightly 2000], existe a verificação de como o efeito de desempenho de uma classe pode influenciar na outra, e isto é incorporado nas decisões do controle de admissão, que pode ser baseado em sessão ou não. Com a chegada de uma nova requisição/sessão, o algoritmo de controle de admissão verifica se o atraso préestabelecido para a classe da nova requisição/sessão é satisfeito, e então, se a chegada da nova requisição/sessão não violará os requisitos de QoS das outras classes. Caso não seja possível respeitar os limites de latência estabelecidos para todas as classes, a nova requisição/sessão deve ser rejeitada ou redirecionada para uma classe de prioridade inferior.

Em [Cardellini et al. 2001], o controle de admissão considera as prioridades das classes dos clientes, para que o tempo de resposta das classes superiores não exceda o determinado, em momentos de sobrecarga. Assim, o controle de admissão pode recusar acesso aos servido- 
res Web, para algumas classes de serviços. Seu fundamento está em negar serviço para as requisições pertencentes às classes de menor prioridade quando a capacidade do sistema ultrapassar um determinado limite, e rejeitar as requisições das classes de maior prioridade somente em condições altamente críticas do sistema. Essa mesma política de controle de admissão é utilizada em [Andreolini et al. 2004].

Chen et al. [Chen et al. 2001] propõem um algoritmo que também visa garantir o desempenho das requisições de maior prioridade, em condições de sobrecarga, por meio da restrição de admissão de requisições de baixa prioridade. A tomada de decisão em relação à admissão da requisição é feita comparando a capacidade disponível do servidor com o tempo de serviço estimado para a requisição. Essa estimativa do tempo de serviço é feita baseando-se no tipo da requisição.

Zhu et al. [Zhu et al. 2001] propõem um algoritmo que emprega controle de admissão para rejeitar requisições excessivas de usuários e oferecer garantias de desempenho. Para isto, o algoritmo calcula, periodicamente, quantos servidores devem ser associados para cada classe e qual a porcentagem de requisições desta classe deve ser rejeitada para que haja diferenciação de serviços e alguma garantia de desempenho. Assim, as requisições de baixa prioridade não são sacrificadas em prol do desempenho das requisições de alta prioridade.

Lee et al. [Lee et al. 2002] propõem um algoritmo de controle de admissão no qual uma nova requisição é rejeitada caso a sua admissão viole a QoS dos clientes já admitidos.

Teixeira [Teixeira 2004] propõe três mecanismos de controle de admissão de requisições. Um deles é baseado no tamanho das filas, outro é baseado nos tempos de respostas das requisições e, finalmente, um algoritmo baseado na média de utilização do sistema.

Barbato [Barbato 2007] propõe dois algoritmos de controle de admissão. Um deles, chamado Controle de Admissão Baseado em Sessão (CA-BS), considera as sessões para a tomada de decisão em relação ao descarte. Quando o sistema está no limite de sua capacidade, a política começa a rejeitar novas sessões. Para garantir a finalização das sessões já aceitas, as futuras requisições dessas sessões são admitidas e encaminhadas aos servidores Web apropriados. Assim, a carga dos servidores pode ser superior ao limite imposto pelo mecanismo de controle, prejudicando o desempenho do sistema. O segundo algoritmo proposto, denominado Controle de Admissão Híbrido (CA-Híb) realiza o descarte de requisições, quando o sistema torna-se sobrecarregado, mesmo que estas requisições pertençam a alguma sessão ativa. Esta política decide qual requisição será descartada baseando-se no tamanho das sessões ativas no sistema. Assim, as requisições descartadas são aquelas pertencentes às sessões menores, para minimizar a perda do trabalho já realizado com o atendimento das sessões. 
Mourão et al. [Mourão et al. 2007] propõem dois algoritmos de controle de admissão de sessões, o Hard-Threshold e o Baseada em Sessão Modelo. Ambos utilizam informações de um buffer de sessões (utilizado para limitar o número de sessões que podem estar ativas no sistema) para rejeitar sessões quando há sobrecarga no sistema. O segundo algoritmo utiliza também, informações do histórico de sessões (outro componente onde são armazenadas informações sobre a quantidade de requisições pertencentes às sessões finalizadas no sistema) para fazer uma estimativa e construir uma sessão modelo, na qual se baseia para prever se o sistema será capaz de finalizar a nova sessão, ou seja, se será capaz de atendê-la completamente. Assim, o sistema pode prevenir possíveis cancelamentos de sessões ao invés de fazer rejeições somente quando já estiver sobrecarregado.

Também foram propostas por Mourão et al. [Mourão et al. 2007] dois algoritmos que visam a admissão de requisições adaptadas ao atendimento de sessões, ambos são baseados no tamanho das filas do cluster. Caso o sistema esteja sobrecarregado, requisições devem ser rejeitadas e conseqüentemente, as sessões as quais elas pertencem devem ser canceladas. O primeiro algoritmo estabelece o tamanho máximo para as filas dos servidores e, caso uma nova requisição encontre esse limite, ela é recusada e a sessão a qual pertence é cancelada, sem nenhuma negociação. O segundo algoritmo utiliza a negociação para escolher a sessão mais adequada para ser cancelada no lugar da sessão a qual pertence a nova requisição que seria descartada. As quatro políticas de negociação de sessões desenvolvidas são baseadas em quantidade de requisições por sessão, tempo de sessão e, prioridade de sessão.

Poggi et al. [Poggi et al. 2007; Poggi et al. 2009] afirmam que os sistemas de controle de admissão baseados em sessão mantêm um alto QoS para um número limitado de sessões, mas não maximiza a renda tratando toda sessão pequena da mesma maneira, negando acesso à usuários em excesso que poderiam ser potenciais compradores. É proposto então, um método que prioriza as sessões de acordo com a renda que elas gerarão. Para isso, são utilizadas técnicas de aprendizagem de máquina e modelos da cadeia de Markov. A arquitetura proposta, AUGURES, é um sistema que pode ser treinado para calcular a probabilidade do usuário efetuar uma compra, e as predições podem ser usadas pelo sistema de controle de admissão para priorizar sessões ou negar serviço caso nenhum recurso esteja disponível, melhorando assim o processamento de vendas por unidade de tempo.

De La Sierra [de la Sierra 2009] propõe um algoritmo de controle de admissão e balanceamento de carga para tráfego Web. O algoritmo distribui o tráfego em clusters de servidores $W e b$, a fim de prover qualidade de serviço. O objetivo do algoritmo é, então, evitar situações em que os sites Web proporcionam rendimento abaixo do desejado, devido a um congestionamento 
nos servidores.

Lu et al. [Lu et al. 2010] afirmam que as técnicas clássicas para controle de admissão de sessões, que são ativados pela violação de um limiar superior, são ineficientes quando a carga de trabalho chega em rajadas. O desempenho percebido pelo usuário é deteriorado rapidamente pois o sistema descarta requisições pertencentes à sessões já aceitas. É proposta então, uma política de controle de admissão baseada em sessões, chamada AWAIT, e baseada em bloqueio. Assim, em condições de sobrecarga, sessões de usuários já aceitas não são descartadas, mas armazenadas em uma fila de bloqueio. As requisições na fila de bloqueio obtêm prioridade mais alta, e são servidas imediatamente após a carga baixar. O tempo de residência na fila de bloqueio possui um custo de desempenho, acrescentando o tempo de bloqueio ao tempo de resposta do usuário.

\subsection{Diferenciação de Serviços}

As políticas para diferenciação de serviços podem ser divididas em dois grupos: escalonamento e particionamento de recursos. A seguir serão tratados esses dois grupos e serão apresentados alguns algoritmos encontrados na literatura.

\subsubsection{Políticas de Escalonamento}

Em geral, os servidores Web atendem suas requisições por meio da disciplina FCFS (First Come First Served), em que a primeira requisição a chegar é a primeira a ser atendida. As políticas de escalonamento para servidores $W e b$ para prover serviços diferenciados tem como objetivo modificar esse tipo de atendimento das filas dos servidores.

Assim, a implementação de algoritmos de diferenciação de serviços necessita de alterações no sistema operacional dos servidores $W e b$, pois é necessária a adequação do algoritmo de escalonamento de processos, ou de threads. Os novos algoritmos dependem das diretrizes estipuladas para o atendimento de requisições no servidor Web. Essas diretrizes devem refletir a filosofia estipulada pelo servidor visando prover a diferenciação de serviços.

Teixeira et al. [Teixeira et al. 2005] implementa um algoritmo de diferenciação de serviços, chamado Mecanismo de Prioridades Rigoroso, baseado no método que atende todas as requisições da classe de maior nível de prioridade, obedecendo a ordem de chegada, para então, atender as requisições das classes de prioridade inferior. Assim, a ordem de atendimento das requisições depende estritamente das prioridades das classes. Como as requisições de prioridade 
inferior são atendidas somente se não houver requisições das classes superiores aguardando na fila, pode haver negação de serviço para essas requisições de menor prioridade, caso em que as requisições de alta prioridade monopolizem os recursos do sistema.

O Mecanismo de Prioridades Adaptativo [Teixeira et al. 2005] faz uso das prioridades, porém, de forma intensificada ou relaxada, dependendo da necessidade. Nesse algoritmo é utilizado um parâmetro, denominado look-ahead, que determina quantas posições serão percorridas na fila de espera do servidor $W e b$, em busca de uma requisição de determinada prioridade. Caso não seja encontrada nenhuma requisição desta prioridade, o algoritmo passa a buscar por requisições da classe de prioridade imediatamente inferior, e assim por diante. Esse algoritmo introduz certa flexibilidade na escolha da próxima requisição a ser atendida, ao se atribuir um valor para o look-ahead dando maior ou menor importância as requisições de mais alta prioridade. Assim, é evitado que as requisições de prioridade superior monopolizem os recursos do sistema, pois as requisições de prioridade inferior não devem ficar indefinidamente esperando nas filas.

O algoritmo Weighted Fair Queuing (WFQ) [Traldi et al. 2006] [Traldi 2006], desenvolvido inicialmente para a camada de rede, deixa de trabalhar com pacotes e passa a trabalhar com requisições HTTP, na camada de aplicação. Esse algoritmo considera um servidor Web com múltiplas filas, uma para cada classe de prioridade, e para cada classe é atribuído um peso, que indica o número de requisições que serão atendidas de sua respectiva fila. Após o atendimento das requisições desta classe, as requisições da classe de prioridade imediatamente inferior serão atendidas, segundo o algoritmo Round-Robin.

Barbato [Barbato 2007] propôs um algoritmo que atende a sessões ao invés de requisições individuais, denominado Algoritmo de Escalonamento Baseado em Sessão (Session-Based Scheduling Algorithm - SBSA). Seu objetivo é priorizar as sessões mais longas, caracterizadas por possuírem maior número de requisições. Assim, cada sessão possui um parâmetro, chamado look-ahead, que aumenta à medida que as suas requisições chegam ao sistema. O servidor Web possui informações de todas as sessões conduzidas a ele, e dos valores de look-ahead; e uma única fila de espera. Assim que o atendimento de uma requisição é concluído, a próxima requisição a ser buscada é aquela que pertence à sessão de maior look-ahead, cujo valor é la1. A busca inicia-se no início da fila de espera e são percorridas, no máximo, la1 posições. Caso não seja encontrada nenhuma requisição desta sessão nas primeiras la1 posições, é iniciada a busca pela requisição pertencente à segunda maior sessão, cujo valor do look-ahead é la2, em que la2 $\leq$ la1, e assim sucessivamente. A velocidade de crescimento do look-ahead de uma sessão é obtida em função do número de requisições que chegam ao sistema, pertencentes a essa sessão. 
O Algoritmo de Escalonamento Baseado em Sessão com Serviços Diferenciados (SessionBased Scheduling Algorithm with Differentiated Services - SBSA-DS) [Barbato 2007] consiste de uma pequena adaptação do algoritmo SBSA. Seu objetivo é diferenciar os serviços dados aos clientes, considerando seu histórico, e levando em conta as sessões. Neste caso, existe a necessidade de classificação dos clientes em classes de serviço. Assim, um cliente pode pertencer a classe alta, média ou baixa ou a classe A, B ou C. A diferença entre o algoritmo SBSA-DS e o SBSA está na definição da função que determina o valor do look-ahead das sessões, pois no SBSA-DS, o valor de look-ahead é definido em função do número de requisições, e também, em função da classe da sessão.

Casagrande et al. [Casagrande et al. 2007] implementa uma política de escalonamento de tempo real para fornecimento de QoS absoluto para servidores Web, denominada EBS (Exigency-Based Scheduling). Esta política tem como objetivo fornecer respostas em menor tempo para as requisições mais urgentes sem, no entanto, degradar a qualidade de serviço em todo o sistema.

\subsubsection{Políticas de Particionamento}

As políticas de particionamento fazem a diferenciação de serviços através da reserva de recursos. Assim, a diferenciação ocorre direcionando as requisições para os recursos apropriados, dando atendimento preferencial àquelas de maior prioridade.

As políticas de particionamento podem ser dividas em estáticas e dinâmicas, como discutido nas seções subsequentes.

\section{Particionamento de Recursos Estático}

Nos algoritmos de particionamento estático, os recursos são divididos entre as classes de serviço, e esta divisão é mantida durante todo o funcionamento do algoritmo, até que seja modificada explicitamente pelo administrador.

O algoritmo StaticPartitioning, proposto por Cardellini et al. [Cardellini et al. 2001], associa um conjunto de servidores a cada classe de serviço. Para um sistema composto por N servidores, é proposto um conjunto de $\mathrm{K}$ elementos, em que $K=\lceil(p N)\rceil$ e p é a porcentagem de requisições pertencentes a determinada classe. Podem ser acrescentadas algumas unidades do número de elementos, para satisfazer os acordos de níveis de serviço firmado com os clientes.

Em [Andreolini et al. 2004] é proposto o algoritmo StaticPart, que difere do StaticPartitioning apenas na escolha de quantos servidores devem ser acrescentados, aumentando o valor 
de K, para que o acordo de nível de serviço seja mantido.

No algoritmo Reserva de Recursos (RSV) [Teixeira 2004], o cluster de servidores é dividido, e cada parte é associada a uma classe ou grupo de classes de serviço. Como a divisão é feita de maneira estática, é necessário que o administrador do sistema conheça antecipadamente a carga de trabalho que lhe será imposta, para que a divisão do cluster resulte em uma diferenciação de serviços.

O particionamento estático é melhor aplicável onde a carga de trabalho é conhecida ou previsível. Em ambientes como a $W e b$, em que a carga pode variar muito, de maneira inesperada, a divisão de recursos feita inicialmente pode se tornar inadequada. Além disso, com o particionamento estático, alguns recursos reservados para determinada classe, podem ficar sobrecarregados, enquanto que outros ficam ociosos ou subutilizados.

Para contornar essas desvantagens, são propostos os algoritmos de particionamento dinâmico.

\section{Particionamento de Recursos Dinâmico}

Usando particionamento de recursos dinâmico, a divisão dos recursos, estabelecida previamente pelo algoritmo, pode mudar de acordo com a carga de trabalho imposta ao sistema.

O algoritmo DynamicPartitioning, proposto por Cardellini et al. [Cardellini et al. 2001], faz a alteração na divisão de recursos caso a soma da carga dos servidores dedicados a classe de maior prioridade ultrapasse determinado limite. Um servidor da classe de menor prioridade é movido para essa classe. Esse servidor, no entanto, continuará atendendo as requisições em fila da classe inferior, e apenas as novas requisições da classe de maior prioridade que serão enviadas a ele. O servidor movido pode voltar para a classe de menor prioridade se a sua ausência não violar o SLA.

Andreolini et al. [Andreolini et al. 2004] consideram o algoritmo DynamicPart, semelhante ao DynamicPartitioning proposto por Cardellini et al. [Cardellini et al. 2001]. No entanto, nesse algoritmo é usado o número de requisições para documentos estáticos e dinâmicos para medir a carga do sistema, diferente do DynamicPartitioning que considera apenas as requisições a documentos estáticos.

Zhu et al. [Zhu et al. 2001] propõem um algoritmo que se adapta dinamicamente as variações na carga de trabalho, modificando a divisão do cluster de servidores Web dependendo da demanda por recursos. Periodicamente, são calculados o número de servidores que devem ser direcionados a uma classe, e qual a porcentagem de requisições desta classe que deve ser rejeitada para que haja diferenciação de serviços e garantia de desempenho, como já discutido 
na Seção 4.2.3.

O algoritmo Reserva Adaptativa de Recursos (RSVAdap) [Traldi et al. 2006], divide os recursos entre as classes presentes, dinamicamente, de acordo com a carga atual no sistema, ou seja, baseando-se no número de requisições de classe. Seu objetivo é garantir melhores serviços para as classes de maior prioridade.

Um dos objetivos do mecanismo WS-DSAC, proposto por Serra et al. [Serra et al. 2005], é utilizar os recursos do sistema de forma eficaz. Para isto, os recursos disponíveis são realocados dinamicamente entre as diferentes classes de serviços, enquanto eles não estiverem em níveis críticos de utilização. Isto é feito para que as classes de menor prioridade não sejam prejudicadas devido aos serviços das classes de maior prioridade, enquanto existirem recursos disponíveis.

Marques [Marques 2008] descreve uma forma de gerenciar dinamicamente a capacidade de alocação de recursos em cluster de servidores Web utilizando sistema multiagente. Os agentes tomam decisões dinâmicas a respeito da taxa de utilização dos recursos e da carga do sistema a fim de melhorar a eficiência na utilização destes recursos. Assim, o suporte necessário às mudanças dos recursos disponíveis na plataforma são realizados sem a interferência do administrador, cuja presença só é necessária para a definição das regras fundamentais para que a plataforma seja inicializada.

\subsection{Considerações Finais}

Neste capítulo foi discutido o controle de admissão, responsável pelo descarte de requisições ou sua negociação para atendimento em uma classe de prioridade menor, para que não haja sobrecarga dos recursos do sistema, gerando uma possível negação de serviço.

Foi discorrido ainda sobre as políticas de escalonamento e de particionamento de recursos, responsáveis pelo isolamento das classes, um dos importantes conceitos relacionados a qualidade de serviços na $W e b$. As políticas de escalonamento decidem qual requisição ou sessão será servida, e as políticas de particionamento de recursos são responsáveis por eleger recursos para ser utilizados por classes de serviço específicas. As políticas de particionamento são dividas em dois grupos: as que têm os recursos do sistema particionados estaticamente, e as que particionam os recursos dinamicamente, ou seja, durante a execução e funcionamento do sistema. Ao final da discussão sobre cada um desses temas, foram apresentados trabalhos relacionados de alguns autores.

No próximo capítulo serão abordados alguns benchmarks e geradores de carga de trabalho usados para avaliar servidores Web. As ferramentas de maior importância abordadas serão 
o benchmark HTTPerf [Httperf 2009] e o W4Gen [Silva 2006], que possui o mesmo objetivo deste trabalho, ou seja, gerar carga de trabalho sintética para modelos de servidores Web, e será usado neste projeto de mestrado para a geração de algumas características e componentes da carga de trabalho. 
$\Gamma_{\text {Capítulo }}$

\section{Geração da Carga de Trabalho}

\subsection{Considerações Iniciais}

O crescimento da $W e b$ tem motivado várias pesquisas que buscam analisar esse ambiente, quantificar seu tráfego, definir características relacionadas à sua carga de trabalho e avaliar servidores $W e b$, tudo isso visando oferecer melhores serviços aos usuários. Apesar disso, poucos geradores de carga de trabalho para servidores Web são encontrados, sendo que, na maioria das vezes, eles se apresentam na forma de benchmarks [WebStone 2002; SPECWeb 2011; Httperf 2009].

Como são bastante úteis para avaliar desempenho de servidores Web, alguns benchmarks e geradores de carga de trabalho foram analisados, a fim de criar os subsídios necessários para o desenvolvimento de um gerador de carga baseada em sessões.

Na Seção 5.2 é apresentado um gerador de carga de trabalho sintética, que será utilizado no desenvolvimento deste projeto de mestrado, o W4Gen, implementado por [Silva 2006]. Na seqüência, são apresentados o gerador de carga de trabalho JMeter (Seção 5.3), e os benchmarks SPECWeb (Seção 5.4), WebStone(Seção 5.5) e HTTPerf (Seção 5.6). Todos os geradores analisados atuam enviando requisições para um servidor Web. Para atingir o objetivo deste trabalho, que é possibilitar a geração de carga baseada em sessões para alimentar simuladores de servidores $W e b$, fez-se um estudo comparativo entre os geradores de carga disponíveis. Essa comparação é apresentada na Seção 5.7. Na Seção 5.8, é apresentada a proposta de um gerador de carga de trabalho baseada em sessões. Nessa seção são apresentados ainda os trabalhos relacionados utilizados para a geração de seus componentes e, as ferramentas utilizadas como base para sua implementação. E finalmente, na Seção 5.9 é apresentado o Gerador de Sessões 
Sintéticas proposto nesta dissertação.

\subsection{W4Gen}

Devido à dificuldade de se obter cargas de trabalho reais, que representem o ambiente atual da $W e b$, com seus principais tipos de requisições, e a frequência com que elas ocorrem, [Silva 2006] desenvolveu um gerador de cargas sintético, denominado W4Gen (World Wide Web Workload Generator), cujo objetivo é gerar carga de trabalho sintética para avaliar e validar o desempenho de servidores $W e b$.

O W4Gen foi desenvolvido na linguagem Java, e suas principais características são [Silva 2006]:

- Gerar cargas sintéticas para modelos de servidores Web;

- Gerar cargas equivalentes a ambientes pré-definidos, como sites acadêmicos e de notícias;

- Permitir a modificação de algumas características da carga de trabalho, permitindo uma configuração específica de um ambiente $W e b$;

- Permitir que uma função de distribuição de probabilidade adequada seja selecionada para reproduzir uma característica da carga de trabalho;

- Permitir a seleção de modelos pré-definidos ou a criação de um novo modelo de carga de trabalho.

Para o desenvolvimento do W4Gen foi utilizada uma biblioteca de classes, escrita em Java, chamada Probability/Statistics Object Library [Siegrist 2005]. Algumas características não disponíveis na biblioteca utilizada foram adicionadas ao conjunto de classes do gerador por Silva [Silva 2006].

\subsubsection{Modelo de Carga de Trabalho}

O W4Gen gera cargas de trabalho segundo quatro características: o intervalo de chegada das requisições, a classe do objeto, o código de resposta devolvido pelo servidor $W e b$, e o tamanho do objeto. Os elementos que compõem a carga de trabalho são apresentados na Figura 5.1.

O primeiro elemento é o timestamp, isto é, o instante em que a requisição chegou ao servidor Web. Este campo pode assumir os valores zero ou qualquer número inteiro positivo. O segundo campo identifica o tipo de objeto requisitado ao servidor Web. Este campo pode assumir nove 


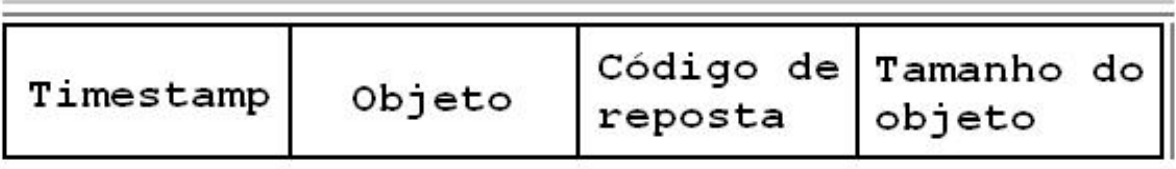

Figura 5.1: Formato da requisição do W4Gen [Silva 2006].

valores diferentes, correspondentes as nove classes criadas para agrupar as variações de objetos. Essas classes são baseadas na extensão do arquivo requisitado. São elas: imagem; linguagem de marcação; dinâmico; texto; documento; script cliente e animação; áudio; binário e compactado; e vídeo [Silva 2006].

O terceiro componente da carga de trabalho representa o código de reposta enviado pelo servidor. Esta informação determina se a requisição foi aceita e processada pelo servidor, alocando seus recursos, ou se ela foi rejeitada por falta de dados ou por ser inválida. Os quatro valores de código de reposta são: 2xx (sucesso), 3xx (redirecionamento), 4xx (erro do cliente) e 5xx (erro do servidor).

E finalmente, o tamanho do objeto informa a quantidade de dados transferidos, em bytes. Assim, apenas as requisições que possuem código de resposta 2xx tomam valores maiores que zero. Para as demais classes, os tamanhos são iguais a zero.

Na Figura 5.2 mostra-se um exemplo de um arquivo produzido pelo W4Gen, contendo os quatro campos citados. No exemplo, todas as requisições chegaram ao mesmo instante, ou seja, no tempo zero. Observa-se a presença de diversos tipos de objetos como, imagem (image), texto (text), script cliente e animação (script). E também, dois tipos de código de resposta, a 2xx (sucesso) e a $3 \mathrm{xx}$ (redirecionamento).

\section{0 html $2 \times x 25397$ \\ 0 image $2 \times x 283$ \\ 0 image $3 \times x 0$ \\ 0 text $2 \times x 264$ \\ 0 html 2xx 19421 \\ 0 video $3 \times x 0$ \\ 0 script $2 \times x 12847$ \\ 0 image $3 \times x 0$ \\ 0 image 2xx 8394 \\ 0 image $2 x \times 4029$}

Figura 5.2: Arquivo de texto produzido pelo W4Gen [Silva 2006].

O W4Gen, além de gerar cargas baseadas em ambientes pré-definidos, permite ao usuário 
criar seu próprio modelo de carga de trabalho, definindo como cada campo da requisição deverá ser determinado, seguindo as opções discutidas a seguir.

O código de resposta pode ser gerado a partir de três técnicas diferentes: usando somente a requisição 200, usando uma função de distribuição e usando valores de porcentagem. No primeiro caso, nenhuma função de distribuição é usada, apenas o código de resposta 200 é acrescentado a todas as requisições. No segundo caso, o código de resposta é gerado segundo a distribuição Geométrica, e o parâmetro que configura a função deve ser definido. E no terceiro caso, cada um dos quatro tipos de código de resposta retornados pelo servidor deve ser configurado, segundo valores de porcentagem.

As nove possíveis classes de objeto podem ser geradas a partir de duas técnicas: usando uma distribuição, neste caso, a Geométrica, e o valor do parâmetro que configura a função deve ser definido; ou usando valores de porcentagem, e então, cada uma das nove classes de objeto deve ser configurada.

O W4Gen permite uma única forma para produzir o intervalo de chegada, baseandose somente em função de distribuição. O usuário pode configurar o tipo de distribuição que melhor se adapta as características do comportamento de chegada das requisições, bem como os parâmetros da função. Um campo chamado Sobrecarga permite ainda, comprimir o tempo de chegada entre as requisições, impondo uma carga de trabalho pesada ao servidor Web, com o objetivo de saturá-lo.

O tamanho do objeto também pode ser configurado somente de acordo com as funções de distribuição e seus parâmetros. Caso a configuração padrão seja mantida, a carga será baseada nos estudos feitos pelo autor sobre os nove logs coletados de servidores Web Apache. Mudanças desses valores podem reproduzir um comportamento diferente da realidade da $W e b$.

\section{$5.3 \quad$ JMeter}

JMeter [JMeter 2010] é uma ferramenta de código aberto, escrita em Java, desenvolvida pela Apache Software Foundation. Foi criada para realizar testes de desempenho em aplicações Web. Atualmente o JMeter é usado para outros tipos de teste, inclusive testes de validação de aplicações.

JMeter pode ser usado para testar recursos estáticos e dinâmicos, como arquivos estáticos, Java Servlets, scripts Pearl, Java Objects e Servidores FTP. Ele pode ser usado para simular cargas para testar o desempenho de servidores, redes ou objetos, no âmbito de diferentes tipos de carga. 
As principais características do JMeter incluem a possibilidade de realizar testes de desempenho com diferentes tipos de servidores ( Web - HTTP e HTTPS, SOAP, banco de dados via JDBC (Java Database Connectivity), LDAP (Lightweight Directory Access Protocol), JMS (Java Message Service), e-mail - POP3 e IMAP), sendo possível também, construir o acesso a um fluxo pré-definido de páginas Web para simular o acesso por diversos usuários concorrentes, através de threads simultâneas. Outra característica importante é a portabilidade por ser uma ferramenta escrita na linguagem Java.

\subsection{SPEC $W e b$}

O SPEC Web [SPECWeb 2011] é uma ferramenta proprietária desenvolvida pela SPEC (Standard Performance Evaluation Corporation), que gera três diferentes tipos de carga de trabalho para avaliar o desempenho dos servidores $W e b$. Os três tipos de carga são baseados em aplicações Web reais: serviço bancário online, comércio eletrônico e, a terceira carga de trabalho é baseada em download de patches para suporte das aplicações informáticas.

A caracterização dos três tipos de carga de trabalho é baseada em estudos de logs de servidores Web reais. Nos estudos dos logs utilizados para o desenvolvimento da carga de trabalho baseada em serviço bancário, foram considerados o tipo de requisição (GET, POST, HEAD), o código de resposta retornado pelo servidor (200, 206, 302, 304, 403), a versão do protocolo HTTP utilizada, e baseando-se nos resultados desse quesito, decidiu-se basear todas as requisições na versão 1.1. Os tamanhos dos arquivos baseam-se apenas nos arquivos estáticos, pois o servidor não registra no log o tamanho da resposta para requisições dinâmicas. Assim, para os tamanhos dos arquivos dinâmicos, considera-se um levantamento em vários sites de serviço bancário, verificando-se que grande parte dos scripts retorna páginas de 10 a $100 \mathrm{~KB}$.

Nos períodos de fluxo intenso de requisições, os intervalos entre as requisições não podem exceder certo limite, definido como 5 segundos. Para modelar o tempo de pensar da carga de trabalho do serviço bancário foi utilizada a distribuição geométrica com média de 9,9 segundos. O tempo de pensar seguiu a distribuição geométrica, também com média de 9,9 segundos para a carga de trabalho de comércio eletrônico. E para a carga de trabalho de support, o tempo de pensar também seguiu a distribuição geométrica, com média de 5,1 segundos.

Um modelo baseado na cadeia de Markov é usado para simular a execução dos scripts dinâmicos, bem como as requisições a arquivos estáticos, para cada cliente, ou seja, é usado para simular as freqüências de requisições a páginas.

Cada requisição envolve a execução de um script dinâmico no servidor. A execução desse 
script retorna um arquivo criado dinamicamente e os arquivos embutidos que são requisitados em seguida, como imagens e outros arquivos estáticos.

Os requisitos de QoS são baseados em atraso de retorno das páginas requisitadas e taxa de bytes, no caso de páginas grandes.

Um dos componentes lógicos do SPEC Web2005 representa os clientes, que são aplicações que enviam requisições HTTP ao servidor e recebe respostas, ou seja, geram a carga. Pode existir um número $\mathrm{N}$ de clientes no sistema. O número de sessões simultâneas no sistema corresponde ao número de processos/threads geradores de carga que enviam pedidos continuamente ao servidor Web durante a execução do benchmark.

\subsection{WebStone}

O WebStone [WebStone 2002] foi originalmente desenvolvido pela Silicon Graphics para medir o desempenho de servidores $W e b$ e, posteriormente a Mindcraft, Inc. adquiriu os seus direitos.

Sua carga de trabalho é gerada pela simulação de vários clientes executando em um ou vários computadores ao mesmo tempo. Esses clientes podem ser vistos como usuários, browsers, ou outro software que recupera arquivos de um servidor Web. É possível executar 100 clientes em um único computador.

Os clientes geram a carga enviando requisições HTTP/1.0 do tipo GET para arquivos específicos no servidor. O conjunto de arquivos utilizados pelos WebStone é baseado no modelo do site da Silicon Graphics, de 1995, e pode ser alterado para melhor representar a carga desejada.

O conjunto de arquivo padrão WebStone é pequeno, o que significa que normalmente será executado a partir da cache do servidor Web. Desta forma, o WebStone é útil para testar o sistema operacional, a CPU e a velocidade da rede, mas não a velocidade de acesso ao disco (exceto em relação à criação de processos de testes CGI (Common Gateway Interface)).

O WebStone realiza seus testes utilizando três diferentes tipos de acesso: HTML, CGI e API. No primeiro caso, o servidor Web retorna ao cliente um arquivo. No segundo caso, o servidor Web necessita executar outro programa, utilizando o protocolo CGI para passar os parâmetros para o programa especificado na requisição. No terceiro caso, o servidor Web passa a requisição para a API (Application Programming Interface) e assim, o programa relacionado responderá a solicitação de determinada página $W e b$.

O Webmaster é o programa que controla o teste e pode ser executado em um dos compu- 
tadores cliente, ou em um computador separado, combinando então, os resultados de todos os clientes em um único relatório. Os principais resultados conseguidos são throughput, latência de conexão (tempo para se estabelecer uma conexão com o servidor $W e b$ ) e latência da requisição (tempo necessário para transferir os dados).

\subsection{Httperf}

HTTPerf [Httperf 2009] é uma ferramenta para testes de desempenho em servidores Web, originalmente escrita por David Mosberger [Mosberger and Jin 1998]. Para realização dos testes são criadas requisições HTTP, tanto na versão HTTP/1.0 como na versão HTTP/1.1, e para isso existem dez geradores de carga de trabalho. Sua operação mais básica é gerar um número fixo de requisições do tipo GET, e medir quantas respostas retornam do servidor, e a que taxa retorna. Os resultados das execuções, resumidos em forma de estatísticas, são impressos ao final.

A ferramenta, escrita na linguagem $\mathrm{C}$ possui três módulos: CORE, geradores de carga de trabalho e coletores de estatísticas. No código fonte, os arquivos pertencentes a cada um desses módulos estão em diretórios distintos. No diretório principal encontram-se os arquivos referentes ao CORE, e em dois subdiretórios gen e stat, encontram-se os arquivos referentes aos módulos de geração de carga e coleta de estatísticas, respectivamente.

O CORE gerencia a comunicação com o servidor, estabelecendo conexões e gerando requisições HTTP. Ele controla a execução do benchmark, fazendo a inicialização e disparando os outros dois módulos. A interação entre os módulos ocorre através da sinalização de eventos.

O módulo de geração da carga é responsável por iniciar requisições HTTP para gerar uma carga particular ao servidor. Os geradores de carga de trabalho oferecidos pelo HTTPerf são:

- call_seq - que executa uma sequência de chamadas em uma conexão;

- conn_rate - que cria conexões a uma taxa fixa especificada por PARAM.RATE ou sequencialmente se PARAM.RATE for definido como zero;

- misc - que implementa diversas operações de linha de comando;

- sess_cookie - gerencia cookies por sessão;

- uri_fixed - gera requisições a uma URI fixa especificada por PARAM.URI; 
- uri_wlog - gera a carga baseada em uma lista de URIs predeterminada, e pode ser usado para recriar uma carga de trabalho baseada em um arquivo log de um servidor;

- uri_wset - gera URIs acessando um conjunto fixo de arquivos a uma determinada velocidade;

- wsess - cria uma carga de trabalho baseada em sessão de acordo com a taxa especificada em PARAM.RATE;

- wsesslog - cria sessões de acordo com descrições lidas a partir de um arquivo de configuração, a uma taxa fixa PARAM.RATE;

- wsesspage - cria sessões que procuram por páginas HTML e objetos embutidos. Este gerador é semelhante ao wsess, mas em vez de gerar rajadas fixas, cada página HTML buscada é analisada e os objetos embutidos são requisitados em uma única rajada.

O módulo coletor de estatísticas é responsável por medir os dados e produzir estatísticas a respeito do desempenho do servidor. O HTTPerf não possui um gerenciador central para as diversas máquinas clientes que podem ser utilizadas em um teste. Terminada a execução, as estatísticas são impressas por cada máquina cliente, e obter um relatório geral é tarefa do usuário.

Existem seis grupos de estatísticas: resultados gerais (Total), resultados referentes a conexões (Connection), referentes a requisições HTTP (Request), respostas recebidas do servidor (Reply), utilização da CPU $(C P U)$, e utilização da rede (Net I/O) e um sumário de erros (Errors).

Além disso, quando são utilizadas sessões, o HTTPerf imprime os resultados a respeito dessas sessões. A linha Session rate apresenta os valores de mínimo, média, máximo e desvio padrão atingidos durante a execução do teste, em termos de sessões por segundo (sess/s), e os números apresentados entre parênteses indicam quantas sessões ocorreram com sucesso e quantas foram criadas. A linha Session mostra o tamanho médio das sessões em termos de conexões por sessão. A linha Session lifetime mostra quantos segundos foram gastos, em média, para completar uma sessão. O valor dado por Session failtime refere-se ao tempo médio até que ocorra uma falha em alguma sessão. A linha Session length histogram apresenta um histograma do número de respostas recebidas por cada sessão.

Alguns dos parâmetros de configuração do HTTPerf, especificados em linha de comando, são descritos no Apêndice A. 


\subsection{Comparação entre os Geradores de Carga Analisa- dos}

A primeira característica a ser observada nos geradores de carga comparados é o suporte ao protocolo HTTP, para que se possa gerar uma carga para servidores Web. No entanto, para que a carga seja mais realista, o gerador deve suportar as versões HTTP/1.0 e HTTP/1.1 do protocolo. O benchmark SPEC Web suporta apenas a versão 1.1 do protocolo HTTP, e o WebStone, apenas a versão 1.0. As ferramentas analisadas que suportam as duas versões do protocolo são o JMeter e o HTTPerf.

Outra característica importante, neste caso, é a geração de conteúdo estático e dinâmico, o que permite melhor representar o ambiente Web. Neste caso, todos os geradores analisados oferecem os dois tipos de conteúdo.

Como o objetivo do projeto em questão é desenvolver um gerador de sessões, é essencial que o gerador utilizado como base para o seu desenvolvimento, ofereça a possibilidade de se criar carga baseada em sessões de usuários. As ferramentas WebStone e JMeter baseam sua geração de carga em requisições individuais. Apenas o SPEC Web e o HTTPerf possibilitam a criação de carga baseada em sessão. No entanto, o SPEC Web é um benchmark proprietário e de código fechado, ou seja, a sua obtenção requer custos e o código não é disponibilizado, o que inviabiliza a sua utilização em ambiente acadêmico.

Devido a todas essa características apresentadas, a ferramenta escolhida para servir como base a criação do gerador de sessões, foi o HTTPerf. Além das características discutidas, o HTTPerf apresenta um conjunto de resultados bastante amplo (completo), e permite a representação de múltiplos usuários, o que viabiliza a sua utilização.

A Tabela 5.1 apresenta um resumo com as características observadas nos geradores de carga de trabalho.

\subsection{Desenvolvimento de uma Carga de Trabalho Basea- da em Sessões}

O gerador de cargas de trabalho sintéticas W4Gen (World Wide Web Workload Generator), desenvolvido em Java por [Silva 2006], tem por objetivo gerar carga de trabalho para avaliar e validar o desempenho de servidores Web e de algoritmos de escalonamento. No entanto, esta ferramenta gera requisições individuais, e não contempla o conceito de sessões de usuários. 
Tabela 5.1: Principais características das cargas de trabalho.

\begin{tabular}{|c|c|c|c|c|}
\hline & SPECWeb & WebStone & JMeter & HTTPerf \\
\hline Última Versão & $\begin{array}{c}2005 \text { (versão } 1.20), \\
2009 \text { (versão } 1.0)\end{array}$ & Versão 2.5 & Versão 2.3 .4 & Versão 0.9 .0 \\
\hline Resultados/Saídas & $\begin{array}{l}\text { Atraso de retorno } \\
\text { e taxa de bytes }\end{array}$ & $\begin{array}{c}\text { Throughput, latência } \\
\text { de conexão e latência } \\
\text { da requisição }\end{array}$ & $\begin{array}{l}\text { Média, mediana, } \\
\text { desvio padrão e } \\
\text { throughput }\end{array}$ & $\begin{array}{c}\text { Gerais, referentes às } \\
\text { conexões, requisições, } \\
\text { respostas, utilização } \\
\text { da CPU e rede, erros, } \\
\text { e sessões }\end{array}$ \\
\hline Sessão & Sim & Não & Não & Sim \\
\hline Conteúdo & Estático e dinâmico & Estático e dinâmico & Estático e dinâmico & Estático e dinâmico \\
\hline Protocolos & $\begin{array}{l}\text { HTTP } / 1.1 \\
\text { e HTTPS }\end{array}$ & HTTP $/ 1.0$ & $\begin{array}{l}\text { HTTP, HTTPS, } \\
\text { SOAP, LDAP, } \\
\text { POP3 e IMAP }\end{array}$ & $\begin{array}{c}\text { HTTP/1.0 e } \\
\text { HTTP/1.1 }\end{array}$ \\
\hline $\begin{array}{l}\text { Número de } \\
\text { usuários/clientes }\end{array}$ & Múltiplos & Múltiplos & Múltiplos & Múltiplos \\
\hline $\begin{array}{l}\text { Linguagem de } \\
\text { Programação }\end{array}$ & Java e C & $\mathrm{C}$ & Java & $\mathrm{C}$ \\
\hline Código & Fechado & Aberto & Aberto & Aberto \\
\hline Livre/Proprietário & Proprietário & Free & Free & Free \\
\hline Tipo de Ferramenta & Benchmark & Benchmark & Gerador & Benchmark \\
\hline
\end{tabular}

Para implementação do conceito de sessões em um gerador de carga de trabalho, foi utilizado como base o HTTPerf. Essa escolha se deve ao fato da ferramenta possuir uma variedade de geradores de carga, inclusive de sessões, ser livre, de código aberto, e amplamente utilizada em trabalhos da área [Semprebom et al. 2006; Sousa et al. 2008; Petrucci et al. 2009; Costa 2009; Sousa and Santos 2010]. Diversos outros trabalhos foram utilizados para definir adequadamente os parâmetros do gerador.

Para o desenvolvimento do gerador de sessões proposto neste trabalho, utilizam-se os mesmos parâmetros definidos pelo HTTPerf: -- sess_cookie, que define um identificador por sessão, --burst-length, que especifica o tamanho das rajadas de requisições enviadas ao servidor; do --period, que especifica o intervalo de tempo entre as sessões, definido por uma função de distribuição de probabilidade; e do gerador --wsess, em que se define que uma sessão consite de uma rajada de requisições, espaçadas por um tempo de pensar. Sendo assim, é criado um número N1 de sessões, cada uma contendo N2 requisições em rajadas de tamanho L fixo, definido pelo usuário, espaçadas por um tempo de pensar X. O intervalo de tempo para a criação das sessões segue uma função de distribuição, que pode ser definida como determinística, exponencial, ou uniforme, e os parâmetros das funções são também definidos pelo usuário.

Um problema observado na definição desses parâmetros no HTTPerf é que todos estes parâmetros - número de sessões, número de requisições por sessão, tempo de pensar, tamanho da rajada, função de distribuição, parâmetro para função determinística, média para função exponencial, e valores mínimo e máximo para função uniforme - são considerados fixos, durante a execução do benchmark, definidos por entradas do usuário. Apenas o identificador do cliente é definido pelo programa, e usado na configuração do vetor usado para geração de números 
pseudo-aleatórios.

A utilização destes parâmetros fixos não se mostra adequada para a criação de uma carga de trabalho realística, devido ao fato da $W e b$ ser um ambiente inconstante, em que o número de requisições de usuário contidas em uma sessão varia, assim como a taxa de chegada, o intervalo entre as sessões, o tempo de pensar do usuário antes de enviar novas rajadas.

Assim, para solucionar o problema apresentado, verificou-se na literatura, caracterizações da carga de trabalho da $W e b$, de forma a desenvolver um gerador de carga que gere uma carga para os simuladores de servidores $W e b$, o mais próximo possível da realidade. A estrutura geral do instante de chegada das sessões criadas pelo gerador de carga proposto baseia-se no benchmark HTTPerf.

\subsubsection{Identificador da Sessão}

Cada cliente, ou seja, cada instância do gerador, recebe um valor inteiro positivo distinto, como identificador. Este valor é usado para a geração do identificador (cookie) da sessão. Sendo assim, cada sessão obtém um único identificador, de acordo com o definido no gerador sess_cookie, do HTTPerf, em que todas as requisições enviadas por uma sessão possui este identificador.

\subsubsection{Número de Sessões}

O número de sessões criadas pelo gerador de sessões sintéticas foi mantido como entrada de usuário. Esse parâmetro define o tamanho da simulação e não deve interfir na carga do sistema. Assim, o mais adequado é que o usuário defina por quanto tempo a simulação deve ser executada.

\subsubsection{Tamanho das Sessões}

Alguns trabalhos afirmam que a distribuição Gaussiana Inversa é adequada para modelar o número de requisições por sessão [Pitkow 1999; Casalicchio et al. 2002]. Pitkow [Pitkow 1999] apresenta a distribuição de cauda pesada com média 3 e desvio padrão 9. Casalicchio et. al [Casalicchio et al. 2002] utiliza os parâmetros $\mu=3,86$ e $\lambda=9,46$. Estes trabalhos se basearam em [Huberman et al. 1998], que mostram que o número de cliques que os usuários fazem nos sites exibem regularidades. Ao utilizar traces obtidos através de trabalhos relacionados e de cinco dias do proxy AOL em dezembro de 1997, verificou-se que a distribuição de todos os 
cliques do usuário por site é Gaussiana Inversa. A distribuição Gaussiana Inversa de cliques também foi encontrada para todos os usuários do Xerox Web site, fazendo uma ponte entre o cliente, proxy e servidor, e observando o comportamento.

Neste projeto de mestrado, foi realizada uma caracterização do log da Copa do Mundo de Futebol de 1998. Para isto, foram avaliados 1 milhão de registros do log do dia 11 de junho de 1998 (arquivo wc_day47_1 disponível para consulta em [Archive 1998]), a partir do registro 3,6 milhões, faixa do $\log$ em que, segundo Teixeira [Teixeira 2004], ocorre um aumento na carga de trabalho. Cada endereço IP é considerado como um cliente e, utiliza-se um timeout de 120 segundos para considerar uma sessão encerrada [Barbato 2007], obtendo-se então a porcentagem de cada tamanho de sessão, como mostrado no gráfico da Figura 5.3.

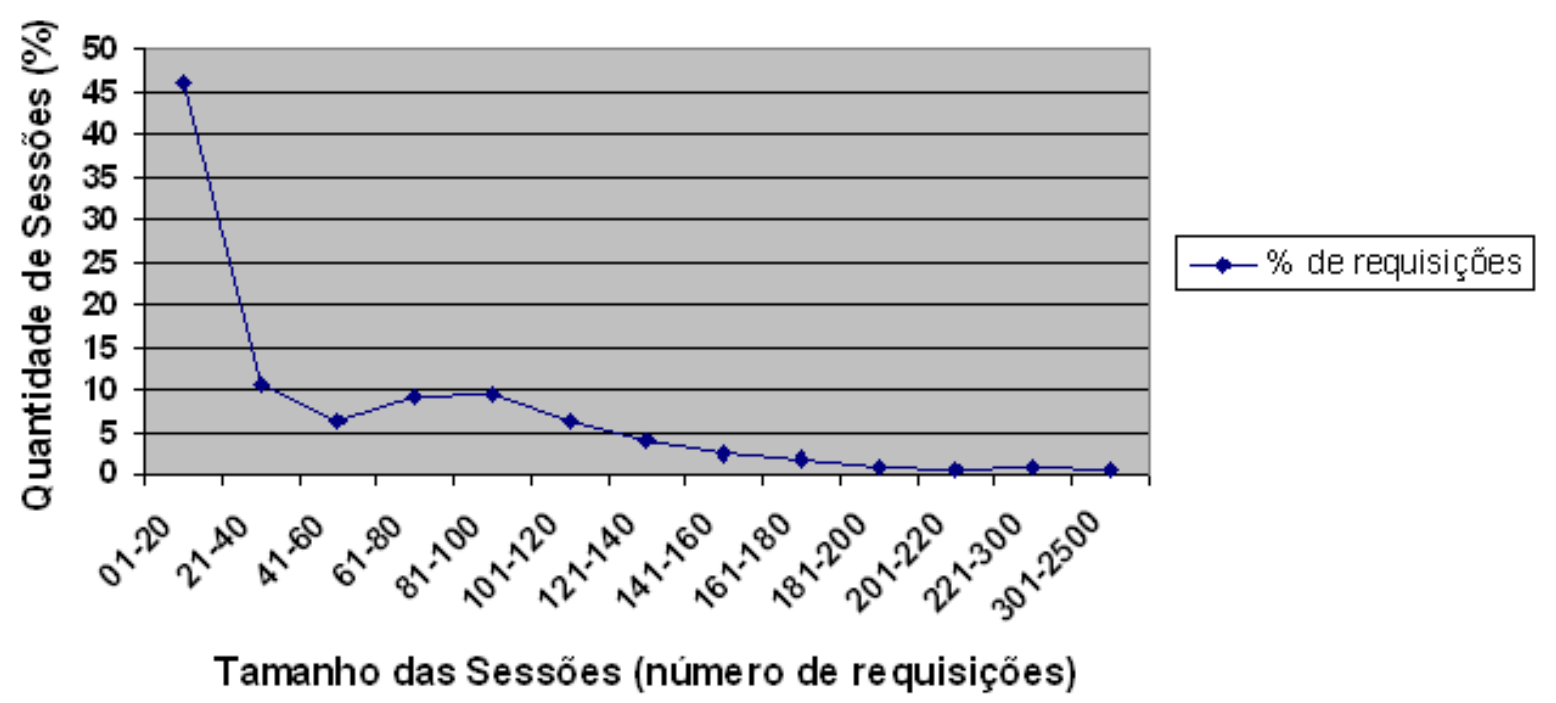

Figura 5.3: Porcentagem de sessões de determinado tamanho.

Como mostrado no gráfico da Figura 5.3, 46,17\% das sessões possuem entre 1 e 20 requisições, 10,72\% possuem entre 21 e 40 requisições, 6,50\% das sessões possuem entre 41 e 60 requisições, e assim sucessivamente. Observa-se também através deste gráfico que, o número de requisições por sessão no log da Copa de 1998 obedece a uma distribuição de cauda pesada.

As sessões obtidas utilizando-se a função Gaussiana Inversa com $\mu=3,86$ e $\lambda=9,46$ são pequenas e, quando há necessidade de analisar o desempenho de um sistema em um cenário sobrecarregado, uma carga com sessões longas mostra-se mais adequada. Assim, os dados obtidos através da caracterização do log da Copa do Mundo de 1998 por número de requisições por sessão foram utilizados na implementação do gerador de sessões sintéticas proposto neste trabalho. 


\subsubsection{Rajada e Tempo de Pensar}

O intervalo de chegada, definido por Silva [Silva 2006] como a diferença de tempo entre duas requisições consecutivas feitas ao servidor, foi usado para criar o intervalo de chegada das requisições das sessões. A variação do tempo verificada por Silva [Silva 2006] foi feita baseada na classificação dos objetos, como imagem, linguagem de marcação, dinâmico, texto, documento, script cliente e animação, áudio, binário e compactado e vídeo.

Assim, as rajadas de requisições e o tempo de pensar do usuário são dados pela função de distribuição que define o intervalo de chegada das requisições das sessões.

As funções de distribuição usadas para gerar o intervalo de chegada das requisições de uma sessão estão resumidas na Tabela 5.2 .

Tabela 5.2: Distribuições para modelar os intervalos de chegada de requisições em uma sessão [Silva 2006].

\begin{tabular}{||l||c||c|}
\hline \hline Classe de Objetos & Função de Distribuição & Parâmetros \\
\hline \hline Imagem & Weibull & $\alpha=0,19 \beta=0,81$ \\
\hline Linguagem de Marcação & Weibull & $\alpha=0,45 \beta=25,07$ \\
\hline Dinâmico & Gamma & $\alpha=0,05 \theta=470354$ \\
\hline Texto & Gamma & $\alpha=0,22 \theta=2610$ \\
\hline Documento & Gamma & $\alpha=0,10 \theta=173958$ \\
\hline Scripts Cliente e Animação & Lognormal & $\mu=2,59 \sigma=5,66$ \\
\hline Áudio & Lognormal & $\mu=3,73 \sigma=4,32$ \\
\hline Binário e Compactado & Gamma & $\alpha=0,09 \theta=563767$ \\
\hline Vídeo & Gamma & $\alpha=0,13 \theta=154949$ \\
\hline \hline
\end{tabular}

A biblioteca de classes Probability/Statistics Object Library [Siegrist 2005], escrita em linguagem de programação Java, foi usada para reproduzir as características dos intervalos de chegada das requisições.

\subsubsection{Tempo entre as Sessões}

A variação de tempo entre as sessões é obtida através da função exponencial com parâmetro $\mu=30$ de acordo com [de la Sierra 2009]. A distribuição de probabilidade exponencial normalmente é utilizada para modelar o tempo entre eventos independentes que acontecem a uma média constante. É bastante usada em teoria de filas, já que permite modelar os tempos entre as chegadas dos clientes a um serviço. 
Na implementação do gerador de sessões, foi utilizada a própria função exponencial fornecida pelo HTTPerf, para reproduzir as características da variação do tempo entre as sessões. Essa função é definida como (-mean * $\log (1.0$ - funcao $))$, em que mean é a média da função exponencial, definida pelo usuário e, funcao é o valor atribuído pela função geradora de números aleatórios.

O HTTPerf foi escrito em linguagem de programação C, a qual fornece a função erand48(), baseada numa fórmula de congruência linear, para a geração de números pseudo-aleatórios.

Como o gerador de sessões sintéticas foi desenvolvido em Java, linguagem esta que não possui esta função em suas bibliotecas, uma instância da classe Random, pertencente ao pacote java.util, é usada para gerar valores pseudo-aleatórios. Nesta classe, também é utilizada uma semente de 48-bits, que é modificada através de uma fórmula de congruência linear. A função nextDouble() é usada para gerar valores distribuídos uniformemente no intervalo $[0,0 ; 1,0)$.

\subsubsection{Classe do objeto}

Os tipos de arquivos requisitados foram gerados de acordo com [Silva 2006], sendo agrupados em nove classes. Os resultados obtidos a partir da análise dos logs coletados entre 2002 e 2005 mostram que, 47,88\% das requisições feitas são à imagens. Os objetos classificados como Linguagem de Marcação obtiveram 28,48\% das referências. As requisições dinâmicas tiveram aumento em relação a trabalhos anteriores, devido a popularização de scripts executados no lado do servidor, como PHP (Hypertext Preprocessor), JSP (JavaServer Pages) e ASP (Active Server Pages), alcançando 14,96\%. A classe Texto obteve 3,60\% das requisições e a classe Documento 1,84\%. Para os scripts cliente/animação, executados na máquina do cliente, observou-se um número pequeno de referências, 1,84\%. Os objetos das classes Áudio, Vídeo e Binário/Compactado também foram referenciados poucas vezes, com 1,22\%, 0,03\% e 0,15\%, respectivamente.

Os objetos da classe Documento, Binário/Compactado, Áudio e Vídeo, apesar do pequeno número de referências, geralmente transferem um grande volume de dados [Silva 2006] [Chehadeh et al. 2006], podendo ser suficientes para produzir sobrecargas na rede e no servidor. As imagens, ao contrário, representam a maioria das requisições, mas o volume de transferências é pequeno. 


\subsubsection{Código de resposta}

Os códigos de resposta foram gerados de acordo com [Modesto et al. 2005], em que é mostrado um estudo sobre a $W e b$ brasileira com base em logs de 2005. Os códigos de resposta 200 (OK) e 206 (conteúdo parcial) foram classificados como OK, obtendo uma taxa de 86,45\%. O código 301 (redirecionado) obteve 6, 81\% e 404 (não encontrado), 5,88\%. A classe Erro do Servidor, que inclui as respostas 500 (erro interno), 502 (gateway com problemas), 503 (indisponível) e 204 (sem conteúdo) representa 0,40\%. E os códigos 401 (desautorizado), 403 (proibido) e 407 (inaceitável), pertencentes a classe Proibido, obtiveram 0,46\%.

\subsubsection{Tamanho do objeto}

O tamanho médio dos arquivos baseado no tipo, foi gerado de acordo com [Chehadeh et al. 2006], em que é realizado um estudo empírico com base em acessos a aproximadamente 34000 sites populares e, determinada estatísticas e distribuições para tamanhos e ocorrência de tipos específicos de objetos.

Os valores utilizados para os tamanhos dos objetos foram, então:

- Aplicação - 16,4 kbytes;

- Áudio - 512,5 kbytes;

- Imagem - 3,6 kbytes;

- Texto - 15,9 kbytes;

- Vídeo - 654,8 kbytes;

- Outros - 6,2 kbytes.

Foram consideradas neste estudo, os acessos a páginas iniciais, e páginas de nível 1, que são páginas referenciadas pela página inicial, representando qualquer página em um site Web.

\subsection{Gerador de Sessões Sintéticas}

Como discutido na seção anterior, o gerador de carga de trabalho desenvolvido neste trabalho baseia-se em cargas de trabalho reais, oferecendo uma carga realista e, ao mesmo tempo, oferecendo flexibilidade para que o usuário possa ajustar a carga gerada para a sua realidade. 
Utilizando o gerador de carga desenvolvido neste trabalho, o usuário poderá avaliar o desempenho de servidores $W e b$ considerando diferentes características, tais como algoritmos de controle de admissão, particionamento de recursos, escalonamento, arquitetura e quantidade de servidores, dentre outros.

Desta forma, o gerador de carga desenvolvido em linguagem Java, oferece ao avaliador de servidores $W e b$, cargas realistas e baseadas em sessão. Utilizando o gerador desenvolvido, o avaliador pode simular o sistema a ser avaliado sem a necessidade de pesquisar previamente as características principais da carga a ser considerada.

Os padrões pré-definidos no Gerador de Sessões Sintéticas são baseados nos estudos apresentados nas seções anteriores.

\subsubsection{Modelo da Carga de Trabalho}

O Gerador de Sessões Sintéticas gera sua carga de trabalho segundo cinco componentes: intervalo de chegada das requisições pertencentes às sessões, identificador da sessão, classe do objeto, código de reposta retornado pelo servidor Web, e o tamanho do objeto.

Na Figura 5.4 apresentam-se os componentes da carga de trabalho, cujos valores são gerados seguindo as características apresentadas na Seção 5.8. O primeiro componente representa o instante em que a requisição chega ao servidor $W e b$. Os valores produzidos pelo gerador estão organizados em ordem crescente.

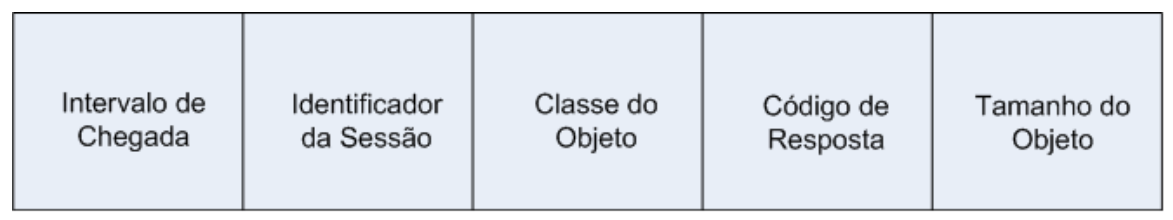

Figura 5.4: Formato da requisição do Gerador de Sessões Sintéticas.

O segundo campo indica o identificador da sessão, ou seja, todas as requisições que possuem o mesmo identicador pertencem a mesma sessão, e cada sessão possui um único identificador.

O terceiro campo identifica o tipo de objeto requisitado ao servidor Web. Este campo pode assumir nove valores, representando as nove classes criadas por Silva [Silva 2006] para agrupar as variações dos tipos de objetos.

O próximo elemento da carga representa o código de resposta retornado pelo servidor Web. Essa informação determina se a requisição gerada foi admitida e processada, utilizando recursos do sistema, ou se ela foi rejeitada por falta de informações ou por estar inválida. Quatro valores 
representam os quatro tipos de código de resposta: 2xx (sucesso), 3xx (redirecionamento), 4xx (erro do cliente) e 5xx (erro do servidor).

Por fim, o tamanho do objeto determina a quantidade de dados transferida, em bytes. Este campo pode assumir sete valores distintos, para cada uma das nove classes de objeto. No entanto, somente as requisições cujo código de resposta é $2 \mathrm{xx}$, assumem valores maiores que zero, para todas as outras, os tamanhos são iguais a zero.

A Figura 5.5 mostra o exemplo de um arquivo produzido pelo Gerador de Sessões Sintéticas, contendo os cinco campos discutidos. No exemplo, todas as requisições chegaram entre os tempos 0,310 e 0,318. Existem requisições pertencentes à dez sessões diferentes. Verifica-se a presença de diversos tipos de objeto, sendo que, 0 representa a classe image, 1 representa a classe html, 2 representa a classe dynamic, 3 representa a classe text, 4 representa document, 5 representa script, 6 representa a classe audio, 7 representa binary e 8 representa a classe video.

$\begin{array}{lllll}0.31099840984741367 & 1455 & 2 & 2 & 16793.6 \\ 0.31236372538050294 & 647 & 6 & 2 & 524800.0 \\ 0.31399341965333655 & 326 & 0 & 2 & 3686.4 \\ 0.3143080703044554 & 1455 & 2 & 2 & 16793.6 \\ 0.31433910565677875 & 976 & 4 & 2 & 16281.6 \\ 0.3144895571612258 & 445 & 0 & 2 & 3686.4 \\ 0.31494826677706494 & 1882 & 2 & 2 & 16793.6 \\ 0.3149482668094703 & 1882 & 0 & 2 & 3686.4 \\ 0.31495582495266844 & 1882 & 4 & 2 & 16281.6 \\ 0.3149611951382252 & 1882 & 2 & 2 & 16793.6 \\ 0.3160397937352436 & 1036 & 0 & 2 & 3686.4 \\ 0.3162451814134899 & 940 & 0 & 2 & 3686.4 \\ 0.31666749076904244 & 636 & 0 & 2 & 3686.4 \\ 0.31812505143231906 & 1749 & 2 & 2 & 16793.6 \\ 0.31812505143231906 & 1749 & 2 & 2 & 16793.6 \\ 0.3181250514323191 & 1749 & 2 & 2 & 16793.6\end{array}$

Figura 5.5: Arquivo texto reproduzido pelo Gerador de Sessões Sintéticas.

Verifica-se também, através Figura 5.5, a presença de apenas um código de resposta, o 2, que representa 2xx. Observa-se vários tamanhos de objeto em bytes, relacionados à classe do objeto.

A Tabela 5.3 resume o domínio dos valores que os componentes da carga de trabalho pode assumir. Para intervalo de chegada e identificador da sessão, os valores podem ser números inteiros positivos. No campo classe do objeto, nove valores podem ser assumidos, enquanto que no campo código de resposta, quatro valores determinam os tipos possíveis de retorno. Já o campo tamanho do objeto pode assumir seis diferentes valores, de acordo com uma das nove classes do objeto. 
Tabela 5.3: Domínio de valores para os componentes da requisição.

\begin{tabular}{||l||c|}
\hline \hline Componentes & Domínio de Valores \\
\hline \hline Intervalo de chegada & {$[0,+\propto]$} \\
\hline Identificador da sessão & {$[0,+\propto]$} \\
\hline Classe do objeto & $\begin{array}{c}{[\text { image, html, dynamic, text, document, }} \\
\text { script, audio, binary, video }]\end{array}$ \\
\hline Código de reposta & {$[2 \mathrm{xx}, 3 \mathrm{xx}, 4 \mathrm{xx}, 5 \mathrm{xx}]$} \\
\hline Tamanho do objeto & {$[0.0,16793.6,524800.0,3686.4$,} \\
& $16281.6,670515.2,6348.8]$ \\
\hline \hline
\end{tabular}

\subsubsection{Modelagem do Gerador de Sessões Sintéticas}

A modelagem é uma parte importante das atividades de desenvolvimento de um software. Ela é uma simplificação da realidade que facilita a compreensão do comportamento do sistema [Fowler and Scott 2000].

Para o desenvolvimento do Gerador de Sessões Sintéticas, partiu-se do modelo inicial de carga de Silva [Silva 2006], com o intuito de se gerar uma carga de trabalho com os mesmo componentes, todavia, baseada em sessão.

O esboço da sessão foi criado utilizando-se os conceitos e código da ferramenta HTTPerf [Httperf 2009]. Como todos os parâmetros do HTTPerf são fixos, definidos como entradas de usuário, surgiu a necessidade de buscar na literatura trabalhos que apresentassem estudos sobre a carga de trabalho da $W e b$, a fim de se criar uma carga mais realista, em que a instabilidade ou irregularidade deste ambiente é representada.

Assim, uma sessão reconhecida por um identificador, é composta por um número de requisições em rajadas, espaçadas por um tempo de pensar, e é assumido um intervalo de tempo entre a criação de várias sessões.

O diagrama da Figura 5.6 mostra a inserção de cada trabalho e/ou ferramenta no desenvolvimento do gerador.

Como visto no diagrama da Figura 5.6, o identificador da sessão é gerado de acordo com a definição de um dos geradores do HTTPerf, o sess_cookie. O número de requisições criadas segue a definição do gerador wsses, também pertencente ao HTTPerf, ou seja, é um número fixo definido pelo usuário. O número de requisições de uma sessão é gerado a partir de uma caracterização do log da Copa de 1998, realizada a partir de intervalos/grupos de tamanhos de sessão. As rajadas e tempos de pensar seguem o trabalho de Silva [Silva 2006], em que utiliza-se 


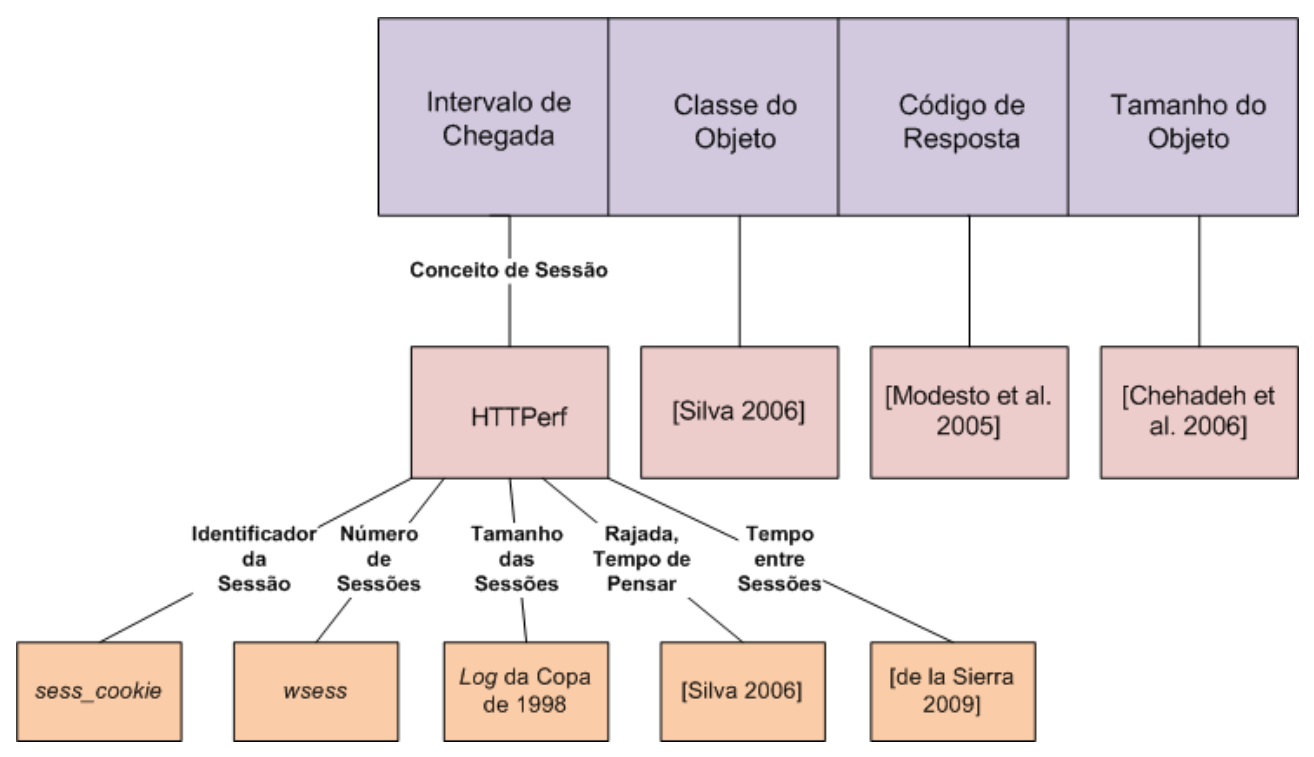

Figura 5.6: Participação dos trabalhos/ferramentas no desenvolvimento do Gerador de Sessões Sintéticas.

diferentes funções e parâmetros para gerar os intervalos de chegada de acordo com a classe do objeto. E finalmente, para gerar o tempo entre as sessões, utiliza-se a função de distribuição exponencial fornecida pelo HTTPerf, com parâmetro $\mu=30$ de acordo com [de la Sierra 2009].

Com o intuito de melhor definir a estrutura do Gerador de Sessões Sintéticas optou-se por utilizar a UML (Unified Modeling Language). Algumas das vantagens da UML são a disseminação do padrão entre os desenvolvedores de software e a facilidade de comunicação. A próxima seção descreve o diagrama de classes do Gerador de Sessões Sintéticas. O objetivo é esclarecer como foi implementado e auxiliar futuros desenvolvedores em uma possível agregação de características a carga de trabalho ou, adaptação para alguma outra situação.

\section{Diagrama de Classes}

O diagrama de classes representa os pacotes, as classes, as interfaces e, as colaborações que farão parte do sistema, assim como o relacionamento entre elas. Além disso, ele também mostra os atributos e operações de uma classe e as restrições à maneira como são conectadas [Fowler and Scott 2000].

Na Figura 5.7 é apresentado o diagrama de classes do pacote sessoes, em que alguns atributos e classes irrelevantes foram excluídos.

As classes IntervaloChegada, ClasseObjeto, CodigoResposta e TamanhoArquivo são os componentes que fazem parte da carga de trabalho produzida pelo Gerador de Sessões Sintéticas. 


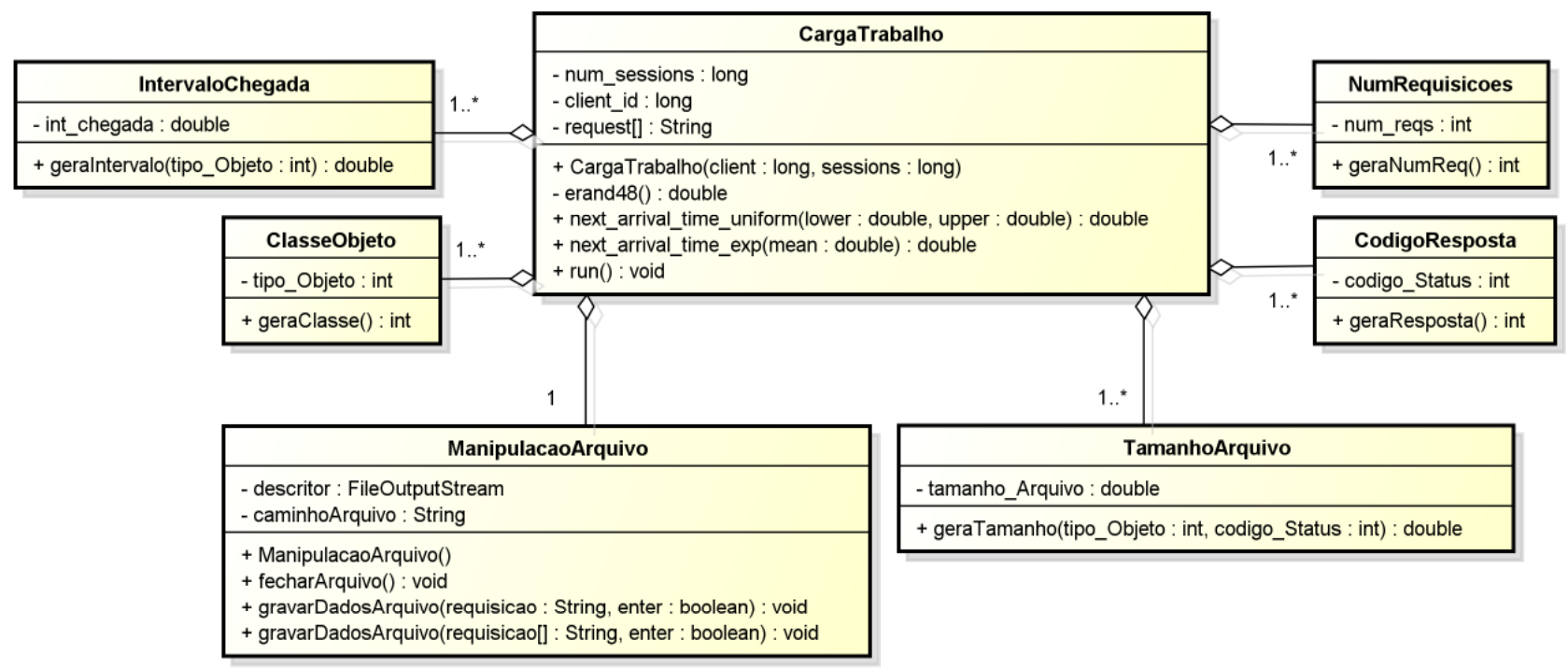

Figura 5.7: Diagrama de classes do pacote sessoes.

Para adicionar novos componentes à carga de trabalho, basta criar uma nova classe e alterar a classe CargaTrabalho para suportar esse novo elemento.

A classe CargaTrabalho por sua vez, define o número de sessões (num_sessions) e identificador do cliente (client_id), que são entradas de usuário, e determina o intervalo de tempo entre as sessões por meio da função exponencial next_arrival_time_exp(double mean). O número de requisições de cada sessão é obtido por meio da classe NumRequisicoes.

Finalmente, a classe ManipulacaoArquivo é utilizada para escrever as requisições de cada sessão no arquivo log de saída.

\subsection{Considerações Finais}

Este capítulo apresentou o gerador de carga de trabalho W4Gen, que utiliza distribuições para modelar as características das requisições, já que este gera requisições individuais. Foram apresentados também, alguns benchmarks e ferramentas utilizadas, dentre outras coisas, para avaliação de servidores $W e b$, e que serviram como base para a criação do Gerador de Sessões Sintéticas.

Posteriormente, a forma como a carga de trabalho foi criada, assim como os trabalhos relacionados utilizados, foram apresentados.

E por fim, foi apresentado o Gerador de Sessões Sintéticas, desenvolvido para suprir a dificuldade de se conseguir cargas de trabalho baseadas em sessões, condizentes com o atual 
ambiente da $W e b$.

As novas cargas de trabalho geradas foram usadas para avaliar algoritmos de escalonamento e controle de admissão, bem como o modelo de servidor Web de Teixeira [Teixeira 2004] [Teixeira et al. 2005]. Os resultados obtidos são apresentados no Capítulo 6. 
Capítulo

\section{Resultados Experimentais}

\subsection{Considerações Iniciais}

Este capítulo apresenta os resultados obtidos através de experimentos realizados com os algoritmos de escalonamento FIFO, SBSA e SBSA-DS, o mecanismo de controle de admissão que limita o tamanho da fila, o mecanismo que limita a utilização média do cluster, e os algoritmos de controle de admissão Drop Tail e RED, a fim de verificar seu desempenho, e validar a carga de trabalho utilizada. Também é proposto um novo mecanismo de controle de admissão, baseado no algoritmo RED (Randon Early Detection) [Floyd and Jacobson 1993].

Inicialmente, na Seção 6.2 descreve-se a avaliação de desempenho realizada e na Seção 6.3 apresenta-se o planejamento do experimento seguido neste trabalho.

$\mathrm{Na}$ Seção 6.4 são mostrados os resultados obtidos com os algoritmos de escalonamento FIFO, e SBSA e SBSA-DS propostos por Barbato [Barbarto et al. 2006; Barbarto et al. 2007; Barbato 2007]. Estes experimentos foram realizados a fim de validar a carga de trabalho utilizada, obtida através do gerador de carga de trabalho baseada em sessão, implementado durante o desenvolvimento deste projeto, e apresentado no Capítulo 5.

As Seções 6.5.1 e 6.5.2 apresentam os resultados obtidos com dois mecanismos de controle de admissão: o mecanismo que limita o tamanho da fila, e o mecanismo que limita a utilização média do cluster. Para realizar o descarte das requisições/sessões foram utilizados os algoritmos CA-nBS, CA-BS e CA-Híb, propostos por Barbato [Barbarto et al. 2007; Barbato 2007]. Estes experimentos também tiveram como objetivo validar a carga obtida através do gerador de sessões.

A Seção 6.5.4 mostra os resultados obtidos com experimentos realizados com os algoritmos 
de controle de admissão Drop Tail e RED [Floyd and Jacobson 1993]. Estes experimentos, assim como os anteriores, têm como objetivo validar a carga de trabalho, bem como comparar os resultados obtidos com a utilização desses dois algoritmos.

Como o algoritmo RED trata as requisições individualmente, sem considerar o conceito de sessões, é proposto, na Seção 6.5.5, uma política RED com tratamento de sessões. Esta nova política foi chamada de RED-SB (RED Session Based). Como é possível utilizar diferentes métodos para escolher as requisições/sessões a serem descartadas, a política RED-SB pode atuar em conjunto com outros algoritmos de controle de admissão. Assim, foram realizados experimentos com este algoritmo juntamente com os algoritmos CA-nBS, CA-BS e CA-Híb, e os resultados são apresentados na Seção 6.5.5.

\subsection{Avaliação de Desempenho}

Para avaliar o desempenho de sistemas computacionais podem-se utilizar técnicas classificadas em dois grupos: Técnicas de Aferição e Técnicas de Modelagem [Santana 1990a; Santana 1990b].

Técnicas de Aferição são aplicadas principalmente na avaliação de sistemas já existentes ou em fase final de desenvolvimento [Santana et al. 1997]. A dificuldade maior na utilização dessas técnicas é não alterar o funcionamento normal do sistema durante a experimentação prática. A complexidade e alta carga de trabalho dos servidores Web são as questões fundamentais que dificultam a utilização de técnicas de aferição. Obter dados confiáveis através de aferição, sem influenciar no funcionamento normal do sistema é um desafio.

O uso da modelagem se mostra atrativo quando os objetos de estudo são sistemas complexos ou ainda inexistentes [Jain 1991]. No caso da Internet, devido ao seu tamanho e constante evolução, esta técnica de avaliação é mais adequada [Teixeira 2004].

A solução de um modelo pode ser obtida utilizando-se tanto uma ferramenta matemática, levando a uma solução analítica, ou a utilização de um programa de simulação que represente o modelo adequadamente e forneça os dados para a avaliação do desempenho [Kobayashi 1978; MacDougall 1987; Jain 1991].

As soluções analíticas são atrativas, principalmente considerando que, quando disponíveis, permitem a avaliação e a inferência de diversos resultados com esforço computacional pequeno. No entanto, nem sempre se têm soluções analíticas adequadas, uma vez que elas podem ser altamente complexas, levando à necessidade de simplificações sucessivas no modelo do sistema, o que pode levar a resultados sem grandes aplicações práticas [MacDougall 1987; Soares 1990]. 
No uso de simulação, tem-se uma possibilidade de solução dos modelos flexível, uma vez que, elaborado um programa de simulação que represente corretamente o modelo, podem ser testadas diversas possibilidades de parametrização do sistema, com resultados computados automaticamente pelo programa de simulação [MacDougall 1987].

A avaliação de desempenho realizada neste trabalho foi feita através de simulação, utilizando o SimpackJ [Fishwick 2005], um simulador constituído de um pacote escrito em JAVA, voltado para simulação de Rede de Filas, orientado a eventos discretos. A simulação é realizada 10 vezes para cada fator com seus respectivos níveis, e calculada a média aritmética e intervalo de confiança dos resultados obtidos. A quantidade de execuções foi definida considerando-se que, para o valor adotado, obteve-se intervalos de confiança suficientemente pequenos e que possibilitam uma conclusão sobre os algoritmos pesquisados.

\subsection{Planejamento de Experimento}

Os experimentos realizados neste trabalho consideram o modelo de servidor Web proposto por Teixeira [Teixeira 2004; Teixeira et al. 2005], em que foi submetido a uma carga de trabalho produzida pelo gerador de sessões desenvolvido neste projeto, e apresentado no Capítulo 5.

As modificações realizadas por Barbato [Barbato 2007] no modelo SWDS foram consideradas. Como o modelo original não considera o conceito de sessões, as requisições pertencentes a uma mesma sessão poderiam receber classificações diferentes. Assim, a alteração no módulo de classificação consistiu em, definir apenas a prioridade da primeira requisição da sessão, como realizada modelo original. Definida a classe da requisição, todas as futuras requisições relacionadas à mesma sessão recebem o mesmo nível de prioridade.

A outra modificação considerada consiste em encaminhar todas as requisições pertencentes a uma mesma sessão, para o mesmo servidor $W e b$, a fim de se evitar a troca de mensagens para o gerenciamento do estado das sessões.

No modelo considerado, devem ser definidas a forma de realização do controle de admissão e a alocação das requisições nos servidores. Com relação a alocação das requisições das requisições, duas características precisam ser definidas. A primeira refere-se a como será obtido o balanceamento de carga entre os servidores e a segunda refere-se a como será selecionada a próxima requisição a ser escalonada (algoritmo de escalonamento).

Com relação ao controle de admissão deve-se avaliar qual característica será utilizada para admitir ou não uma próxima requisição ou sessão (mecanismo de controle de admissão) e como essa característica será utilizada (algoritmo de controle de admissão). 
O balanceamento de carga será implementado em todos os experimentos considerando-se o algoritmo SQF (Shortest Queue First). Este algoritmo trabalha encaminhando as tarefas ao nó que possuir o menor número de requisições em fila. Ele introduz certa sobrecarga ao sistema, pois precisa de informações sobre a carga dos nós a cada momento.

Quando se considera sessões, as diferenças de tamanho entre as tarefas submetidas aos servidores tornam-se maiores, pois a quantidade de requisições que cada sessão possui é diferente. Assim, o uso do algoritmo SQF resulta em um desempenho semelhante, quando se faz ou não o uso de sessões, porque ele distribui a carga de maneira mais uniforme, tentando manter os tamanhos das filas dos servidores iguais.

Os algoritmos de escalonamento e os mecanismos e algoritmos de controle de admissão são considerados fatores e serão discutidos nas próximas seções.

\subsection{Algoritmos de Escalonamento}

O objetivo dos Experimentos 1 e 2 apresentados nas Seções 6.4.1 e 6.4.2 é validar a carga de trabalho baseada em sessão, obtida através do gerador de carga desenvolvido neste trabalho.

Os Algoritmos de Escalonamento considerados foram o FIFO (First In First Out), o Algoritmo de Escalonamento Baseado em Sessão (Session-Based Scheduling Algorithm - SBSA) e o Algoritmo de Escalonamento Baseado em Sessão com Serviços Diferenciados (SessionBased Scheduling Algorithm with Differentiated Services - SBSA-DS) [Barbarto et al. 2006; Barbarto et al. 2007; Barbato 2007]. O diagrama da Figura 6.1 apresenta os algoritmos de escalonamento avaliados e os parâmetros considerados.

O algoritmo SBSA possui o valor k, que consiste no índice de crescimento da janela e foram considerados os seguintes valores: 0,0;1,0; 1,4 e 1,5. Já o algoritmo SBSA-DS, possui o valor k, fixado no experimento em 1,5, o valor classes de serviço, fixado em três, e os pesos das classes, definidos como 3, 2 e 1, para as classes A, B e C, respectivamente.

A parametrização utilizada para o modelo de servidor Web SWDS [Teixeira 2004] para a avaliação dos algoritmos de escalonamento é a mesma empregada pelo seu autor. Cada nó do cluster é modelado individualmente, com CPU, disco e interface de rede. Para o cálculo do tempo de serviço das requisições estáticas, a taxa de transferência dos discos dos servidores foi parametrizada como $37 \mathrm{Mbps}$, e a latência como 8,5 ms, utilizando como referência um disco IBM Deskstar 75GXP [IBM 2003]. A escolha do disco IBM como referência se deve ao fato desse ter sido usado no trabalho de Barbato [Barbato 2007], o qual foi utilizado na avaliação dos resultados obtidos neste trabalho.O tempo de serviço das requisições dinâmicas é definido 


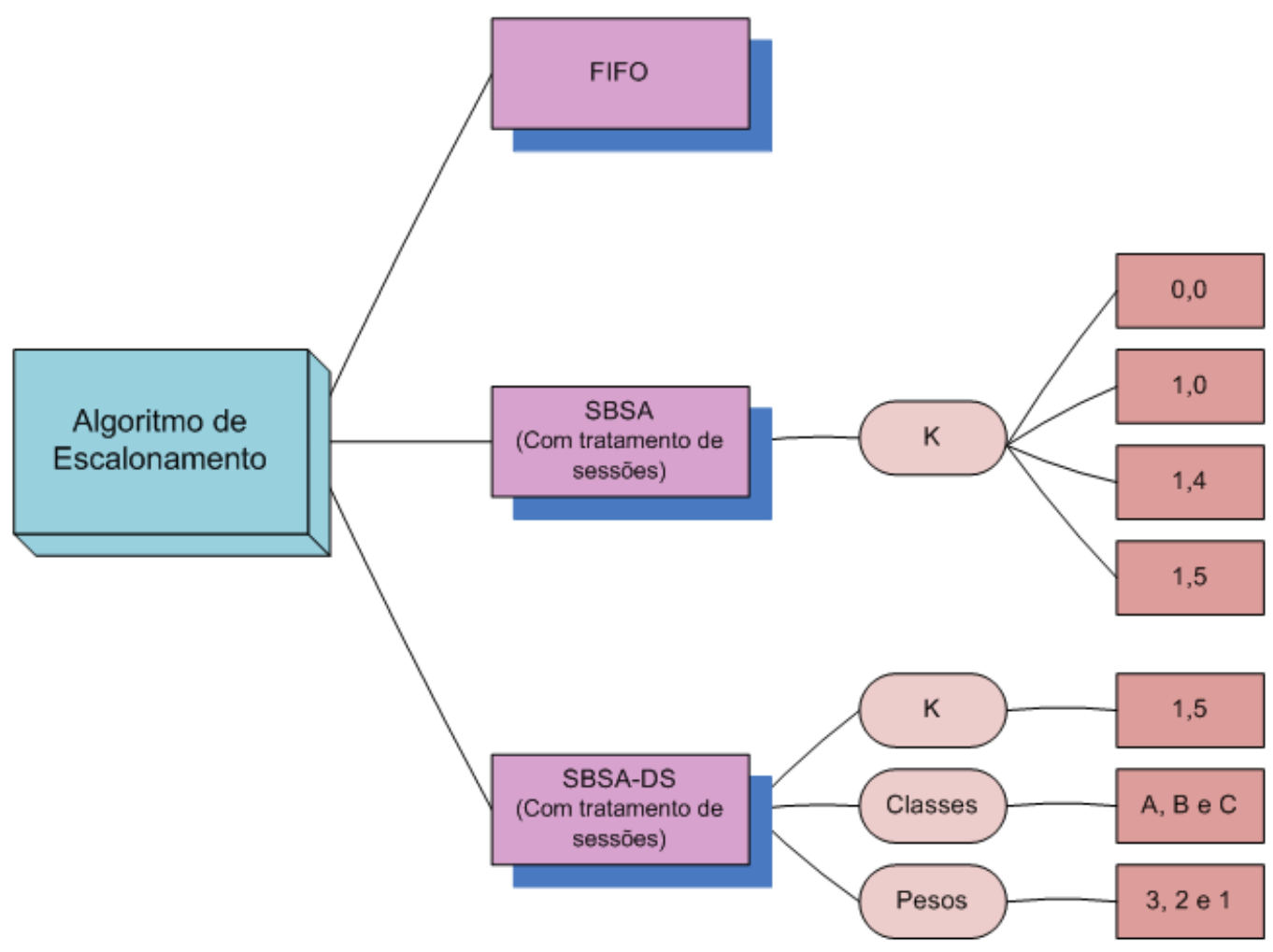

Figura 6.1: Fator Algoritmo de Escalonamento.

como $10 \mathrm{~ms}$ e a capacidade da interface de rede como $80 \mathrm{Mbps}$. A capacidade de processamento do Classificador é determinada como 8000 requisições/s.

É utilizado um cluster homogêneo com oito servidores, e o algoritmo de balanceamento de carga adotado foi o SQF (Shortest Queue First). A carga submetida ao sistema foi obtida através do Gerador de Sessões Sintéticas, desenvolvido neste projeto, para um total de 2 mil sessões.

Como variáveis de resposta para os algoritmos de escalonamento tem-se:

- Tempo Médio em Fila - média dos tempos em fila gastos pelas sessões de determinado tamanho (média de 10 simulações);

- Tempo Médio de Resposta - média dos tempos de resposta das requisições de sessões de determinado tamanho (média de 10 simulações).

\subsubsection{Experimento 1 - SBSA}

Objetivo - Validar a carga de trabalho obtida através do Gerador de Sessões Sintéticas. 
Fatores - O Experimento 1 possui como fatores, o algoritmo de escalonamento e o índice $\mathrm{k}$ do algoritmo SBSA. E também, a carga de trabalho, o algoritmo de balanceamento de carga, o número de servidores do cluster e a parametrização do modelo, mantidos fixos.

Níveis - O fator algoritmo de escalonamento possui dois níveis: FIFO e SBSA. E o índice k possui os níveis $0,0,1,0,1,40,1,50$, para o algoritmo SBSA.

Variáveis de Resposta - Tempo em fila e tempo de resposta.

O objetivo do algoritmo SBSA é priorizar as sessões mais longas, caracterizadas por possuírem maior número de requisições. Assim, quanto maior for a sessão, melhores serviços devem ser oferecidos. Cada sessão possui um parâmetro, chamado look-ahead (la), que aumenta à medida que as suas requisições chegam ao sistema. A Equação 6.1, define os valores do look-ahead das sessões, sendo k o fator de crescimento da janela.

$$
l_{\text {look_ahead }}=\left\lfloor\text { num_requisicoes }_{i}^{k}\right\rfloor
$$

Como a maioria dos servidores Web utiliza o algoritmo FIFO para o atendimento das suas requisições, este algoritmo é também utilizado para fins de comparação com o SBSA. O algoritmo FIFO corresponde aos mesmos resultados apresentados pelo SBSA quando o valor de k é igual a zero, ou seja, não existe priorização de sessões de tamanho maior em relação às sessões menores.

Os resultados apresentados nesta seção consideram os parâmetros do modelo SWDS descritos (Seção 6.4), e o módulo de controle de admissão e o módulo de classificação não são acionados, para não interferir no desempenho do algoritmo, já que esse não realiza diferenciação de serviços baseada nas classes dos usuários.

O gráfico da Figura 6.2 mostra o tempo médio em fila das sessões finalizadas, reunidas a partir do número de requisições que estas sessões possuem, numa média de 10 simulações, juntamente com os intervalos de confiança, de 95\%, calculados para cada valor de $\mathrm{k}$, relativos a cada intervalo do tamanho das sessões (número de requisições que essas sessões possuem). Estes resultados foram obtidos utilizando como carga de trabalho 2 mil sessões geradas pelo Gerador de Sessões Sintéticas.

Para os resultados apresentados no gráfico da Figura 6.2, quando $\mathrm{k}=0$, para o algoritmo SBSA, o desempenho do sistema é estatisticamente igual àquele quando se usa o algoritmo FIFO, isto porque, o valor de look-ahead para todas as sessões é igual a um. 


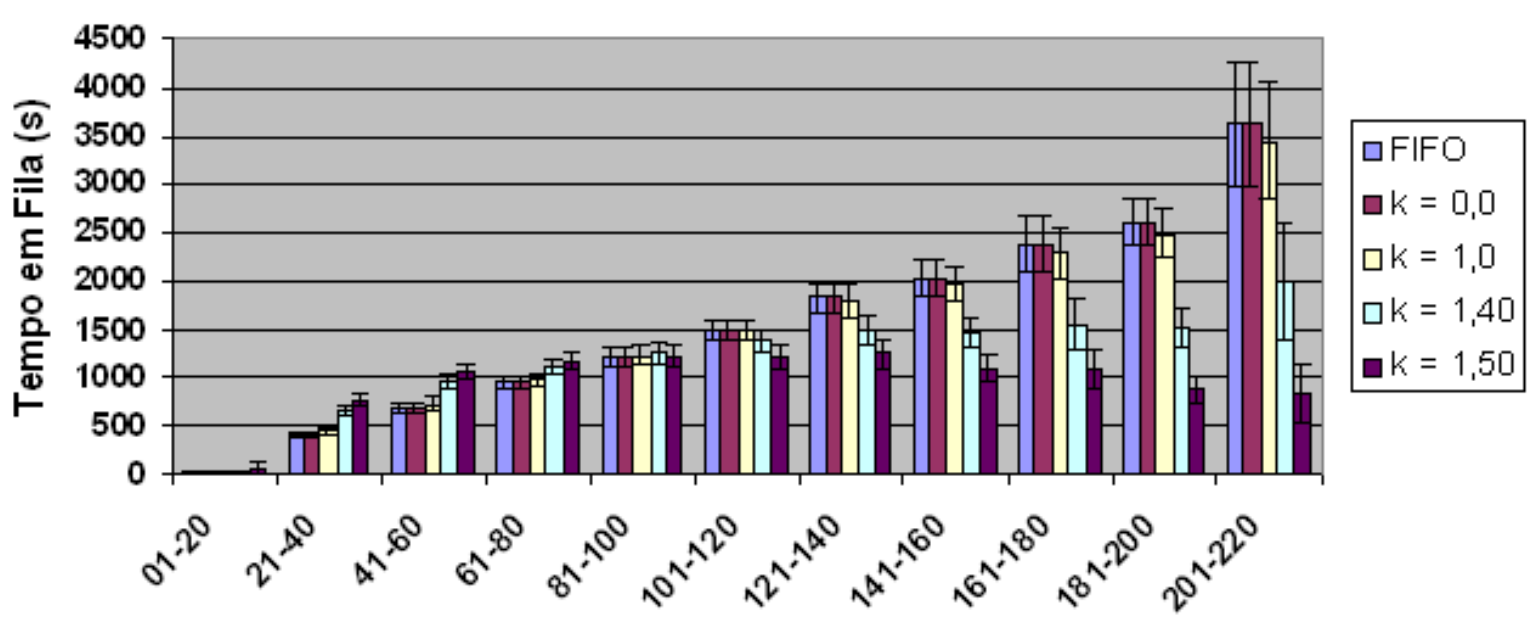

Tamanho das Sessões (número de requisições)

Figura 6.2: Tempo médio em fila das sessões finalizadas.

Pode-se verificar também que, usando o algoritmo FIFO, o tempo médio em fila aumenta, a medida que o tamanho das sessões aumenta. Utilizando o SBSA, o tempo médio em fila das sessões longas diminui, para valores de $\mathrm{k}>1$, proporcionando melhores serviços às requisições pertencentes a essas sessões. Quando $\mathrm{k}=1$, o algoritmo apresentou resultados estatisticamente iguais àqueles em que $\mathrm{k}=0$. Esta priorização das sessões longas custa, no entanto, um certo atraso das sessões pequenas, que tem seu tempo médio em fila acrescido, como por exemplo, as sessões que possuem entre 21 e 40 requisições, em que, quando k aumenta de 1,4 para 1,5, o tempo em fila aumenta de $664,95 \pm 50,43$ para $779,76 \pm 58,18$.

No trabalho de Barbato [Barbato 2007] foram utilizados os seguintes valores para o índice k: $0 ; 1 ; 1,25$ e 1,50. E os resultados apresentados são semelhantes aos resultados obtidos neste trabalho, quanto ao comportamento do algoritmo SBSA em priorizar as sessões longas, obtendose menores tempos em fila para essas sessões ao se aumentar os valores de k e, consequentemente, maiores tempos em fila para as sessões curtas.

O adiantamento das sessões longas é conseqüência da diminuição do tempo de resposta de suas requisições, como mostra o gráfico da Figura 6.3.

Observa-se a partir do gráfico da Figura 6.3 que, o tempo médio de resposta das requisições pertencentes às sessões longas diminui para valores de $\mathrm{k}>0$, a medida em que esses valores aumentam. As sessões que possuem de 181 à 200 requisições, por exemplo, tiveram o tempo de resposta reduzido de 13,60 $\mathrm{ms} \pm 1,22(\mathrm{k}=0)$ para 4,62 $\mathrm{ms} \pm 0,70(\mathrm{k}=1,5)$. As sessões com número de requisições entre 201 e 220, tiveram seus tempos de residência reduzidos de $17 \mathrm{~ms} \pm 3,01(\mathrm{k}=0)$ para $3,93 \mathrm{~ms} \pm 1,46(\mathrm{k}=1,5)$. As sessões pequenas, no entanto, com 


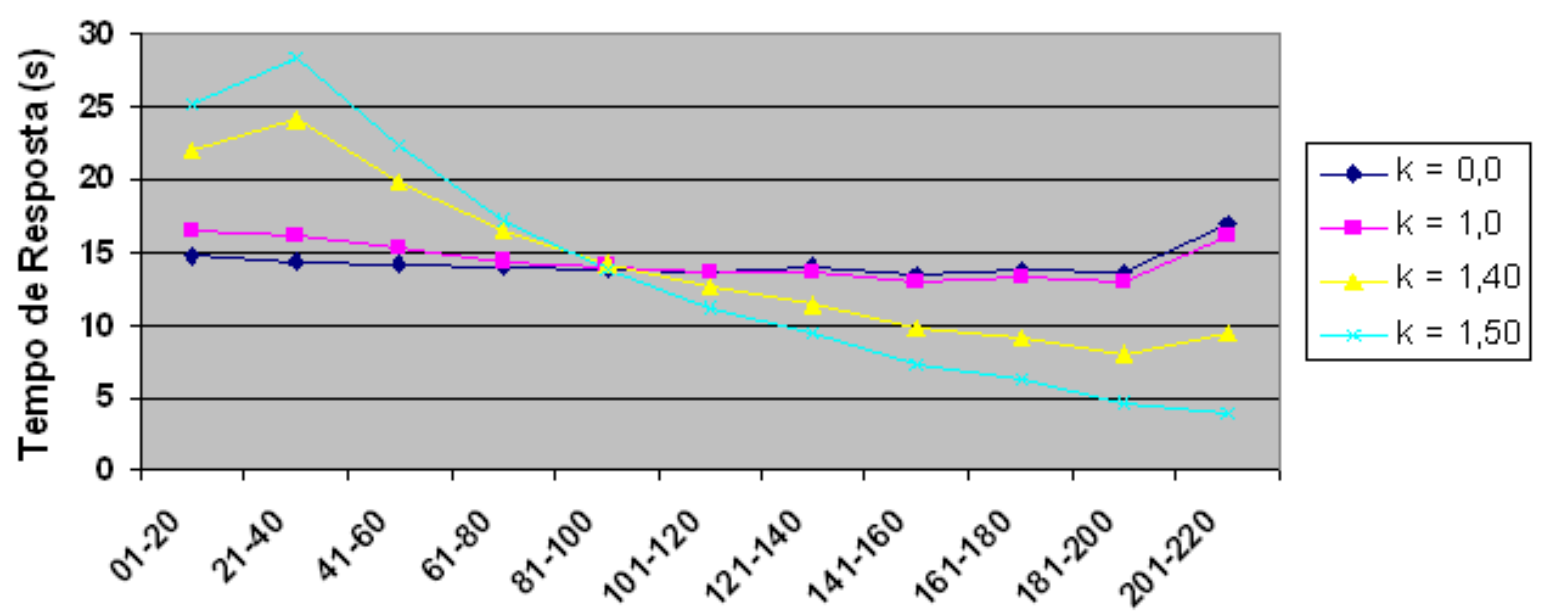

Tamanho das Sessões (número de requisições)

Figura 6.3: Tempo médio de resposta das requisições pertencentes às sessões finalizadas.

até aproximadamente 80 requisições, sofreram atrasos e os tempos de resposta gastos foram maiores, a medida que os valores de $\mathrm{k}$ foram acrescidos.

Quando se aumenta os valores de k, tem-se maiores look-ahead e assim, um maior número de requisições das sessões longas são adiantadas. Quanto maior o número de requisições adiantadas, maiores os atrasos das demais requisições. Segundo Barbato [Barbato 2007], esses atrasos podem diminuir o throughput das sessões, pois atende-se um número reduzido de sessões longas.

\subsubsection{Experimento 2 - SBSA-DS}

Objetivo - Validar a carga de trabalho obtida através do Gerador de Sessões Sintéticas.

Fatores - O Experimento 2 possui como fatores o algoritmo de escalonamento, o índice $\mathrm{k}$ para os algoritmos SBSA e SBSA-DS e o peso das classes de serviço para o algoritmo SBSA-DS. E possui também, como parâmetros fixos, a carga de trabalho, o algoritmo de balanceamento de carga, o número de servidores do cluster e a parametrização do modelo.

Níveis - O fator algoritmo de escalonamento possui três níveis: FIFO, SBSA e SBSA-DS. O índice $\mathrm{k}$ é em 1,50 para os algoritmo SBSA-DS pois este é o valor mais alto utilizado nos experimentos e, com qual, obtém-se um aumento na priorização das sessões longas.

Variáveis de Resposta - Tempo em fila e tempo de resposta. 
Além de priorizar as sessões longas, o algoritmo SBSA-DS possui ainda o objetivo de diferenciar os serviços dados aos clientes, através de classes de serviço.

No experimento realizado nesta seção, são utilizados os parâmetros e características descritos anteriormente. Como o algoritmo SBSA-DS considera o módulo Classificador para diferenciação de serviços, três classes são consideradas: A, B e C, em que a classe A tem prioridade sobre a $\mathrm{B}$, e a classe $\mathrm{B}$ tem prioridade sobre a C. Cada classe recebe o mesmo número de sessões, ou seja, 1/3 das sessões admitidas no sistema pertence a cada classe de serviço. Os pesos 3,2 e 1 foram considerados para as classes A, B, e C, respectivamente. Para cálculo dos valores de look-ahead das sessões, é utilizada a Equação 6.2.

$$
{\operatorname{look} \_a h e a d_{i}}=\left\lfloor\text { num_requisicoes }{ }_{i}^{k} * \text { peso_classe }{ }_{i}\right\rfloor
$$

em que é assumido $\mathrm{k}=1,5$.

Para facilitar a comparação, os resultados do algoritmo SBSA-DS são mostrados juntamente com os resultados obtidos pelos algoritmos FIFO e SBSA, em que todos foram submetidos às mesmas condições de carga e sistema. Para o algoritmo SBSA, foi utilizada a fórmula definida na Equação 6.1, com valor de $\mathrm{k}=1,5$.

Os gráficos da Figuras 6.4 apresentam o tempo médio em fila das sessões finalizadas, agrupadas a partir do número de requisições que possuem. Juntamente são apresentados os intervalos de confiança de $95 \%$ para cada valor de k. Os resultados foram obtidos utilizando-se uma carga de trabalho composta por 2 mil sessões. O gráfico da Figura 6.4(a) mostra o tempo médio em fila das sessões finalizadas para todo o sistema, independentemente da classe de serviço e, os gráficos das Figuras 6.4(b), 6.4(c) e 6.4(d) apresentam os tempos em fila das sessões pertencentes às classes $\mathrm{A}, \mathrm{B}$ e $\mathrm{C}$, respectivamente.

Verifica-se, a partir do gráfico da Figura 6.4(a), que o algoritmo SBSA-DS apresenta comportamento semelhante ao SBSA, em que os tempos médio em fila das sessões longas foram reduzidos quando comparados com os tempos obtidos pelo algoritmo FIFO. Oberva-se que que o algoritmo SBSA-DS priorizou ainda mais as sessões longas, em relação ao SBSA, na maioria dos casos. Isto ocorre porque o valor do look-ahead obtido pelo algoritmo SBSA-DS é maior que o valor obtido pelo algoritmo SBSA, pois o mesmo valor para $\mathrm{k}$ foi adotado $(\mathrm{k}=1,5)$, e o algoritmo SBSA-DS considera ainda o peso das classes no cálculo do look-ahead (como mostrado na Equação 6.2). Assim, quanto maior o valor do look-ahead, melhores serviços oferecidos às sessões longas.

Os gráficos das Figuras 6.4(b) e 6.4(c) apresentam os resultados obtidos pelas classes de 


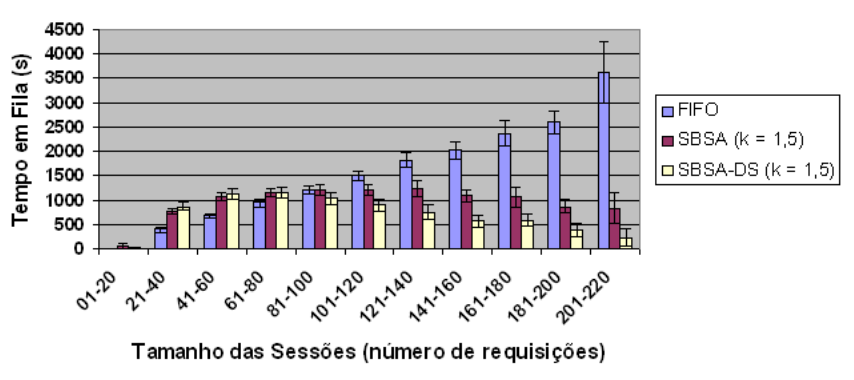

(a) Sistema - sem distinção de classes.

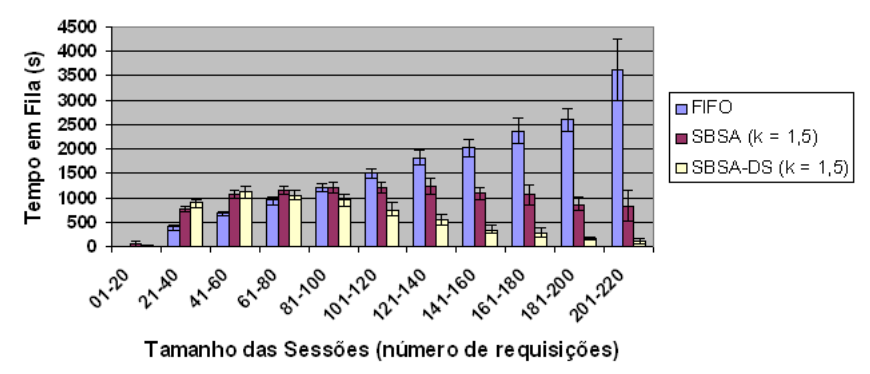

(c) Sessões pertencentes à classe B.

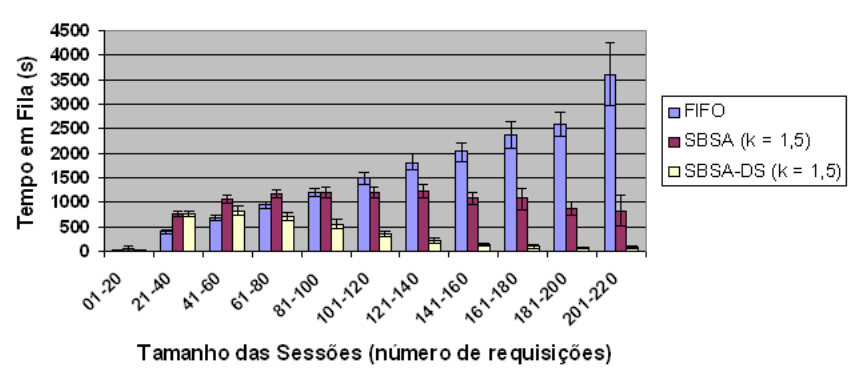

(b) Sessões pertencentes à classe A.

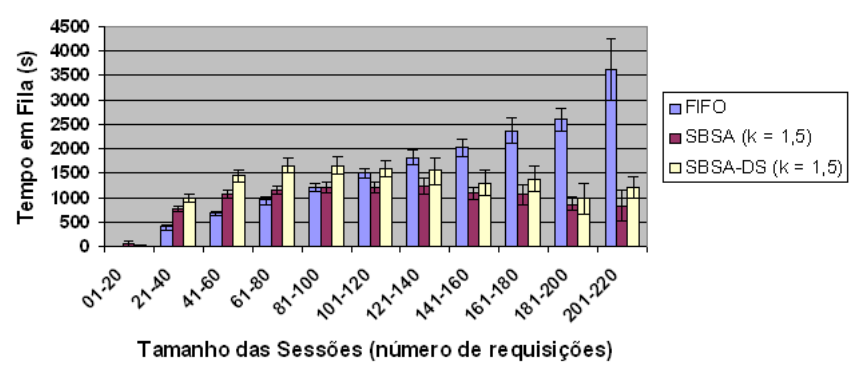

(d) Sessões pertencentes à classe C.

Figura 6.4: Tempo médio em fila das sessões finalizadas.

maior prioridade, e mostram que o desempenho obtido pelo algoritmo SBSA-DS foi superior ao obtido pelo SBSA, pois este não realiza diferenciação de serviços. Entretanto, os bons desempenhos das classes superiores, quando se utiliza o algoritmo SBSA-DS, ocorrem as custas da redução do desempenho da classe C, que apresenta tempos em fila estatisticamente iguais, na maioria dos casos, aos obtidos pelo SBSA, que não realiza diferenciação de serviços, como mostrado no gráfico da Figura 6.4(d). Comparando com o algoritmo FIFO, o SBSA-DS ofereceu às sessões longas, com mais que 140 requisições, melhor atendimento, mesmo no caso em que as sessões pertenciam a classe de menor prioridade.

A priorização das classe superiores fornecida pelo algoritmo SBSA-DS, pode ser melhor visualizada no gráfico da Figura 6.5, que apresenta o tempo médio de resposta das requisições para todo o sistema, independentemente da classe, e o tempo médio de resposta de cada classe de serviço considerada, ou seja, classes A, B e C.

Pode-se verificar, no gráfico da Figura 6.5, que as requisições pertencentes a classe A, de maior prioridade, apresentou menores tempos de resposta que as demais classes, recebendo então, melhores serviços. As requisições da classe B, obtiveram desempenho próximo ao desempenho médio do sistema. E as requisições da classe $\mathrm{C}$ tiveram o pior desempenho obtendo pior atendimento. Observando os grupos de sessões, de acordo com seu número de requisições, verifica-se que em todos os casos as sessões tiveram qualidade de serviço equivalentemente a sua 


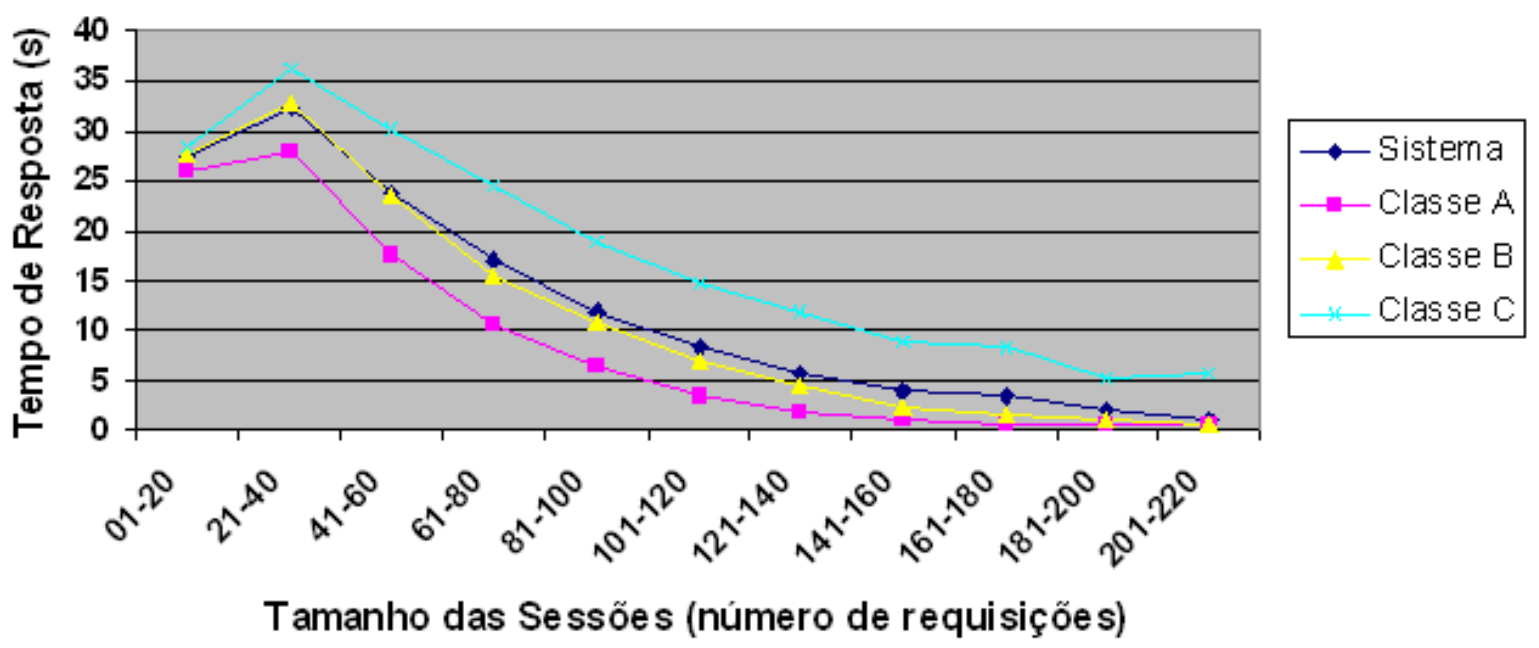

Figura 6.5: Tempo médio de resposta das requisições pertencentes às sessões finalizadas - $\mathrm{k}=$ 1,5 .

classe de prioridade. Observa-se também que as requisições da classe C, pertencentes as sessões longas (com mais de 100 requisições), receberam melhor serviço que as requisições da classe A pertencentes as sessões pequenas, com menos de 60 requisições. Isso mostra a eficiência do algoritmo, ao diferenciar as classes de serviços, considerando também o tamanho das sessões.

Os resultados apresentados pelo algoritmo SBSA-DS também são semelhantes àqueles apresentados por Barbato [Barbato 2007], quanto ao seu comportamento. Nesse trabalho, o valor para o índice k dos algoritmos SBSA e SBSA-DS foi fixado em 1,25.

\subsection{Políticas de Controle de Admissão}

O objetivo dos Experimentos 3 e 4 apresentados nas Seções 6.5.1 e 6.5.2, é validar a carga de trabalho obtida através da ferramenta desenvolvida neste trabalho, o Gerador de Sessões Sintéticas. Na Seção 6.5.3 é apresentada uma comparação entre os resultados dos Experimentos 3 e 4. O Experimento 5, cujos resultados são apresentados na Seção 6.5.4 tem como objetivo comparar os algoritmos Drop Tail e RED, utilizando-se a carga de trabalho já validada nas seções anteriores. E finalmente, o Experimento 6, apresentado na Seção 6.5.5, tem como objetivo verificar a validade do algoritmo RED-SB para o tratamento de sessões.

Para Mecanismo de Controle de Admissão foram avaliados o mecanismo que limita o tamanho da fila e o mecanismo que limita a utilização média do cluster, ambos descritos na Seção 4.2.2. O diagrama da Figura 6.6 apresenta um diagrama com os Mecanismos de Controle de Admissão avaliados. 


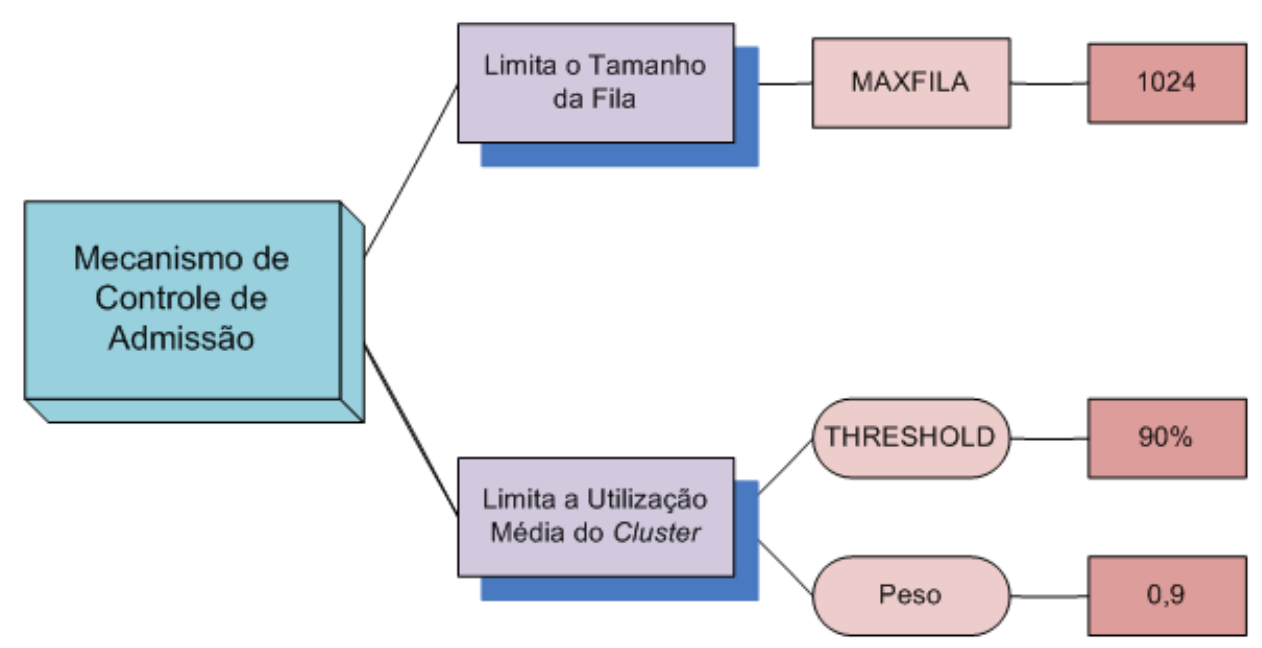

Figura 6.6: Fator Mecanismo de Controle de Admissão.

O mecanismo que limita o tamanho da fila possui um limite máximo para o tamanho da filade cada um dos servidores do cluster, MAXFILA, fixado em 1024 requisições, que é o padrão dos servidores Apache, e como definido em [Teixeira 2004].

No mecanismo que limita a utilização média do cluster, o cálculo da média de utilização do cluster é dado por:

$$
U_{\text {med }}=(1-p) * U_{\text {ant }}+p * U_{\text {atual }}
$$

em que $U_{\text {atual }}$ é a utilização atual do cluster, medida cada vez que uma requisição chega ao sistema. $U_{\text {ant }}$ caracteriza o histórico de utilização dos servidores, e este, juntamente com $U_{\text {atual }}$ determina a média exponencialmente ponderada $U_{\text {med }}$. O fator p é o coeficiente de sensibilidade a mudanças ocorridas no sistema, e foi definido como 0,9. O limite de utilização do cluster foi fixado em 90\%, ou seja, quando a utilização média ultrapassa 90\%, as requisições são descartas.

Nos experimentos deste trabalho, a capacidade de processamento do controle de admissão do modelo SWDS foi definida como 4000 requisições/segundos, de acordo com [Teixeira 2004].

Os Algoritmos de Controle de Admissão avaliados foram o Drop Tail, o RED (Randon Early Detection), o CA-nBS (Controle de Admissão não Baseado em Sessão), o CABS (Controle de Admissão Baseado em Sessão), o CA-Híb (Controle de Admissão Híbrido) [Barbarto et al. 2007; Barbato 2007] e o RED-SB (RED Session Based) proposto neste trabalho, sendo que, apenas os dois primeiros não possuem tratamento de sessões. A Figura 6.7 apresenta um diagrama com os Algoritmos de Controle de Admissão avaliados.

No algoritmo Drop Tail, estipula-se um limite para a métrica considerada. Se o limite é 


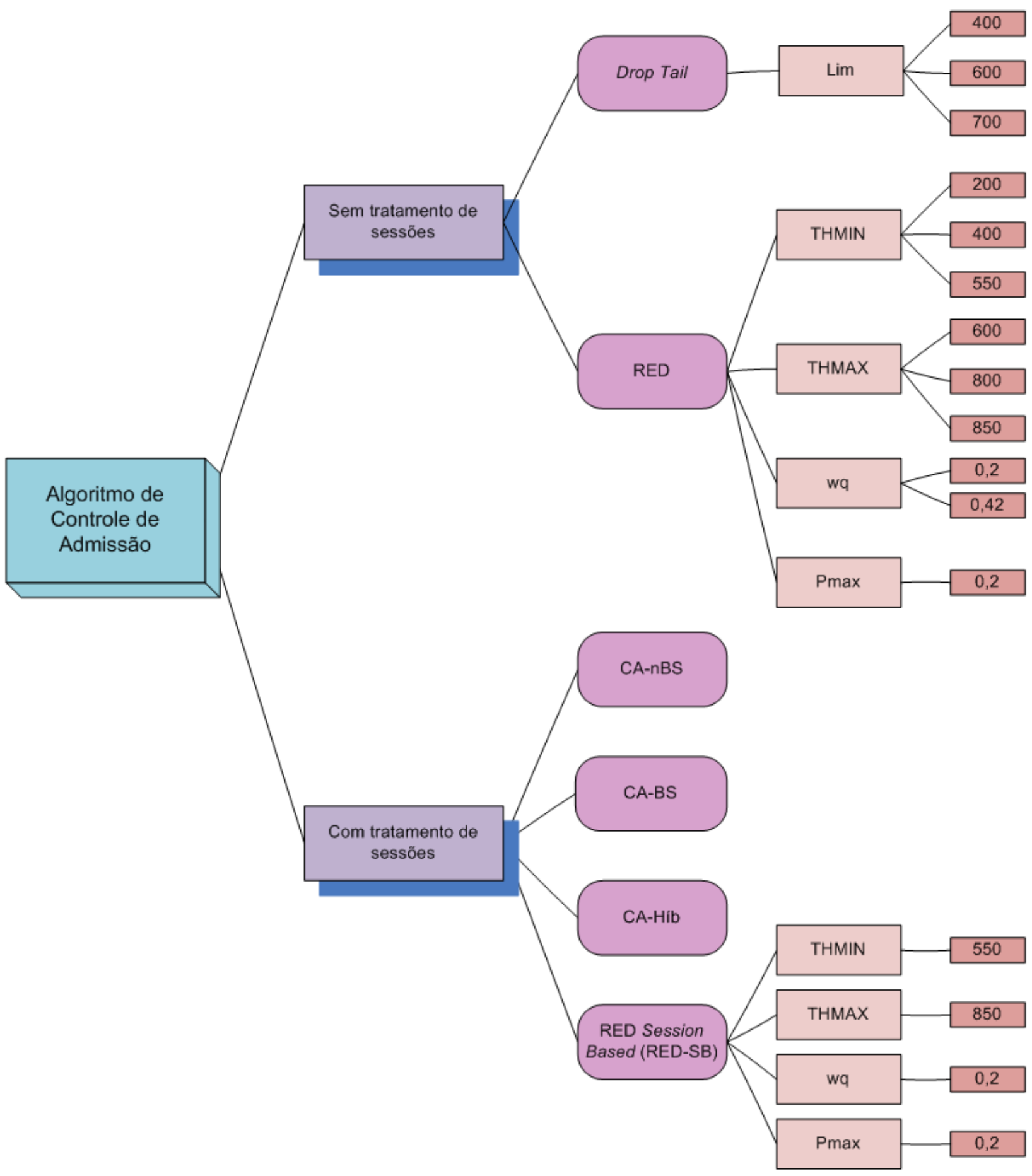

Figura 6.7: Fator Algoritmo de Controle de Admissão.

ultrapassado, as requisições não são admitidas. Nos experimentos deste trabalho, utilizouse a métrica tamanho da fila para o Drop Tail, sendo os valores assumidos para este limite: 400, 600 e 700. O RED, por sua vez, possui os parâmetros THMIN e THMAX para limites 
mínimo e máximo no tamanho médio da fila, wq, para o peso da fila, e Pmax para maior valor possível para probabilidade temporária $P b$. Os parâmetros THMIN e THMAX assumem nesse experimento os valores, 200 e 600, 400 e 800 e, 550 e 850. O parâmetro wq assume os valores 0,2 e 0,42. O parâmetro Pmax foi fixado em 0,2.

O algoritmo CA-nBS descarta requisições quando os recursos não são suficientes para atender a carga submetida ao sistema, independente da sessão ao qual pertençam. O algoritmo CA-BS descarta novas sessões quando os recursos do sistema estão sobrecarregados pela carga de trabalho presente. E o algoritmo CA-Híb descarta requisições, pertencentes às menores sessões ativas, quando o sistema torna-se sobrecarregado.

O algoritmo RED-SB possui os níveis limite mínimo para o tamanho médio da fila, THMIN, fixado em 550, o limite máximo THMAX, fixado em 850, o peso da fila, wq, fixado em 0,2 e, $P \max$, o valor máximo para a probabilidade temporária $P b$ foi fixado em 0,2 .

Os fatores Mecanismo de Controle de Admissão (Figura 6.6) e Algoritmo de Controle de Admissão (Figura 6.7) interagem entre si. Os algoritmos RED e Drop Tailtêm como mecanismo para verificação da necessidade de descarte o limite no tamanho da fila. Os algoritmos de controle de admissão CA-nBS, CA-BS e Ca-Híb foram testados utilizando-se o mecanismo que limita o tamanho da fila, e o mecanismo que limita a utilização média do cluster. No algoritmo RED-SB também se utiliza o mecanismo que limita o tamanho da fila.

Para a obtenção dos resultados nos Experimentos 3 e 4, emprega-se a mesma parametrização e configuração do modelo SWDS, discutidos na Seção 6.4, também adotada por Barbato [Barbato 2007]. Esses experimentos têm como objetivo realizar uma análise dos resultados e verificar sua validade.

A parametrização usada no Experimento 5 é a mesma discutida na Seção 6.4 e definida por [Teixeira 2004]. No entanto, para o cálculo do tempo de serviço das requisições estáticas, foram utilizadas as características do disco Samsung HD161HJ SATA II [Samsung 2010], usado nos servidores do cluster do Laboratório de Sistemas Distribuídos e Programação Concorrente (LaSDPC), do ICMC-USP. Assim, a taxa de transferência dos discos dos servidores foi parametrizada como $300 \mathrm{Mbps}$, e o tempo de busca como 8,9 ms. O tempo de serviço das requisições dinâmicas foi mantido em $10 \mathrm{~ms}$.

No Experimento 6, é utilizada a mesma parametrização adotada nos Experimentos 3 e 4, a fim de verificar a validade do algoritmo proposto comparando-o com o mecanismo que limita o tamanho e o mecanismo que limita a utilização média do cluster.

Em todos os experimentos realizados com controle de admissão, utilizou-se um cluster homogêneo com quatro servidores e o algoritmo de balanceamento de carga Shortest Queue First 
(SQF) são adotados. A carga submetida ao sistema foi obtida através do Gerador de Sessões Sintéticas, para um total de 2 mil sessões.

Como variáveis de resposta para os algoritmos de controle de admissão CA-nBS, CA-BS e CA-Híb, tem-se:

- Sessões Finalizadas - quantidade de sessões finalizadas até o final da simulação, expressa em termos de porcentagem em relação ao total de sessões que chegaram ao sistema (média de 10 simulações);

- Sessões Descartadas - porcentagem, em relação ao total que chegou ao sistema, de sessões que não tiveram nenhuma requisição admitida, ou seja, a primeira requisição da sessão não foi admitida (média de 10 simulações);

- Sessões Abortadas - porcentagem de sessões admitidas no sistema que, tiveram requisições descartadas devido a uma sobrecarga (média de 10 simulações);

- Utilização Efetiva dos Recursos - tempo em que os recursos do sistema estiveram ocupados com sessões bem sucedidas (média de 10 simulações);

- Throughput de Sessões - vazão das sessões finalizadas por segundo (média de 10 simulações);

- Throughput de Requisições - vazão das requisições finalizadas por segundo (média de 10 simulações);

- Tamanho Médio das Sessões - média do tamanho, em termos de quantidade de requisições, das sessões finalizadas (média de 10 simulações);

- Tempo Médio de Resposta das Requisições - tempo médio gasto pelas requisições finalizadas no sistema, ou seja, os tempos em fila e em atendimento, expressos em segundos (média de 10 simulações).

Para os algoritmos de controle de admissão Drop Tail e RED, foram utilizadas as variáveis tempo médio de resposta, e porcentagem média de descarte de requisições.

\subsubsection{Experimento 3 - Mecanismo que Limita o Tamanho da Fila}

Objetivo - Validar a carga de trabalho obtida através do Gerador de Sessões Sintéticas. 
Fatores - O Experimento 3 possui como fator, o algoritmo de controle de admissão. E possui também, os seguintes parâmetros fixos: limite máximo para admissão, carga de trabalho, o algoritmo de balanceamento de carga, o número de servidores do cluster e a parametrização do modelo.

Níveis - O fator algoritmo de controle de admissão possui três níveis: CA-nBS, CA-BS e CA-Híb.

Variáveis de Resposta - Sessões finalizadas, sessões descartadas, sessões abortadas, utilização efetiva dos recursos, throughput de sessões, throughput de requisições, tamanho das sessões, tempo de resposta das requisições.

A Tabela 6.1 apresenta os resultados obtidos com o experimento realizado considerando o mecanismo que limita o tamanho da fila e os três algoritmos de controle de admissão discutidos. Os resultados referem-se a média de 10 simulações e os intervalos de confiança são de $95 \%$.

Tabela 6.1: Avaliação dos algoritmos de CA - mecanismo que limita o tamanho da fila.

\begin{tabular}{||l||c||c||c|}
\hline \hline & CA-nBS & CA-BS & CA-Híb \\
\hline \hline Sessões Finalizadas (\%) & $92,41 \pm 0,22$ & $90,05 \pm 0,27$ & $95,58 \pm 0,16$ \\
\hline Sessões Descartadas (\%) & $0,00 \pm 0,00$ & $9,92 \pm 0,27$ & $0,00 \pm 0,00$ \\
\hline Sessões Abortadas (\%) & $7,56 \pm 0,22$ & $0,00 \pm 0,00$ & $4,40 \pm 0,16$ \\
\hline Utilização Efetiva dos Recursos (\%) & $78,08 \pm 0,74$ & $100,00 \pm 0,00$ & $98,63 \pm 0,00$ \\
\hline Throughput (sessões/s) & $0,07 \pm 0,01$ & $0,07 \pm 0,01$ & $0,07 \pm 0,01$ \\
\hline Throughput (requisições/s) & $0,42 \pm 0,08$ & $0,43 \pm 0,08$ & $0,44 \pm 0,08$ \\
\hline Tamanho Médio Sessões (\# requisições) & $4,55 \pm 0,08$ & $5,63 \pm 0,09$ & $5,92 \pm 0,10$ \\
\hline Tempo Médio Resposta Requisições (s) & $7,46 \pm 0,46$ & $4,26 \pm 0,48$ & $7,06 \pm 0,43$ \\
\hline \hline
\end{tabular}

CA-nBS - Controle de Admissão não Baseado em Sessão.

CA-BS - Controle de Admissão Baseado em Sessão.

CA-Híb - Controle de Admissão Híbrido.

A partir dos resultados mostrados na Tabela 6.1, observa-se que o algoritmo CA-BS atingiu seu objetivo de não abortar sessões já aceitas pelo sistema. Verifica-se que nenhuma sessão foi abortada, e apenas uma porcentagem pequena de sessões foi descartada $(9,92 \% \pm 0,27 \%)$, assim como em [Barbato 2007]. A utilização efetiva dos recursos neste caso foi de 100\%, ou seja, o sistema esteve ocupado durante todo o tempo com sessões finalizadas com sucesso.

Comparando o algoritmo CA-BS com o algoritmo não baseado em sessão CA-nBS, o segundo finaliza uma quantidade maior de sessões $(92,41 \% \pm 0,22 \%$ na política CA-nBS e 90,05\% \pm 
0,27\% na política CA-nBS). Entretanto, utilizando-se o algoritmo CA-nBS, uma porcentagem de sessões é abortada, impactando na utilização efetiva dos recursos $(78,08 \% \pm 0,74 \%)$.

O algoritmo CA-Híb, por sua vez, não descartou nenhuma sessão e abortou apenas 4,40\% $\pm 0,16 \%$, se diferenciando dos resultados apresentados por Barbato [Barbato 2007], em que houve certo número de descartes, e a porcentagem de abortos realizado pelo algoritmo CA-Híb foi maior que aquela realizada pelo CA-nBS. No entanto, como objetivo do algoritmo CA-Híb é aumentar a utilização efetiva dos recursos do sistema, escolhendo para o descarte as requisições pertencentes às sessões menores; verifica-se através da Tabela 6.1 que ele alcançou seu objetivo, fazendo com que a utilização efetiva dos recursos fosse igual a 98,63\%, superior à obtida pelo algoritmo CA-nBS. Esse resultado é similiar ao obtido por Barbato em [Barbato 2007].

O algoritmo CA-BS finalizou uma porcentagem menor de sessões em relação ao algoritmo CA-nBS, no entanto, o tamanho das sessões finalizadas foi maior. Já o algoritmo CA-Híb finalizou uma porcentagem maior de sessões, em relação aos demais algoritmos, e o tamanho médio das sessões finalizadas, também foi maior. Para ilustrar melhor tal fato, o gráfico da Figura 6.8 apresenta a porcentagem de sessões finalizadas, agrupadas segundo seu tamanho, para cada algoritmo de controle de admissão considerado.

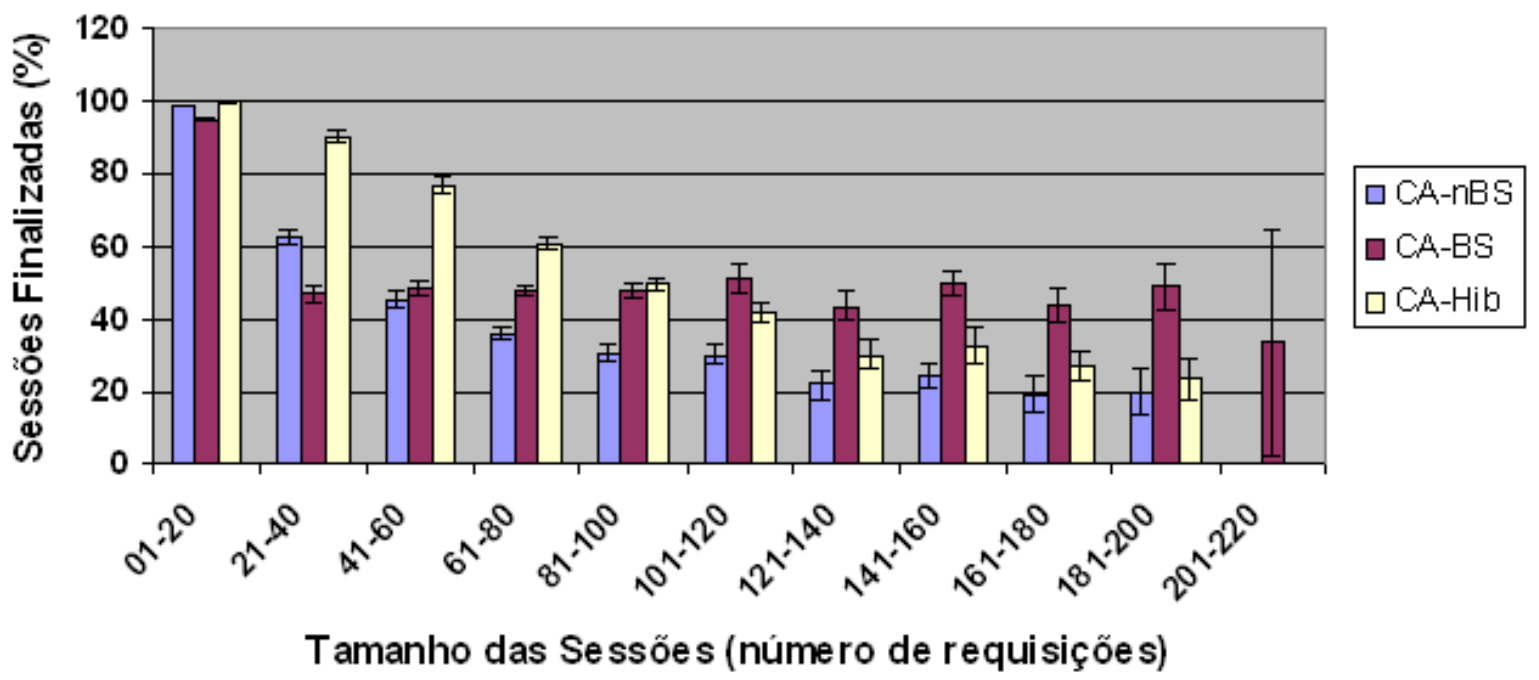

Figura 6.8: Porcentagem de sessões finalizadas - mecanismo que limita o tamanho da fila.

Verifica-se, a partir do gráfico da Figura 6.8, que o algoritmo CA-BS finalizou maior quantidade sessões que possuem mais que 60 requisições, em relação ao algoritmo CA-nBS, e mais que 100 requisições, em relação aos dois outros algoritmos. Já o algoritmo CA-Híb obteve resultados superiores ao CA-nBS, para as sessões com até 160 requisições e, para tamanhos maiores, os resultados dos dois algoritmos foram estatisticamente iguais. 
Os resultados apresentados pelo CA-Híb se mostraram díspares dos resultados obtidos por Barbato [Barbato 2007], em que o algoritmo CA-Híb finaliza menor porcentagem de sessões que o CA-nBS, para sessões com até 60 requisições, e para sessões com mais de 61 requisições, os resultados obtidos pelo algoritmo CA-Híb são superiores. No entanto, Barbato [Barbato 2007] utilizou como carga de trabalho, o $\log$ da Copa de 1998, e a simulação foi realizada apenas uma única vez, não apresentando um intervalo de confiança para os seus resultados.

Assim, os algoritmos CA-nBS e CA-Híb apresentam resultados próximos para sessões que possuem a partir de 121 requisições, e aquelas que possuem a partir de 161 requisições, em que a quantidade de sessões geradas destes tamanhos foi menor, os intervalos de confiança de sobrepõem.

Analisando a Tabela 6.1 e o gráfico da Figura 6.8, conclui-se que, o algoritmo CA-BS finalizou uma porcentagem menor de sessões, no entanto, essas sessões eram longas e obtiveram tratamento prioritário. O algoritmo CA-nBS realiza o descarte de requisições sem analisar a que sessões essas tarefas pertencem, prejudicando as sessões que deveriam receber melhor atendimento. O CA-Híb tenta priorizar as sessões longas, e os resultados obtidos mostraram que este, finalizou maior quantidade de sessões, e de maior tamanho médio. No entanto, para as sessões com mais que 161 requisições, o algoritmo CA-Híb apresentou os mesmos resultados que CA-nBS.

\subsubsection{Experimento 4 - Mecanismo que Limita a Utilização Média do Cluster}

Objetivo - Validar a carga de trabalho obtida através do Gerador de Sessões Sintéticas.

Fatores - O Experimento 4 possui como parâmetros fixos: limite máximo para admissão, carga de trabalho, o algoritmo de balanceamento de carga, o número de servidores do cluster e a parametrização do modelo. E como fator, o algoritmo de controle de admissão.

Níveis - O fator algoritmo de controle de admissão possui três níveis: CA-nBS, CA-BS e CA-Híb.

Variáveis de Resposta - Sessões finalizadas, sessões descartadas, sessões abortadas, utilização efetiva dos recursos, throughput de sessões, throughput de requisições, tamanho das sessões, tempo de resposta das requisições. 
Os resultados dos experimentos apresentados nesta seção foram obtidos utilizando o mecanismo que limita a utilização média nos processadores do cluster, juntamente com as políticas CA-nBS, CA-BS e CA-Híb. A Tabela 6.2 apresenta esses resultados, e os respectivos intervalos de confiança de $95 \%$.

Tabela 6.2: Avaliação dos algoritmos de CA - mecanismo que limita a utilização média do cluster.

\begin{tabular}{||l||c||c||c||}
\hline \hline \multicolumn{1}{||c||}{ CA-nBS } & CA-BS & CA-Híb \\
\hline \hline Sessões Finalizadas (\%) & $85,99 \pm 0,47$ & $88,75 \pm 0,26$ & $88,22 \pm 0,24$ \\
\hline Sessões Descartadas (\%) & $8,49 \pm 0,27$ & $11,22 \pm 0,27$ & $5,89 \pm 0,17$ \\
\hline Sessões Abortadas (\%) & $5,49 \pm 0,28$ & $0,00 \pm 0,00$ & $5,87 \pm 0,17$ \\
\hline Utilização Efetiva dos Recursos (\%) & $65,88 \pm 2,55$ & $100,00 \pm 0,00$ & $73,62 \pm 0,00$ \\
\hline Throughput (sessões/s) & $0,06 \pm 0,01$ & $0,06 \pm 0,01$ & $0,06 \pm 0,01$ \\
\hline Throughput (requisições/s) & $0,36 \pm 0,06$ & $0,38 \pm 0,07$ & $0,36 \pm 0,07$ \\
\hline Tamanho Médio Sessões (\# requisições) & $3,35 \pm 0,16$ & $5,09 \pm 0,08$ & $3,78 \pm 0,08$ \\
\hline Tempo Médio Resposta Requisições (s) & $3,39 \pm 0,59$ & $3,19 \pm 0,56$ & $3,24 \pm 0,60$ \\
\hline \hline
\end{tabular}

CA-nBS - Controle de Admissão não Baseado em Sessão.

CA-BS - Controle de Admissão Baseado em Sessão.

CA-Híb - Controle de Admissão Híbrido.

Como esperado, os resultados obtidos com o mecanismo que limita a utilização média do cluster são semelhantes aos obtidos quando com o mecanismo que limita o tamanho da fila, discutidos na seção anterior.

De acordo com os dados da Tabela 6.2, o algoritmo CA-BS não abortou nenhuma sessão, realizando apenas descartes $(11,22 \% \pm 0,27 \%)$. Assim, a utilização efetiva dos recursos foi de $100 \%$, diferentemente dos demais algoritmos considerados.

O algoritmo CA-nBS realizou 8,49\% $\pm 0,27 \%$ de descarte e $5,49 \% \pm 0,28 \%$ de abortos, reduzindo a utilização efetiva dos recursos para 65,88\% $\pm 2,55 \%$. O algoritmo CA-Híb utiliza um critério para descartar sessões e descartou 5,89\% \pm 0,17\%, porém, também realizou 5,87\% \pm 0,17\% de abortos, impactando na utilização dos recursos. Ainda assim, o algoritmo CA-Híb obteve uma utilização efetiva dos recursos superior ao algoritmo CA-nBS (73,62\% para CA-Híb e $65,88 \% \pm 2,55 \%$ para CA-nBS), que não utiliza nenhum critério para descartar sessões.

Observa-se que o algoritmo CA-BS finalizou maior quantidade de sessões, e também que o tamanho médio das sessões finalizadas foi maior que dos algoritmos CA-nBS e CA-Híb, o que significa que o algoritmo CA-BS finalizou maior quantidade de sessões longas, como mostra o 
gráfico da Figura 6.9.

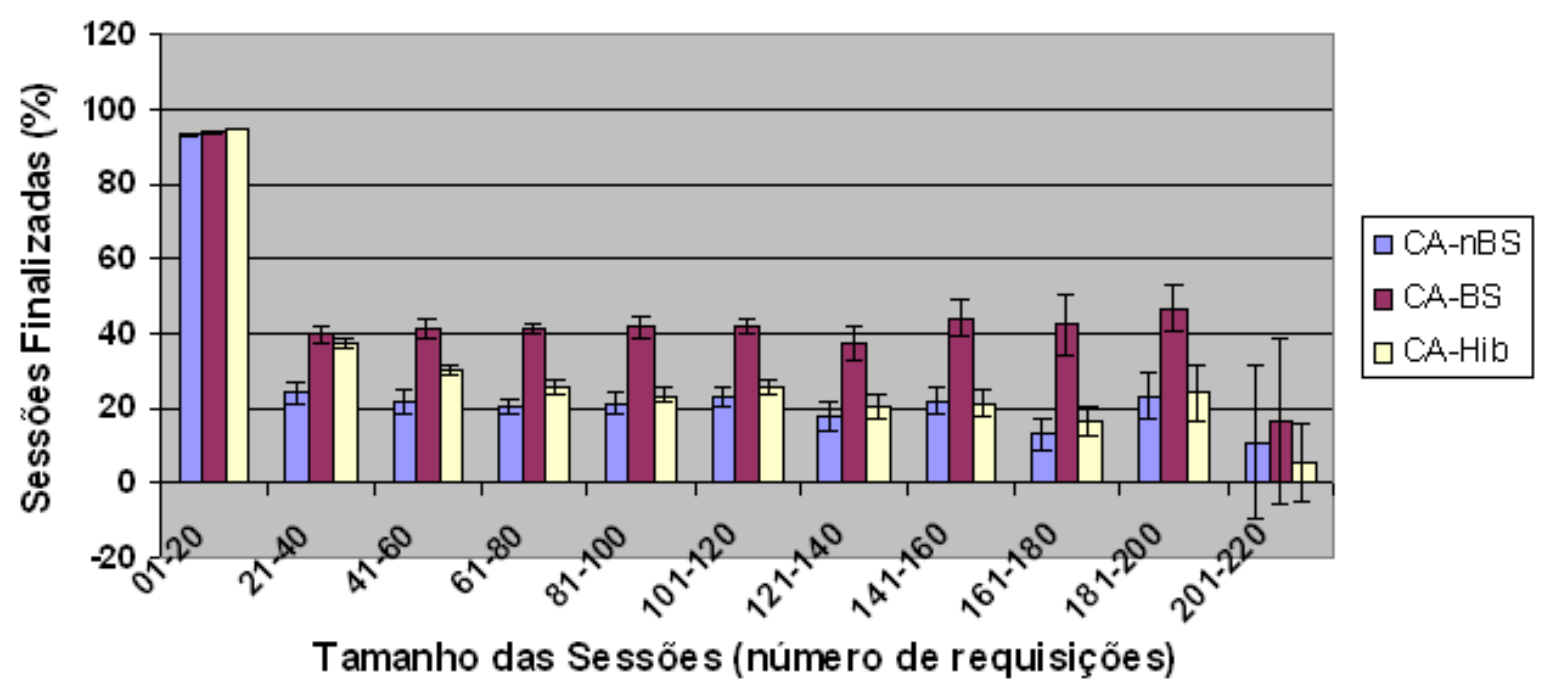

Figura 6.9: Porcentagem de sessões finalizadas - mecanismo que limita a utilização média do cluster.

Analisando-se o gráfico da Figura 6.9, verifica-se que o algoritmo CA-BS finalizou maior quantidade de sessões que possuem mais que 40 requisições, exceto para as sessões que possuem entre 201 e 220 requisições, em que todos os algoritmos apresentaram resultados estatisticamente iguais. Isto ocorreu porque, em cada uma das 10 execuções do gerador de carga de trabalho, um número muito pequeno de sessões deste tamanho é gerado: nenhuma, uma ou duas sessões. Assim, ao utilizar esta carga na simulação, a porcentagem de sessões atendidas e finalizadas para este tamanho foi $0 \%, 50 \%$ e 100\%, apresentando um grande intervalo de confiança.

O algoritmo CA-Híb, por sua vez, obteve um melhor desempenho que o algoritmo CA-nBS, para sessões com até 80 requisições. Para sessões maiores, os dois algoritmos apresentaram resultados estatisticamente iguais.

\subsubsection{Experimentos 3 e 4: Uma Comparação}

Verificou-se a partir dos resultados obtidos com os experimentos 3 e 4 que, o mecanismo que limita o tamanho da fila e o mecanismo que limita a utilização média do cluster apresentam comportamento com eficácia semelhante.

Devido a utilização do algoritmo baseado em sessão CA-BS, um número reduzido de sessões é descartado, e não ocorre nenhum aborto de sessão, impactando positivamente na utilização 
efetiva de recursos. Nesse caso, a utilização dos recursos do sistema foi de 100\%, nos dois experimentos, indicando a sua utilização por sessões que foram finalizadas.

Utilizando-se o algoritmo não baseado em sessão CA-nBS como comparativo, verifica-se que esse, realiza o maior número de abortos no experimento 3, e a mesma porcentagem de abortos que o algoritmo híbrido CA-Híb, no experimento 4. E isso tem um impacto na utilização efetiva dos recursos, que é menor nos dois experimentos, para o CA-nBS. No caso do algoritmo CA-Híb, sua utilização dos recursos também é reduzida no experimento 4. No experimento 3, o número de abortos do algoritmo CA-Híb é menor que no experimento 4, obtendo-se assim, uma melhor utilização dos recuros do sistema.

No caso da porcentagem de sessões finalizadas, e do tamanho médio dessas sessões, no experimento 3, o algoritmo que finaliza maior número de sessões, e de maior tamanho é o CAHíb. Apesar de finalizar uma boa porcentagem de sessões, o algoritmo CA-nBS finaliza sessões menores que os demais. No experimento 4, o algoritmo que finaliza maior número de sessões, e de maior tamanho é o CA-BS. O algoritmo CA-nBS finaliza a menor porcentagem de sessões, e de menor número de requisições. Isso mostra a ineficiência do algoritmo ao se utilizar uma carga de trabalho baseada em sessões de usuários.

Verifica-se através dos gráficos da Figura 6.10 que a porcentagem de sessões finalizadas obteve maior influência do mecanismo de controle de admissão utilizado (Figura 6.10(a)). E o que mais influênciou na utilização efetiva dos recursos (Figura 6.10(b)), e na porcentagem de descartes (Figura 6.10(c)) e abortos (Figura 6.10(d)), foi o algoritmo utilizado (CA-nBS ou CA-BS).

Observa-se nos gráficos da Figura 6.11 que o mecanismo de controle de admissão teve maior influência na porcentagem de sessões finalizadas (Figura 6.11(a)), na utilização efetiva dos recursos do sistema (Figura 6.11(b)) e na porcentagem de sessões descartadas (Figura 6.11(c)). Já a porcetagem de sessões abortadas (Figura 6.11(d)) recebeu maior influência ao algoritmo de contole de admissão utilizado (CA-nBS ou CA-Híb).

O cálculo de influência de fatores para o mecanismo que limita o tamanho da fila e o mecanismo que limita a utilização média do cluster, e os algoritmos CA-BS e CA-Híb, mostra que o fator que mais teve influência para a porcentagem de sessões finalizadas foi o mecanismo de controle de admissão (Figura 6.12(a)). Para as demais variáveis de resposta (utilização efetiva dos recursos, sessões descartadas e sessões abortadas), o fator de maior influência foi o algoritmo de controle de admissão, como mostrado nos gráficos das Figuras 6.12(b), 6.12(c), $6.12(d)$, respectivamente. 


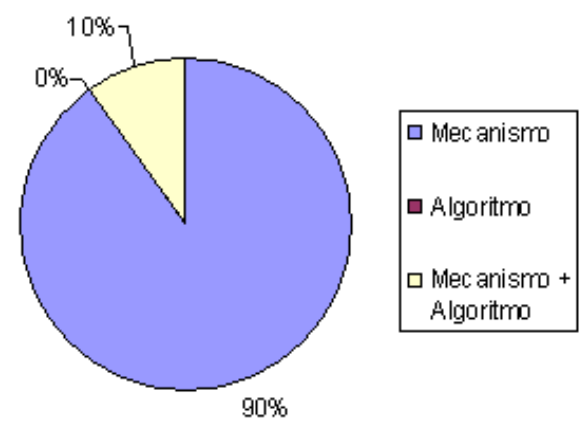

(a) Sessões finalizadas.

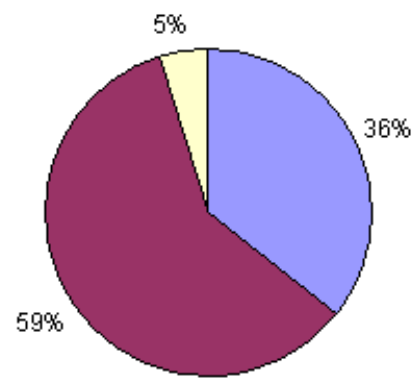

(c) Sessões descartadas.

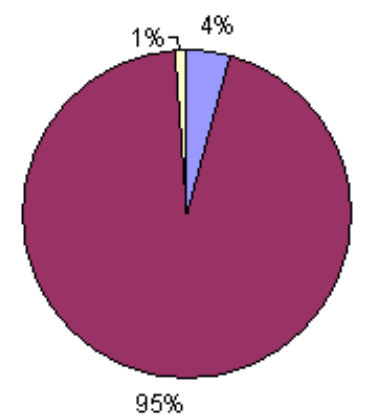

(b) Utilização efetiva dos recursos do sistema.

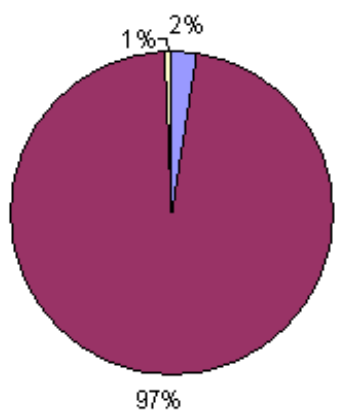

(d) Sessões abortadas.

Figura 6.10: Influência dos fatores - mecanismos: que limita o tamanho da fila e a utilização média do cluster - algoritmos: CA-nBS e CA-BS.

\subsubsection{Experimento 5 - Drop Tail e RED: Tratamento de Requisições Individuais}

Objetivo - Comparar os algoritmos de controle de admissão Drop Tail e RED.

Fatores - O Experimento 5 possui como parâmetros fixos: carga de trabalho, algoritmo de balanceamento de carga, número de servidores do cluster e, parametrização do modelo. E como fatores, os algoritmos de controle de admissão, os limites para admissão e descarte e o peso da fila para o algoritmo RED.

Níveis - O fator algoritmo de controle de admissão possui dois níveis: Drop Tail e RED. E o fator limite para admissão/descarte possui os níveis 400, 600 e 700 para o algoritmo Drop Tail e, 200-600, 400-800 e 550-850 para o algoritmo RED. O peso da fila para o algoritmo RED possui os níveis 0,2 e 0,42 .

Variáveis de Resposta - Tempo de resposta e porcentagem de descarte. 


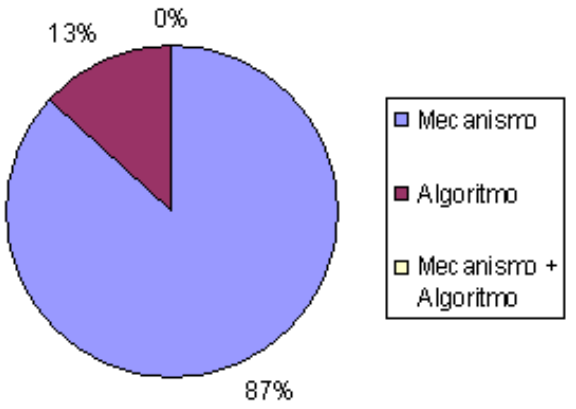

(a) Sessões finalizadas.

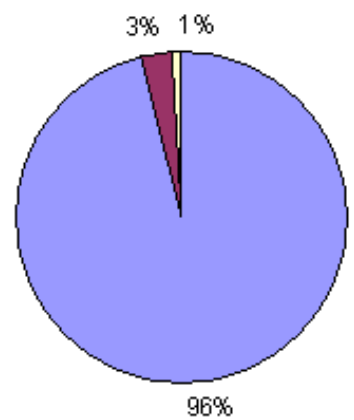

(c) Sessões descartadas.

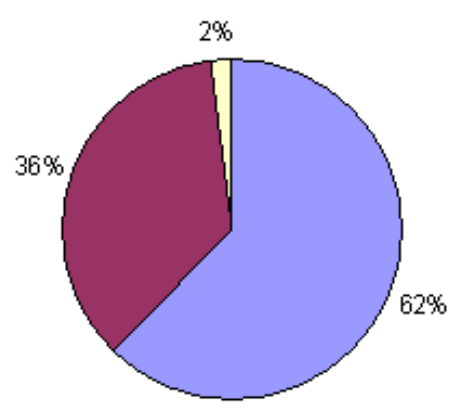

(b) Utilização efetiva dos recursos do sistema.

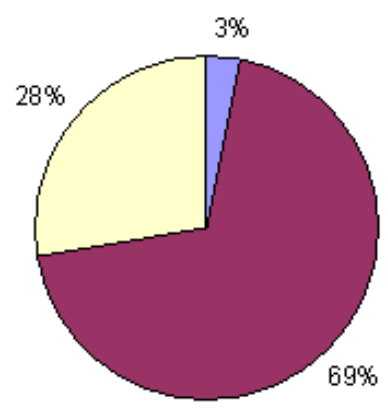

(d) Sessões abortadas.

Figura 6.11: Influência dos fatores - mecanismos: que limita o tamanho da fila e a utilização média do cluster - algoritmos: CA-nBS e CA-Híb.

Esta seção apresenta os resultados obtidos com os algoritmos de controle de admissão Drop Tail e RED (Random Early Detection).

O algoritmo Drop Tail é um gerenciador de fila usado por roteadores de Internet para decidir quando descartar pacotes em redes TCP/IP. Assim, o algoritmo Drop Tail adaptado para a camada de aplicação, atua limitando o tamanho médio máximo das filas, ou seja, quando a média do tamanho das filas dos servidores alcança um limite pré-definido, a requisição corrente é descartada.

Já o algoritmo RED foi proposto inicialmente para atuar na camada de rede, como mecanismo de controle de congestionamento, tendo como principais objetivos, evitar o congestionamento, evitar sincronização global, e evitar a tendência de sobrecarga nas fontes receptoras [Floyd and Jacobson 1993].

No processamento de requisições à servidores $W e b$, na camada de aplicação, o algoritmo RED determina se cada requisição que chega à fila dos servidores será aceita. A forma utilizada para determinar a admissão inicia-se com o cálculo do tamanho médio das filas avg. Posteriormente, o avg é comparado com um limite mínimo THMIN e um limite máximo THMAX. 


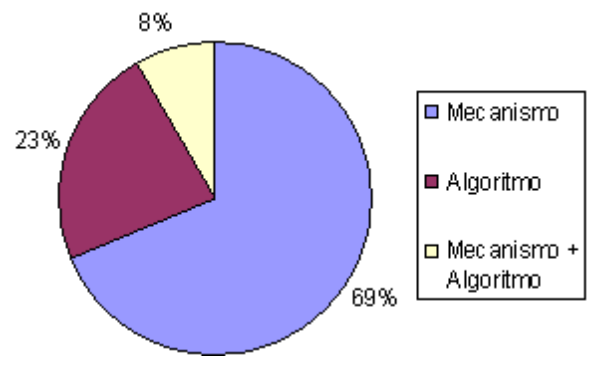

(a) Sessões finalizadas.

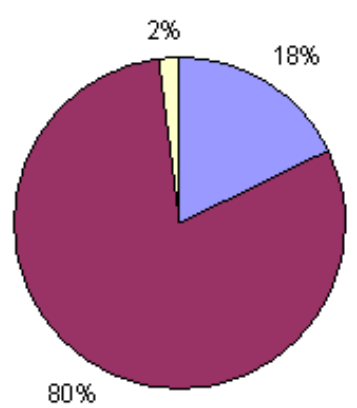

(c) Sessões descartadas.

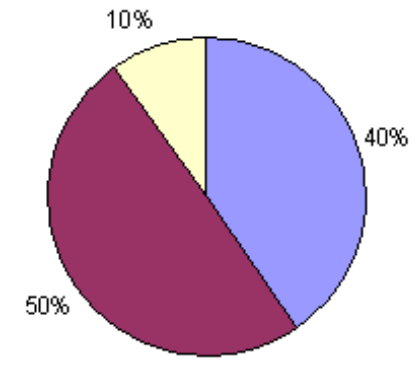

(b) Utilização efetiva dos recursos do sistema.

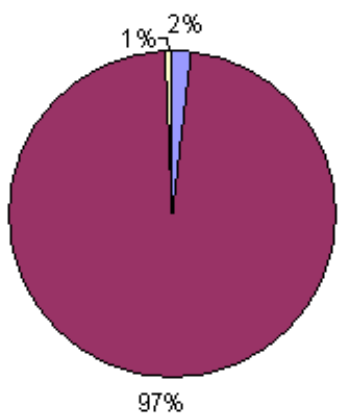

(d) Sessões abortadas.

Figura 6.12: Influência dos fatores - mecanismos: que limita o tamanho da fila e a utilização média do cluster - algoritmos: CA-BS e CA-Híb.

Se avg for menor que o limite mínimo THMIN, a requisição é admitida no sistema. Se avg for maior que o limite máximo THMAX, a requisição é descartada. Se avg estiver entre os dois limiares, pode ser indício do início de uma sobrecarga. Nessa região, a probabilidade de descarte $P a$ é calculada e, então, a requisição é descartada com essa probabilidade ou admitida no sistema com a sua complementar.

O tamanho médio da fila é calculado usando-se uma média ponderada móvel dos tamanhos das filas anteriores. Utiliza-se um parâmetro fixo $w q$ (peso da fila) que determina quão rápido avg muda em resposta à mudança do tamanho atual da fila. O cálculo do avg é dado pela seguinte fórmula:

$$
a v g=(1-w q) * a v g+w q * q
$$

em que, $q$ é a média do tamanho atual das filas dos servidores do cluster.

Quando o avg está na região entre o limite mínimo e o máximo, quanto mais próximo estiver de THMAX, maior a probabilidade de descarte. Adicionalmente, mantém-se uma variável contadora (count) do número de requisições consecutivas que escaparam do descarte; quanto 
maior o valor de count, maior a probabilidade de descarte. A fórmula da probabilidade de descarte $P a$ é dada por:

$$
P a=P b /(1-\text { count } * P b),
$$

com:

$$
P b=P \max *[(a v g-T H M I N) /(T H M A X-T H M I N)],
$$

em que, $P b$ é uma probabilidade temporária usada no cálculo de $P a$ e $P$ max é o valor máximo que $\mathrm{Pb}$ pode atingir.

Assim como os testes realizados com os algoritmos de escalonamento e controle de admissão, mostrados nas Seções 6.4.1, 6.4.2, 6.5.1, 6.5.2, os testes realizados com os algoritmos Drop Tail e $R E D$ também têm como objetivo validar a nova carga de trabalho obtida através do gerador de sessões, assim como comparar o desempenho obtidos por estes dois algoritmos.

Bem como nos demais testes, utilizou-se o modelo SWDS, e a parametrização usada foi a mesma definida pelo seu autor [Teixeira 2004]. No entanto, para o cálculo do tempo de serviço das requisições estáticas, foram utilizadas as características do disco Samsung HD161HJ SATA II [Samsung 2010], usado nos servidores do cluster do Laboratório de Sistemas Distribuídos e Programação Concorrente (LaSDPC), do ICMC-USP. Cada nó do cluster é modelado individualmente, com CPU, disco e interface de rede. Para o cálculo do tempo de serviço das requisições estáticas, a taxa de transferência dos discos dos servidores foi parametrizada como $300 \mathrm{Mbps}$, e o tempo de busca como 8,9 ms. O tempo de serviço das requisições dinâmicas é definido como $10 \mathrm{~ms}$ e a capacidade da interface de rede como 80 Mbps. A capacidade de processamento do Classificador é determinada como 8000 requisições/s, e do controle de admissão é definida como 4000 requisições/s.

Foi utilizado um cluster homogêneo com quatro servidores, e o algoritmo de escalonamento empregado foi o SQF. Foi utilizada uma carga de trabalho com 2000 sessões. No entanto, esses programas de simulação não possuem a capacidade de reconhecer e tratar sessões, já que os algoritmos não são baseados em sessão.

O limite máximo para o tamanho médio da fila, para o algoritmo Drop Tail, foi assumido como, 400, 600 e 700 requisições.

Os valores para os parâmetros THMIN e THMAX do algoritmo RED foram definidos como 200 e 600,400 e 800 , e 550 e 850 respectivamente. O peso da fila $w q$ assumiu os valores 0,2 e 0,42 e a probabilidade auxiliar Pmax, foi fixada em 0,2 [Zheng and Atiquzzaman 2008]. A 
Tabela 6.3 apresenta um resumo dos nove testes realizados.

Tabela 6.3: Configuração dos testes realizados.

\begin{tabular}{||l||c|}
\hline \hline Experimento & Algoritmos e Parâmetros \\
\hline \hline Teste 1 & Drop Tail - Limite $=400$ \\
\hline Teste 2 & RED - THMIN $=200 ;$ THMAX $=600 ; \mathrm{wq}=0,2$ \\
\hline Teste 3 & RED - THMIN $=200 ;$ THMAX $=600 ; \mathrm{wq}=0,42$ \\
\hline Teste 4 & Drop Tail - Limite $=600$ \\
\hline Teste 5 & RED - THMIN $=400 ;$ THMAX $=800 ; \mathrm{wq}=0,2$ \\
\hline Teste 6 & RED - THMIN $=400 ;$ THMAX $=800 ; \mathrm{wq}=0,42$ \\
\hline Teste 7 & Drop Tail - Limite $=700$ \\
\hline Teste 8 & RED - THMIN $=550 ;$ THMAX $=850 ; \mathrm{wq}=0,2$ \\
\hline Teste 9 & RED - THMIN $=550 ;$ THMAX $=850 ; \mathrm{wq}=0,42$ \\
\hline \hline
\end{tabular}

O gráfico da Figura 6.13, apresenta a porcentagem de descarte para os algoritmos Drop Tail, RED com wq =0,2 e RED com wq $=0,42$.

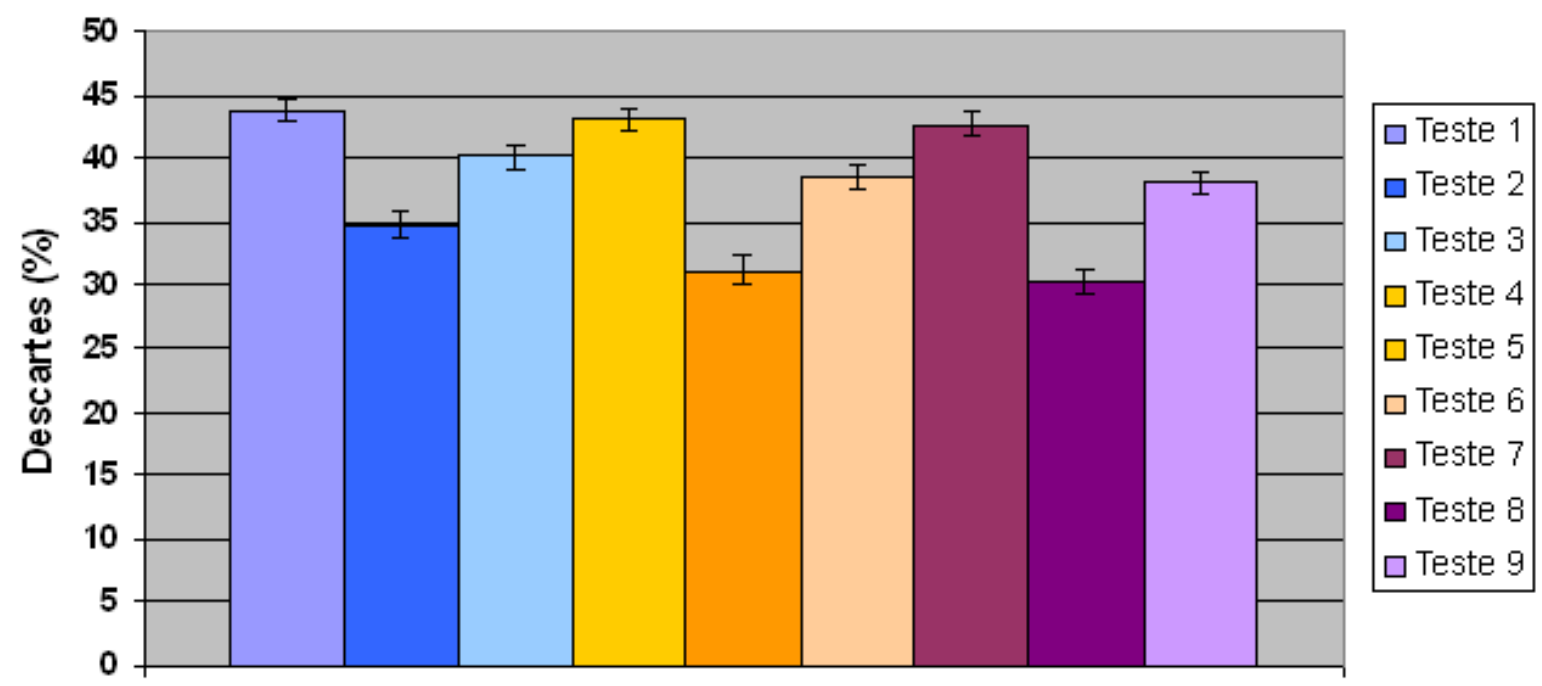

Figura 6.13: Porcentagem de descartes obtida pelos algoritmos Drop Tail e RED.

O gráfico da Figura 6.13 mostra que, ao se comparar os resultados obtidos nos testes, o algoritmo Drop Tail realiza a maior quantidade de descartes. Isto porque, ao se alcançar o limite máximo para tamanho das filas, as requisições são descartadas sem nenhuma negociação ou verificação extra.

Já o algoritmo RED calcula uma probabilidade de descarte, quando o tamanho da fila está 
entre o limite mínimo e o limite máximo, sendo assim, mais cauteloso ao descartar. Dessa forma, em todos os testes, o RED apresenta um melhor aproveitamento que o Drop Tail. Nos testes 1, 2 e 3, por exemplo, o RED descarta 34,68\% $\pm 0,99 \%$ no teste 2 e 40,19\% $\pm 0,93 \%$ no teste 3, enquanto que o Drop Tail descarta $43,80 \% \pm 0,89 \%$.

Verifica-se que o descarte realizado pelo algoritmo RED é influenciado pelo $w q$, que determina quão rápido a média muda em resposta a uma mudança no tamanho atual da fila. Assim, quando $\mathrm{wq}=0,2$, a resposta a mudanças na fila não reflete na média tão rapidamente quanto quando $\mathrm{wq}=0,42$, e a porcentagem de descarte é menor.

Verifica-se também que, quanto mais se aumenta os limites para descarte, mais as diferenças entre os descartes obtidos com o Drop Tail e o RED com wq $=0,42$, e aqueles obtidos com o RED com wq $=0,2$ se acentuam. Assim, quando se aumenta o limite máximo para o tamanho da fila para o algoritmo Drop Tail, a porcentagem de descarte não diminui, bem como o algoritmo RED com $\mathrm{wq}=0,42$, em que a porcentagem de descarte permanece a mesma quando se aumenta os limites mínimo e máximo. Já com o algoritmo RED com wq =0,2, quando se aumenta os limites THMIN e THMAX de 200 e 600 (teste 2) para 400 e 800 (teste 5), a uma diminuição na porcentagem de descarte, e quando se aumenta os limites de 400 e 800 (teste 5) para 550 e 850 (teste 8), as porcentagens de descarte são estatisticamente iguais.

Uma conseqüência para o menor número de descartes é um tempo de resposta das requisições maior, como mostra o gráfico da Figura 6.14.

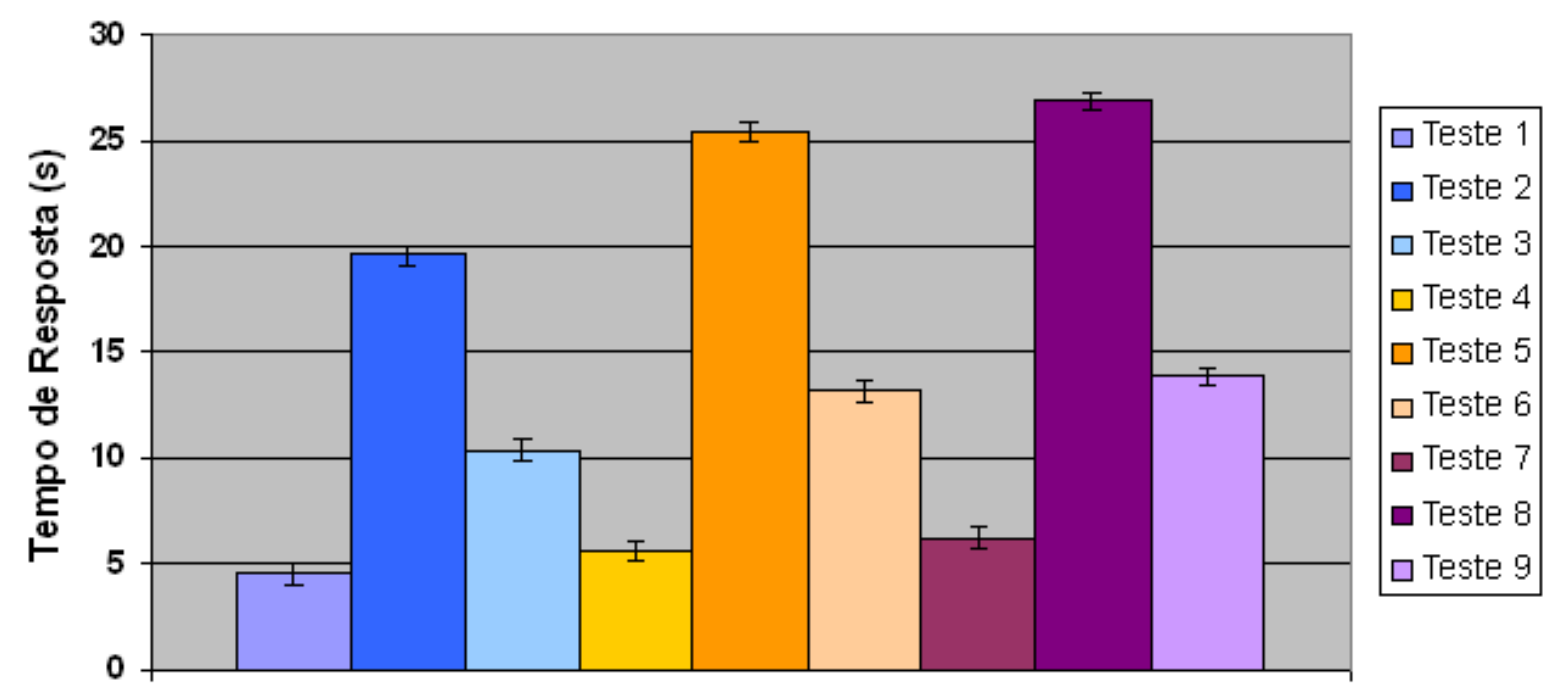

Figura 6.14: Tempo de resposta das requisições.

Observa-se no gráfico da Figura 6.14, que os testes 2, 5 e 8, que proporcionaram menor 
número de descartes, obtiveram maior tempo de resposta. Isto ocorre não porque o algoritmo obteve pior desempenho, mas porque o sistema foi submetido a uma carga mais intensa, com maior número de requisições.

Como mostrado nos gráficos das Figuras 6.15, 6.16 e 6.17, considerando-se os fatores algoritmo de controle de admissão e limites para descarte, o fator que teve mais influência sobre as variáveis de resposta tempo de resposta e descarte de requisições, foi o algoritmo. Nesse caso, o peso da fila para o algoritmo RED foi fixado em $w q=0,2$, pois o algoritmo Drop Tail não possui esse parâmetro.

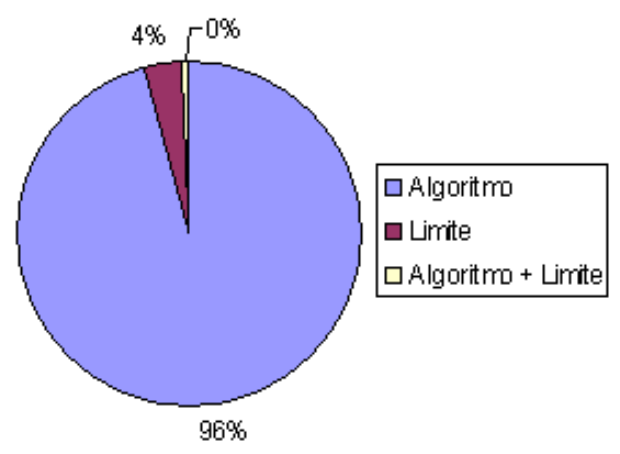

(a) Tempo de resposta.

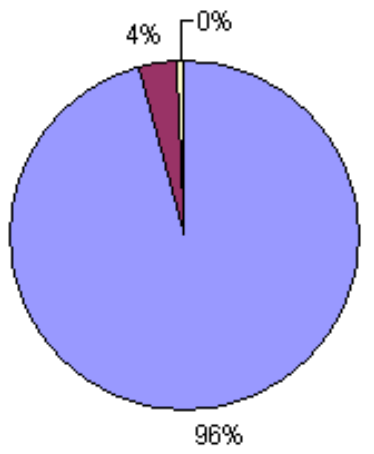

(b) Descarte de requisições.

Figura 6.15: Influência dos fatores - algoritmos: Drop Tail e RED - limites para Drop Tail: 400 e 600 - limites THMIN-THMAX para o RED: 200-600 e 400-800 - peso da fila ( wq) para o RED: 0,2 .

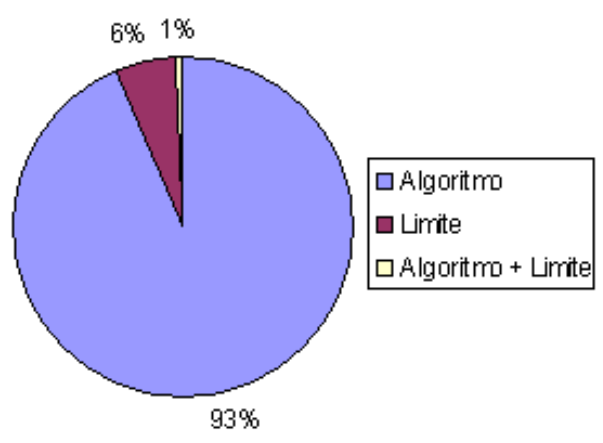

(a) Tempo de resposta.

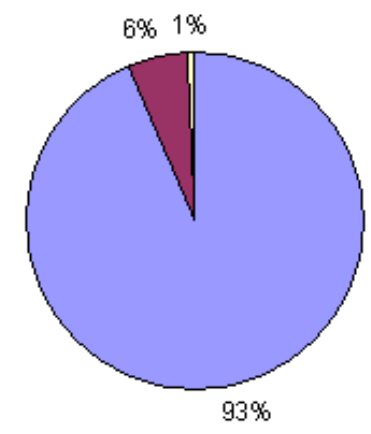

(b) Descarte de requisições.

Figura 6.16: Influência dos fatores - algoritmos: Drop Tail e RED - limites para Drop Tail: 400 e 700 - limites THMIN-THMAX para o RED: 200-600 e 550-850 - peso da fila (wq) para o RED: 0,2 . 


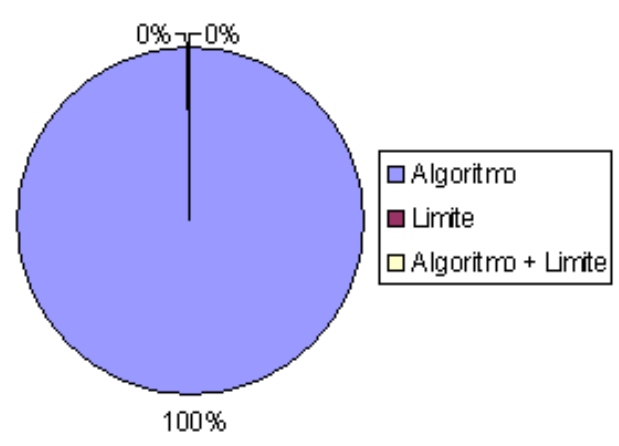

(a) Tempo de resposta.

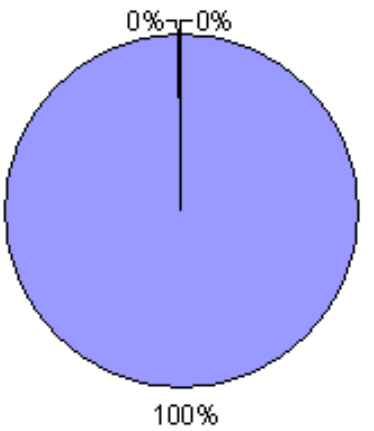

(b) Descarte de requisições.

Figura 6.17: Influência dos fatores - algoritmos: Drop Tail e RED - limites para Drop Tail: 600 e 700 - limites THMIN-THMAX para o RED: 400-800 e 550-850 - peso da fila (wq) para o RED: 0,2 .

Os gráficos das Figuras 6.18, 6.19 e 6.20 mostram a influêcia dos mesmos fatores mostrados anteriormente, quando o peso da fila para o algoritmo RED é 0,42 . Bem como quando $w q=0,2$, o fator de maior influência nos resultados foi o algoritmo de controle de admissão.

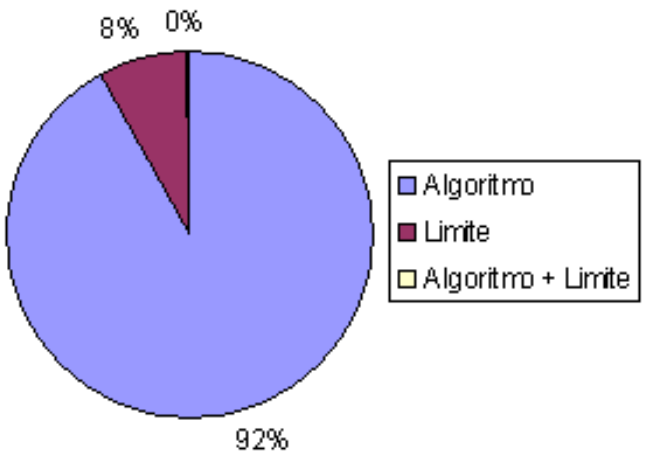

(a) Tempo de resposta.

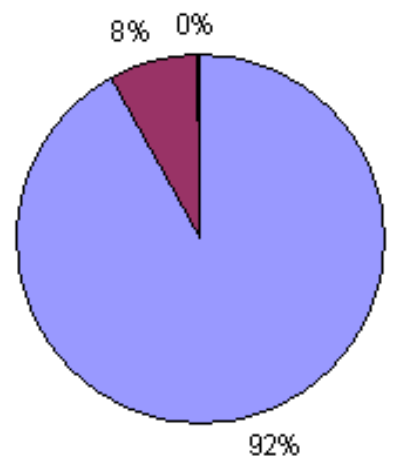

(b) Descarte de requisições.

Figura 6.18: Influência dos fatores - algoritmos: Drop Tail e RED - limites para Drop Tail: 400 e 600 - limites THMIN-THMAX para o RED: 200-600 e 400-800 - peso da fila (wq) para o RED: 0,42 .

Considerando-se os fatores que influenciaram nos resultados obtidos com algoritmo RED, limite mínimo THMIN e limite máximo THMAX e, peso da fila $w q$, verifica-se através dos gráficos das Figuras 6.21, 6.22 e 6.23 que, aquele que teve maior influência nas váriaveis de resposta, tempo de resposta e descarte de requisições, foi o peso da fila $w q$. 


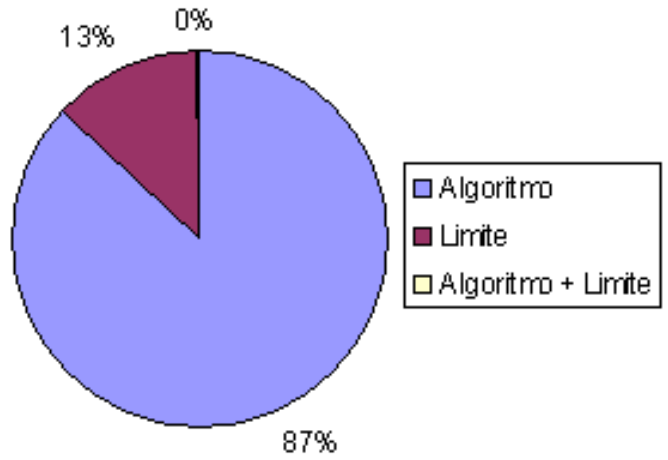

(a) Tempo de resposta.

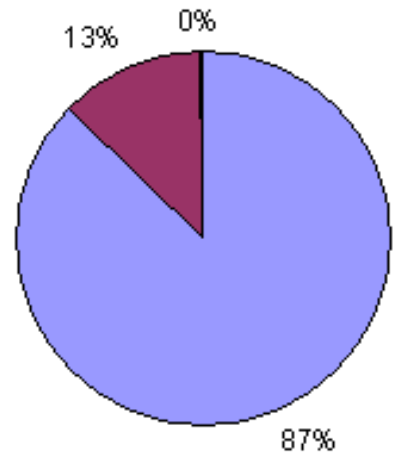

(b) Descarte de requisições.

Figura 6.19: Influência dos fatores - algoritmos: Drop Tail e RED - limites para Drop Tail: 400 e 700 - limites THMIN-THMAX para o RED: 200-600 e 550-850 - peso da fila ( $w q)$ para o RED: 0,42 .

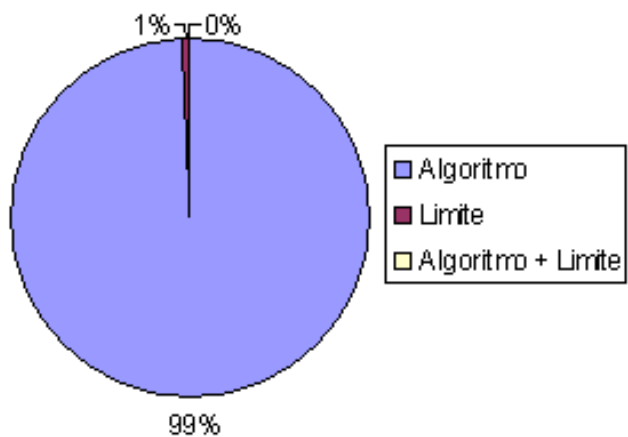

(a) Tempo de resposta.

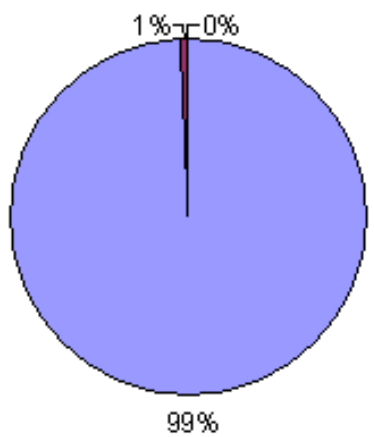

(b) Descarte de requisições.

Figura 6.20: Influência dos fatores - algoritmos: Drop Tail e RED - limites para Drop Tail: 600 e 700 - limites THMIN-THMAX para o RED: 400-800 e 550-850 - peso da fila ( wq) para o RED: 0,42 .

\subsubsection{Experimento 6 - RED-SB (RED Session Based)}

Objetivo - Validação do algoritmo RED-SB.

Fatores - O Experimento 6 possui como parâmetros fixos, a carga de trabalho, olimite para admissão/descarte, o algoritmo de balanceamento de carga, o tipo de cluster, o número de servidores do cluster e parametrização do modelo. E possui como fatores, os limites para admissão/descarte e o algoritmo de controle de admissão.

Níveis - O fator algoritmo de controle de admissão possui três níveis: CA-nBS, CA-BS e CA-Híb. 


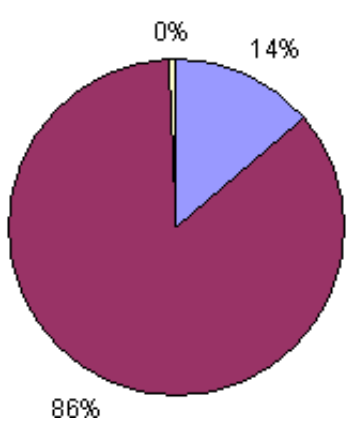

(a) Tempo de resposta.

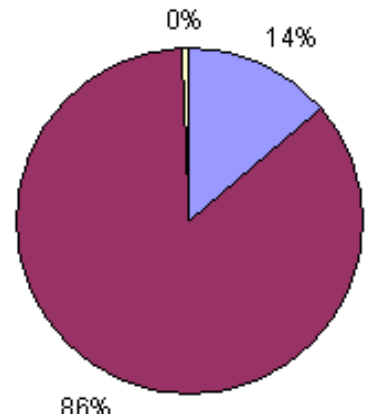

(b) Descarte de requisições.

Figura 6.21: Influência dos fatores para o algoritmo RED - THMIN-THMAX: 200-600 e 400-800 - (wq): 0,2 e 0,42 .

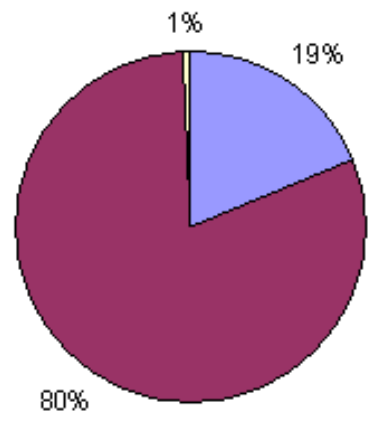

(a) Tempo de resposta.

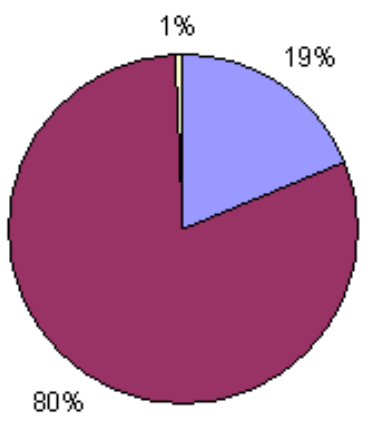

(b) Descarte de requisições.

Figura 6.22: Influência dos fatores para o algoritmo RED - THMIN-THMAX: 200-600 e 550-850 - (wq): 0,2 e 0,42 .

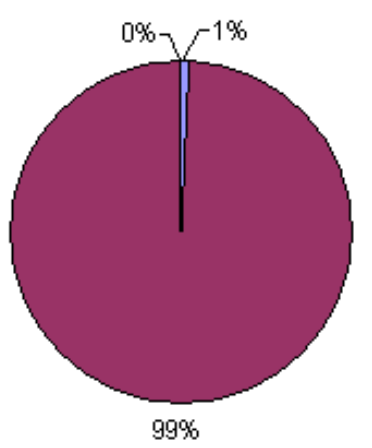

(a) Tempo de resposta.

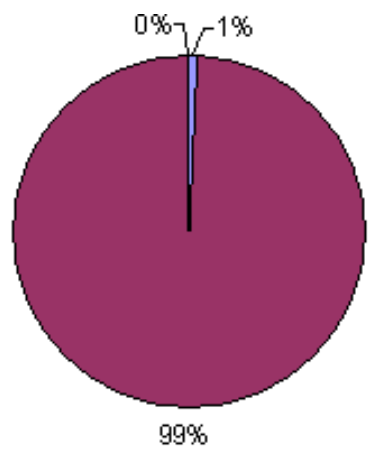

(b) Descarte de requisições.

Figura 6.23: Influência dos fatores para o algoritmo RED - THMIN-THMAX: 400-800 e 550-850 - (wq): 0,2 e 0,42 .

Variáveis de Resposta - Sessões finalizadas, sessões descartadas, sessões abortadas, utilização efetiva dos recursos, throughput de sessões, throughput de requisições, tamanho 
das sessões, tempo de resposta das requisições.

A proposta apresentada nesta seção é inserir o algoritmo RED no contexto de sessões, para que seja possível realizar o reconhecimento de sessões e o descarte baseado nestas, e não apenas nas requisições individuais. Desta forma, ao se reconhecer as sessões, a alteração realizada no algoritmo, foi para que ao se realizar o descarte de uma requisição, a sessão a qual a requisição pertence seja buscada e descartada. A este novo método de controle de admissão, deu-se o nome de RED-SB (RED Session Based).

Este possui como mecanismo para verificação da necessidade de descarte, o limite do tamanho da fila, no entanto, essa necessidade de descarte é verificada através da média dos tamanhos das filas e de dois limites, o mínimo THMIN e o máximo THMAX.

Como o algoritmo trata sessões pode-se optar pelo descarte de novas requisições (descartando consequentemente as sessões as quais estas requisições pertencem); pelo descarte de novas sessões; ou pelo descarte das requisições pertencentes às menores sessões. Assim, o algoritmo proposto foi testado em conjunto com os algoritmos CA-nBS, CA-BS e CA-Híb [Barbarto et al. 2007; Barbato 2007].

Os testes foram realizados com o modelo SWDS, aplicando-se ao algoritmo proposto, uma carga obtida através do gerador de sessões sintéticas, com 2 mil sessões. A parametrização utilizada para este modelo é a mesma empregada por Teixeira [Teixeira 2004], apresentada na Seção 6.4. É utilizado um cluster homogêneo com quatro servidores, e o algoritmo de balanceamento de carga SQF (Shortest Queue First), pois este possibilita certa igualdade nas filas dos servidores do cluster, enviando sessões para as menores filas e não permitindo que alguns recursos fiquem ociosos e outros sobrecarregados. Assim, o desempenho do sistema não é prejudicado ao se calcular uma média entre as filas do cluster.

Os valores para os parâmetros THMIN e THMAX do mecanismo RED-SB também foram definidos como 550 e 850, respectivamente, e o peso da fila $w q$ foi fixado em 0,2, pois nos experimentos realizados com o algoritmo RED, esta configuração obteve a maior porcentagem de requisições aceitas. A probabilidade auxiliar Pmax foi fixada em 0,2, bem como nos demais testes com o RED.

Os resultados dos experimentos apresentados a seguir foram obtidos utilizando o novo algoritmo RED-SB, juntamente com as políticas CA-nBS, CA-BS e CA-Híb [Barbarto et al. 2007; Barbato 2007]. A Tabela 6.4 apresenta esses resultados e os respectivos intervalos de confiança com $95 \%$.

A partir dos dados da Tabela 6.4 nota-se que o algoritmo CA-BS, que descarta novas sessões, 
Tabela 6.4: Avaliação do mecanismo RED-SB.

\begin{tabular}{||l||c||c||c|}
\hline \hline \multicolumn{1}{||c||c||c||}{ CA-nBS } & CA-BS & CA-Híb \\
\hline \hline Sessões Finalizadas (\%) & $92,92 \pm 0,23$ & $93,15 \pm 0,28$ & $96,49 \pm 0,17$ \\
\hline Sessões Descartadas (\%) & $0,00 \pm 0,00$ & $6,83 \pm 0,28$ & $0,19 \pm 0,04$ \\
\hline Sessões Abortadas (\%) & $7,05 \pm 0,23$ & $0,00 \pm 0,00$ & $3,30 \pm 0,14$ \\
\hline Utilização Efetiva dos Recursos (\%) & $71,10 \pm 1,28$ & $100,00 \pm 0,00$ & $97,51 \pm 0,00$ \\
\hline Throughput (sessões/s) & $0,07 \pm 0,01$ & $0,07 \pm 0,01$ & $0,07 \pm 0,01$ \\
\hline Throughput (requisições/s) & $0,52 \pm 0,10$ & $0,54 \pm 0,10$ & $0,54 \pm 0,10$ \\
\hline Tamanho Médio Sessões (\# requisições) & $5,08 \pm 0,09$ & $6,81 \pm 0,29$ & $6,93 \pm 0,19$ \\
\hline Tempo Médio Resposta Requisições (s) & $24,12 \pm 0,39$ & $24,09 \pm 0,40$ & $23,56 \pm 0,37$ \\
\hline
\end{tabular}

alcança seu objetivo não abortando nenhuma sessão admitida no sistema (0,00\%). Assim, houve apenas descartes, de 6,83\% $\pm 0,28 \%$. Como a utilização dos recursos foi de $100 \%$, isto significa que durante todo o tempo que os recursos estiveram ocupados, foram com sessões finalizadas com sucesso.

Quando comparado ao algoritmo CA-nBS, observa-se que este aborta certa quantidade de sessões $(7,05 \% \pm 0,23)$, impactando na utilização dos recursos $(71,10 \% \pm 1,28)$. O algoritmo finaliza a mesma quantidade de sessões que o CA-nBS, no entanto, as sessões finalizadas pelo CA-BS são de maior tamanho, o que significa que houve uma priorização das sessões longas.

O algoritmo CA-Híb, por sua vez, descartou um número pequeno de requisições $(0,19 \%$ $\pm 0,04 \%)$, e obteve certo número de abortos $(3,30 \% \pm 0,14 \%)$, o que também impactou na utilização dos recursos $(97,51 \%)$. Em comparação ao algoritmo CA-nBS, o CA-Híb finalizou maior número de sessões, e de tamanho médio maior, o que significa que o algoritmo alcançou seu objetivo, de escolher para descarte as requisições pertencentes às sessões menores.

Observa-se que os algoritmos CA-BS e CA-Híb finalizaram sessões de maior tamanho em relação ao algoritmo CA-nBS. Além disso, o algoritmo CA-Híb também finalizou maior número de sessões, o que significa que os algoritmos CA-Híb e CA-BS finalizaram maior quantidade de sessões longas. O gráfico da Figura 6.24 apresenta a quantidade de sessões finalizadas, agrupadas de acordo com o número de requisições que possuem, para cada algoritmo de controle de admissão considerado.

Verifica-se, a partir do gráfico da Figura 6.24, que o algoritmo CA-BS finalizou maior quantidade sessões que possuem mais que 141 requisições, em relação às demais políticas. E finalizou maior quantidade de sessões com mais que 41 requisições, em relação ao CA-nBS. O algoritmo CA-nBS realiza o descarte de requisições sem verificar a que sessões essas tarefas 


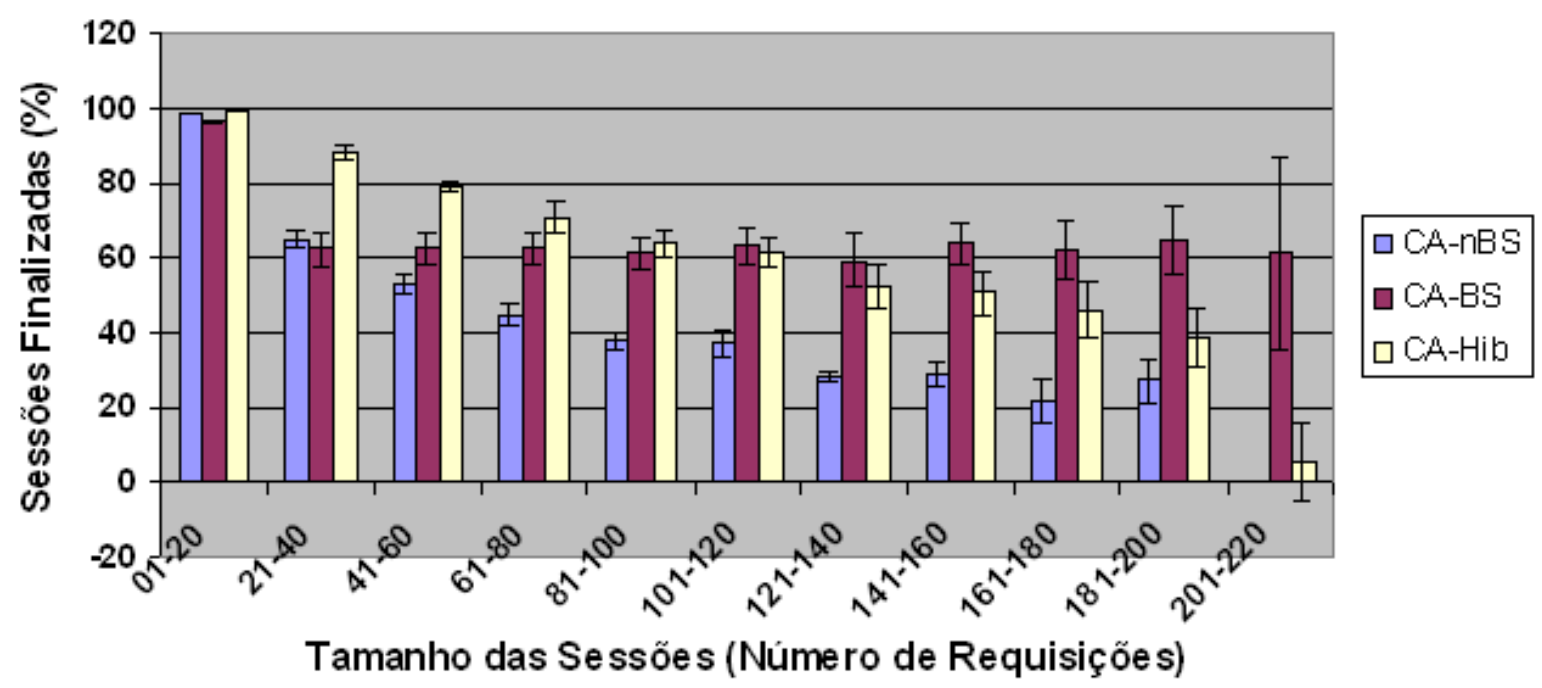

Figura 6.24: Porcentagem de sessões finalizadas - algoritmo RED-SB.

pertencem, prejudicando as sessões que deveriam receber melhor atendimento.

O algoritmo CA-Híb, que tem por objetivo priorizar as sessões maiores, descartando requisições das menores sessões, obteve os melhores resultados para as sessões pequenas, com até 60 requisições, e ainda, fez um balanceamento entre os dois algoritmos (CA-nBS e CA-BS), para sessões de tamanho a partir de 141. Além disso, os resultados obtidos pelo CA-Híb foram superiores ao obtidos pelo CA-nBS para todos os tamanhos de sessões (exceto para sessões de tamanho entre 181-200, em que ambos apresentaram resultados estatisticamente iguais).

Assim, verifica-se que o algoritmo CA-nBS não utiliza nenhum critério para descarte. No intuito de admitir requisições pertencentes às sessões ativas no sistema, o algoritmo CA-BS realiza maior número de descartes. E o algoritmo CA-Híb realiza um balanceamento entre os demais, descartando menor número de sessões que CA-BS, e abortando menor número de sessões já aceitas que CA-nBS. Desta forma, o CA-Híb finaliza maior número de sessões. E como, CA-BS descarta as novas sessões (pequenas) e o CA-Híb escolhe para aborto, as menores, CA-BS e CA-Híb finalizam sessões maiores que CA-nBS.

Ao atuar juntamente com os algoritmos de controle de admissão, e esses manterem sua características e finalidade inalteradas, verifica-se a validade do algoritmo RED-SB, assim como os demais mecanismos testados (mecanismo que limita o tamanho da fila e mecanismo que limita a utilização do cluster).

Os gráficos da Figura 6.25 mostram a influência dos fatores mecanismo de controle de admissão e algoritmo de controle de admissão, sobre as variáveis de resposta porcentagem de sessões finalizadas (Figura 6.25(a)), utilização efetiva dos recursos (Figura 6.25(b)), porcen- 
tagem de sessões descartadas (Figura 6.25(c)) e porcentagem de sessões abortadas (Figura $6.25(\mathrm{~d}))$. Utilizou-se como mecanismos de controle de admissão, aquele que limita o tamanho da fila puramente, e aquele que limita o tamanho da fila usando dois limites e uma probabilidade de descarte (algoritmo RED-SB), e como algoritmo de controle de admissão, o algoritmo não baseado em sessão CA-nBS e o baseado em sessão CA-BS. Verifica-se atráves do gráfico da Figura 6.25(a) que o fator que mais influenciou na porcentagem de sessões finalizadas foi o mecanismo de controle de admissão. Nas demais variáveis de resposta, o fator de maior influência foi o algoritmo.

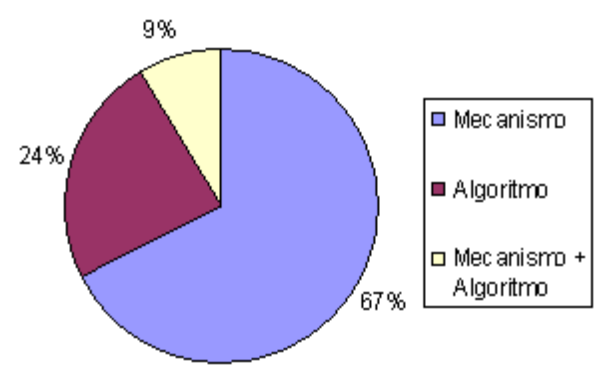

(a) Sessões finalizadas.

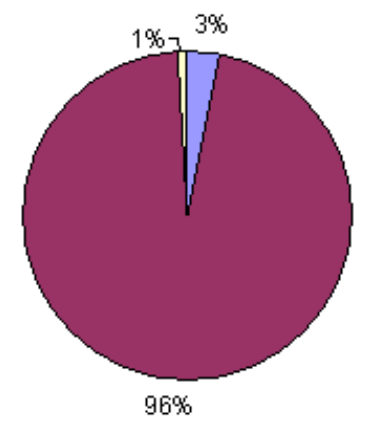

(c) Sessões descartadas.

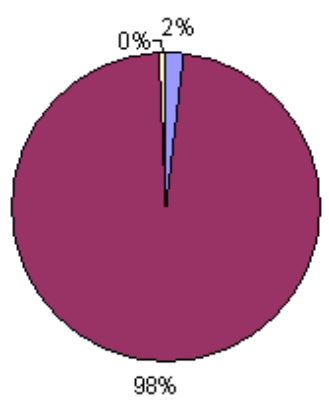

(b) Utilização efetiva dos recursos do sistema.

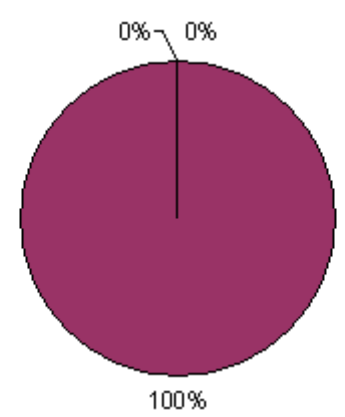

(d) Sessões abortadas.

Figura 6.25: Influência dos fatores - mecanismo que limita o tamanho da fila e RED-SB algoritmos: CA-nBS e CA-BS.

No cálculo de influência de fatores entre o mecanismo que limita o tamanho da fila e o RED-SB, e os algoritmos que CA-nBS e CA-Híb, a variável de resposta porcentagem de sessões descartadas (Figura 6.26(c)) recebeu maior influência do fator mecanismo de controle de admissão. As demais variáveis de resposta, porcentagem de sessões finalizadas (Figura 6.26(a)), utilização efetiva dos recursos (Figura 6.26(b)) e porcentagem de sessões abortadas (Figura 6.26(d)), obtiveram maior influência do fator algoritmo de controle de admissão.

No cálculo de influência de fatores entre o mecanismo que limita o tamanho da fila e o RED-SB, e os algoritmos que CA-BS e CA-Híb, o fator de maior influência foi o mecanismo de 


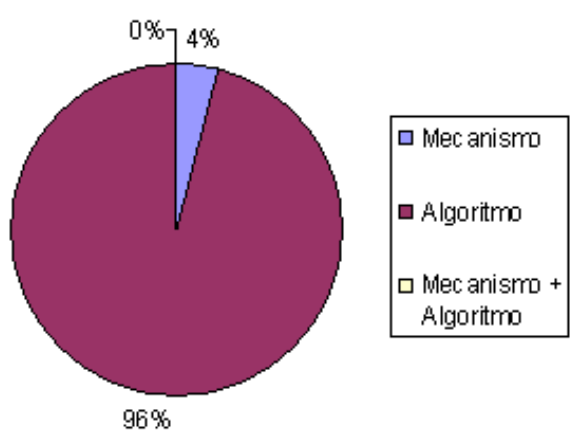

(a) Sessões finalizadas.

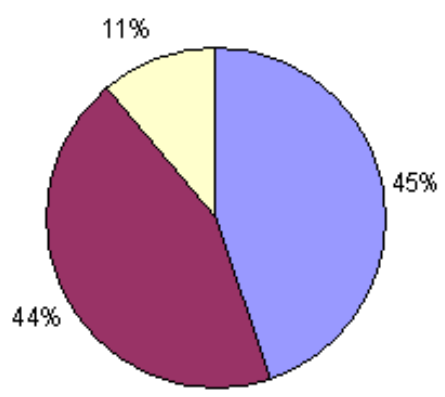

(c) Sessões descartadas.

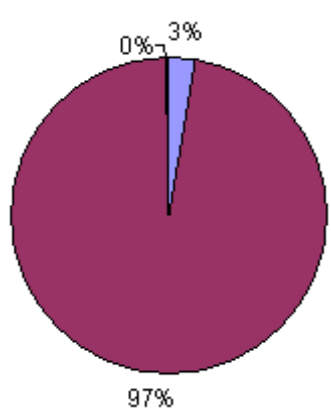

(b) Utilização efetiva dos recursos do sistema.

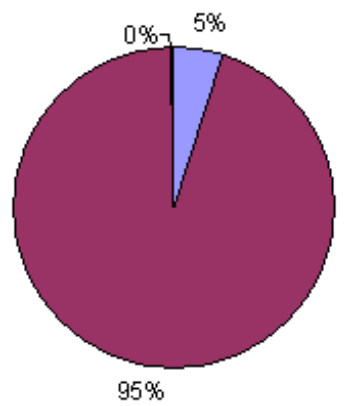

(d) Sessões abortadas.

Figura 6.26: Influência dos fatores - mecanismo que limita o tamanho da fila e RED-SB algoritmos: CA-nBS e CA-Híb.

controle de admissão, como mostrado nos gráficos da Figura 6.27.

Também foi realizado o cálculo de influência de fatores entre o mecanismo que limita a utilização média do cluster e o RED-SB, e os algoritmos de controle de admissão CA-nBS, CA-BS e CA-Híb.

Os gráficos da Figura 6.28 mostram a influência dos fatores nas variáveis de resposta, utilizando-se como níveis para o fator algoritmo de controle de admissão, o CA-nBS e o CABS. Verifica-se através das Figuras 6.28(a) e 6.28(c) que o fator que teve maior influência nas porcentagens de sessões finalizadas e descartadas foi o mecanismo. Já as variáveis de resposta utilização efetiva dos recursos (Figura 6.28(b)) e porcentagem de sessões abortadas (Figura $6.28(\mathrm{~d})$ ), foram mais influenciadas pelo algoritmo de controle de admissão.

Utilizando-se como níveis para o fator algoritmo de controle de admissão, os níveis CAnBS e CA-Híb, verifica-se a mesma influência do mecanismo de controle de admissão sobre as variáveis de resposta porcentagem de sessões finalizadas (Figura 6.29(a)) e porcentagem de sessões descartadas (Figura 6.29(c)). E também, a influência do fator algoritmo de controle de admissão sobre as variáveis de resposta utilização efetiva dos recursos (Figura 6.29(b)) e 


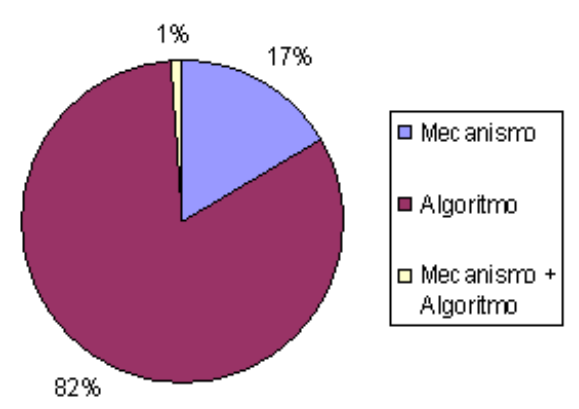

(a) Sessões finalizadas.

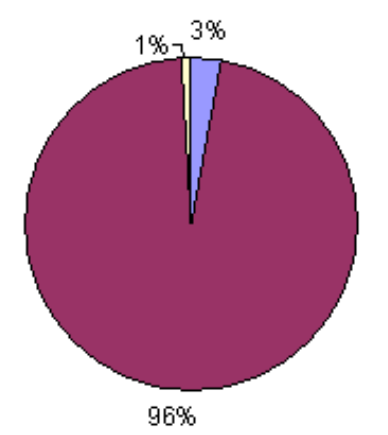

(c) Sessões descartadas.

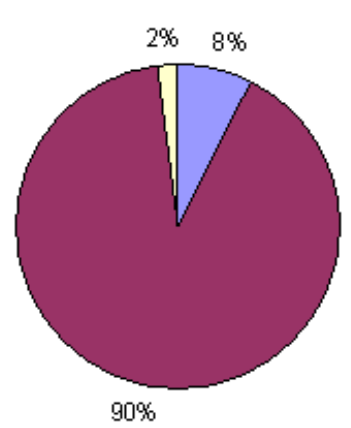

(b) Utilização efetiva dos recursos do sistema.

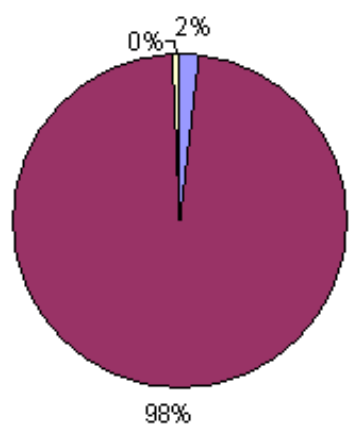

(d) Sessões abortadas.

Figura 6.27: Influência dos fatores - mecanismo que limita o tamanho da fila e RED-SB algoritmos: CA-BS e CA-Híb.

porcentagem de sessões abortadas (Figura 6.29(d)).

No cálculo de influência de fatores utilizando-se como níveis para o fator algoritmo de controle de admissão o algoritmo baseado em sessão CA-BS e o algoritmo híbrido CA-Híb, verificou-se uma maior influência do mecanismo de controle de admissão sobre a porcentagem de sessões finalizadas, como mostrado no gráfico da Figura 6.30(a). Nas demais variáveis de resposta, utilização efetiva dos recursos (Figura 6.30(b)), porcentagem de sessões descartadas (Figura 6.30(c)) e porcentagem de sessões abortadas (Figura 6.30(d)), o fator de maior influência foi o algoritmo de controle de admissão.

\subsection{Considerações Finais}

Este capítulo tratou de técnicas utilizadas em servidores Web para controle de admissão e escalonamento, a fim de validar o gerador de carga de trabalho sintética proposto neste trabalho.

Inicialmente foram discutidos os métodos de avaliação de desempenho, e posteriormente 


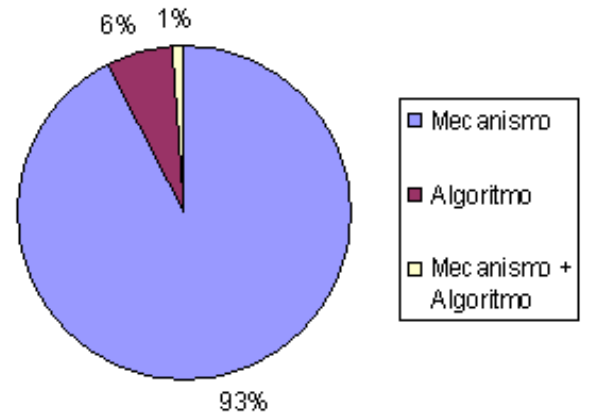

(a) Sessões finalizadas.

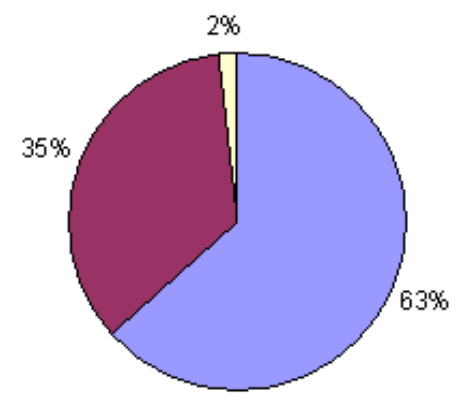

(c) Sessões descartadas.

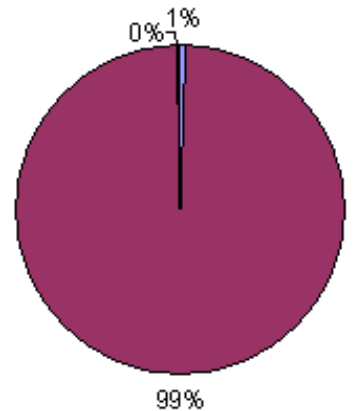

(b) Utilização efetiva dos recursos do sistema.

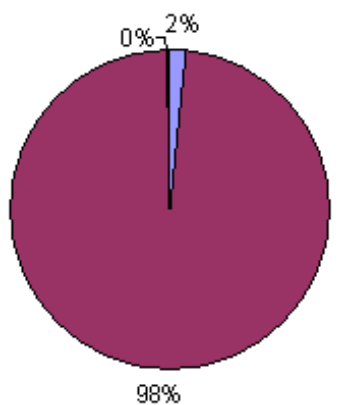

(d) Sessões abortadas.

Figura 6.28: Influência dos fatores - mecanismo que limita a utilização média do cluster e RED-SB - algoritmos: CA-nBS e CA-BS.

apresentado um planejamento de experimento, discutindo os fatores utilizados na avaliação de desempenho e seus níveis.

Foram ainda mostrados os resultados obtidos com algoritmos de escalonamento de sessões e mecanismos e algoritmos de controle de admissão, a fim de validar a carga obtida pelo gerador de sessões desenvolvido. Estes resultados foram comparados aos resultados apresentados por Barbato [Barbato 2007].

A carga gerada foi utilizada para comparar os algoritmos de controle de admissão Drop Tail e RED. Estes algoritmos não possuem o controle de sessões, tratando cada requisição individualmente.

A observação do algoritmo RED foi útil para definição de um novo algoritmo de controle de admissão, o RED-SB. E a sua análise foi útil para definição dos parâmetros do algoritmo. Esse novo algoritmo foi testado em conjunto com algoritmos testados anteriormente com o mecanismo que limita o tamanho da fila e mecanismo que limita a utilização do cluster. E, apresentou resultados similares aos resultados apresentados nos experimentos realizados com esses algoritmos, confirmando então, a validade do método. 


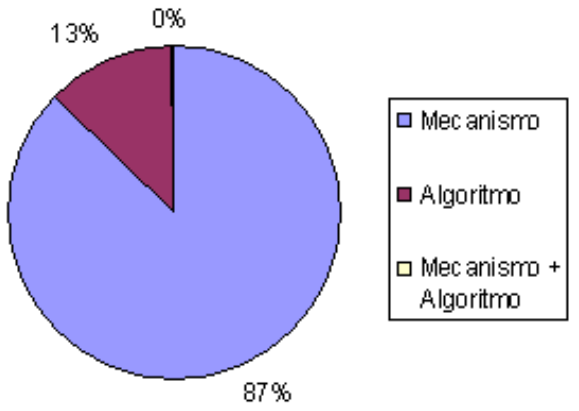

(a) Sessões finalizadas.

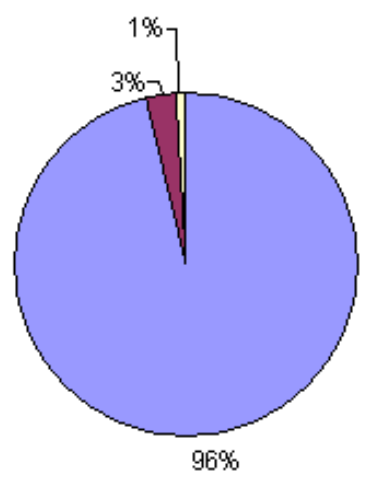

(c) Sessões descartadas.

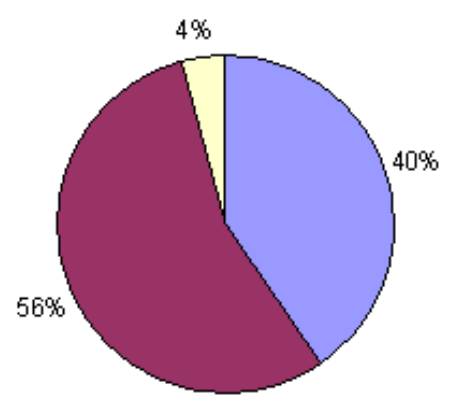

(b) Utilização efetiva dos recursos do sistema.

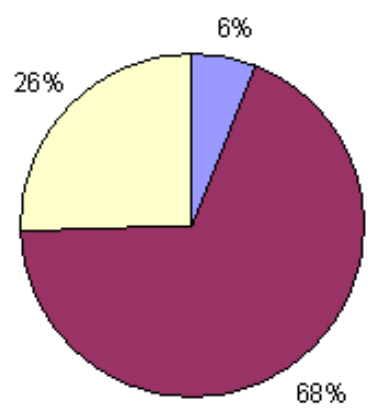

(d) Sessões abortadas.

Figura 6.29: Influência dos fatores - mecanismo que limita a utilização média do cluster e RED-SB - algoritmos: CA-nBS e CA-Híb.

Diferentemente do mecanismo que limita o tamanho da fila, por exemplo, em que, caso seja escolhido um limite máximo ruim, os recursos podem ficar sobrecarregados ao se admitir grande número de requisições, ou ociosos, ao realizar grande número de descartes; o algoritmo RED-SB possui um região entre os dois limites de admissão, em que é verificada uma probabilidade de aceitação da requisição/sessão. Assim, verifica-se que este é um algoritmo mais cauteloso ao decidir pelo admissão/descarte.

Outro ponto importante a ser considerado é a escolha do algoritmo de escalonamento de recursos, pois uma escolha ruim pode deixar as filas do cluster desbalanceadas, e assim, um cálculo de média prejudicaria o desempenho total do sistema.

O próximo capítulo apresenta as conclusões obtidas com o desenvolvimento deste trabalho, bem como as principais contribuições. Também são feitas propostas para trabalhos futuros relacionadas à avaliação de desempenho de servidores $W e b$. 


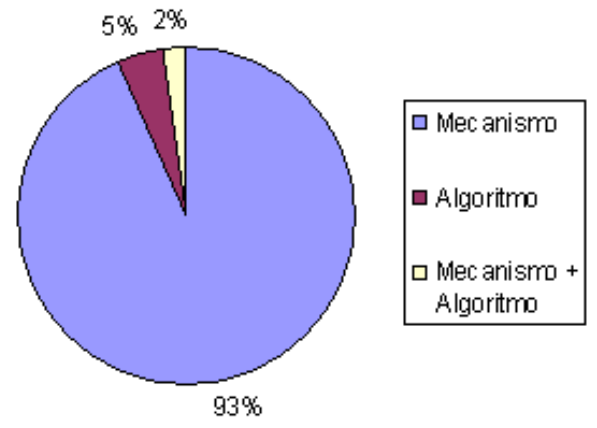

(a) Sessões finalizadas.

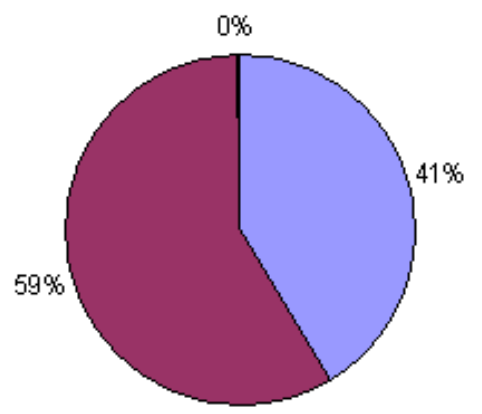

(c) Sessões descartadas.

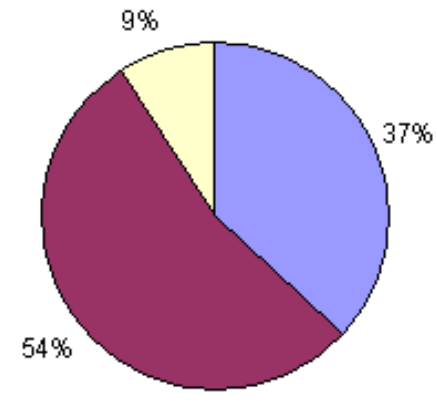

(b) Utilização efetiva dos recursos do sistema.

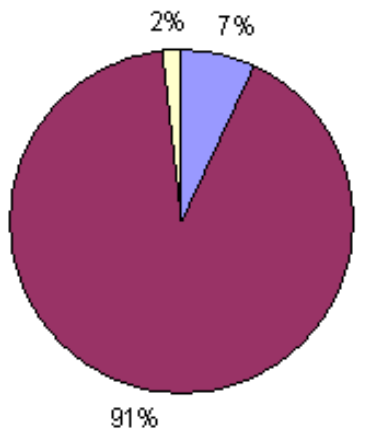

(d) Sessões abortadas.

Figura 6.30: Influência dos fatores - mecanismo que limita a utilização média do cluster e RED-SB - algoritmos: CA-BS e CA-Híb. 
$\prod_{\text {Capítulo }}$

\section{Conclusão}

\subsection{Visão Geral}

A finalidade deste trabalho é o desenvolvimento de um gerador de carga de trabalho, possibilitando a caracterização dessa carga e a criação de uma carga que diferenciasse as sessões dos usuários e representasse o tráfego da $W e b$, ou seja, a situação a qual os servidores $W e b$ são impostos. A motivação para o tema surgiu da dificuldade de se obter uma carga de trabalho que represente a carga da $W e b$ de maneira fiel, devido ao fato da $W e b$ ser um ambiente muito variável. Muitos trabalhos encontrados na literatura usam logs de acesso a sites reais como carga para o sistema a ser avaliado. No entanto, além desses logs não representarem toda a carga imposta a $W e b$, por serem bastante específicos, também não é possível, utilizando-se logs, aumentar a intensidade da carga imposta ao sistema - a fim de saturá-lo, por exemplo mantendo as mesmas características da carga real.

Para alcançar esse objetivo, inicialmente foi feita uma revisão sobre alguns tópicos pertinentes à área. E posteriormente, fez-se uma comparação entre benchmarks para servidores $W e b$ e também geradores de carga de trabalho. Esta comparação foi utilizada para escolha das ferramentas usadas como base para a criação de um gerador de sessões. Assim, é proposto neste trabalho, um gerador de sessões sintéticas baseado no benchmark HTTPerf, no gerador de requisições individuais na forma também de carga de trabalho sintética, W4Gen, e utilizando-se de pesquisas relacionadas e de uma caracterização do log da Copa do Mundo de 1998.

Utilizando-se a carga obtida através do gerador de sessões sintéticas, foram realizados experimentos com algoritmos de escalonamento e de controle de admissão que realizam o reconhecimento e controle de sessões, a fim de validar a carga empregada. São também implementados, 
dois algoritmos de controle de admissão, que não possuem controle de sessões, e realizados testes de desempenho. E finalmente, a partir da análise de um dos algoritmos que não reconhece sessões, é proposto um novo algoritmo de controle de admissão, baseado em sessões.

\subsection{Conclusões}

O gerador desenvolvido neste projeto, chamado Gerador de Sessões Sintéticas, teve como base para seu desenvolvimento, o benchmark HTTPerf. Assim, tinha-se o desafio de transformar uma carga gerada para servidores $W e b$ reais, em uma representação dessa carga, sem perder parte de sua característica. Então, de acordo com o HTTPerf, um número de sessões a serem geradas é definido pelo usuário, cada sessão contendo um número N2 de requisições, enviadas ao servidor em rajadas contendo um número L de requisições, e espaçadas por um tempo de pensar X, que separa as rajadas consecutivas. O tempo entre as sessões é gerado por uma função de distribuição que especifica o intervalo de tempo entre a criação das sessões.

A principal dificuldade encontrada durante o desenvolvimento deste trabalho foi modificar os parâmetros fixos do HTTPerf, pois esses não representam a realidade da $W e b$, e os resultados obtidos com os experimentos realizados considerando o conceito de sessões, não foram satisfatórios. Assim, para cada uma das características das sessões, foi buscada uma fundamentação, seja na literatura, ou na forma de caracterização de uma carga de trabalho da Web.

Assim, o número de sessões N1 foi definido como parâmetro de entrada do usuário. Para o tamanho das sessões, foi feita uma caracterização do log da Copa do Mundo de 1998, obtendose a porcentagem do tamanho das sessões, dentro de cada intervalo desejado. Para as demais características, rajada, tempo de pensar e tempo entre as sessões, foram buscadas na literatura, funções de distribuição que pudessem representá-las. Como as requisições geradas possuem cinco campos, a geração dos demais campos, classe do objeto, código de status e tamanho, foi baseada em trabalhos encontrados na literatura.

Em comparação ao demais geradores e benchmarks estudados, o gerador resultante deste trabalho foi escrito em Java, é uma ferramenta acadêmica disponível, de código aberto, em que pode-se criar múltiplos usuários. As requisições HTTP geradas representam conteúdo estático e dinâmico, estão contidas em sessões e são escritas em um arquivo log de saída.

A validação da carga de trabalho do Gerador de Sessões Sintéticas se deu utilizando esses logs como entrada para o programa de simulação que representa o modelo SWDS, no qual foi avaliado o desempenho dos algoritmos de escalonamento FIFO, SBSA e SBSA-DS, dos mecanismos de controle de admissão que limita o tamanho da fila e a utilização do cluster, e 
dos algoritmos de controle de admissão CA-nBS, CA-BS e CA-Híb.

O algoritmo de controle de admissão, SBSA, tem por objetivo, atender as sessões longas com prioridade, e para isso, utiliza-se um parâmetro de configuração $k$. Verificou-se através do experimento realizado que, quanto maior o valor de $k$, melhor o desempenho obtido pelas sessões mais longas, e para valores de $k>0$ o melhor desempenho do algoritmo em relação ao algoritmo FIFO, comumente usado em servidores Web.

O algoritmo SBSA-DS, além de priorizar as sessões longas, utilizando o parâmetro k, prioriza também as classes de serviços que devem receber melhor tratamento, realizando então, diferenciação de serviços. No experimento realizado, foram utilizadas três classes de serviços com diferentes prioridades, e os resultados obtidos com $k=1,5$ foram comparados com os resultados obtidos com o algoritmo FIFO e o algoritmo SBSA. Verificou-se o melhor desempenho do algoritmo SBSA-DS para todas as classes de serviços e para o sistema como um todo, em relação ao algoritmo FIFO, atendendo com prioridade, as sessões longas. Verificou-se também, o melhor desempenho do SBSA-DS, para o sistema como um todo e as classes prioritárias (classes A e B), em relação ao algoritmo SBSA. Para a classe de menor prioridade, C, o desempenho dos dois algoritmos, para as sessões longas, foi equivalente.

Nos experimentos realizados com os algoritmos de controle de admissão, CA-nBS, CABS e CA-Híb, tanto com o mecanismo que limita o tamanho da fila, como com o que limita a utilização média do cluster, verificou-se o não descarte de sessões já admitidas através do algoritmo CA-BS, obtendo-se a máxima utilização dos recursos do sistema. Verificou-se também o baixo número de descartes e abortos do algoritmo CA-Híb, obtendo maior utilização efetiva dos recursos do sistema que o algoritmo CA-nBS, pois esse escolhe para descarte as requisições pertencentes às menores sessões. Os algoritmos CA-BS e CA-Híb finalizaram uma porcentagem maior de sessões longas (os resultados obtidos com os algoritmos CA-Híb e CA-nBS para o mecanismo que limita a utilização média do cluster se mostraram equivalentes).

O experimento realizado com os algoritmos Drop Tail e RED permitiu verificar a cautela do algoritmo RED ao descartar requisições, em relação ao Drop Tail. Isto ocorre porque o algoritmo RED possui dois limites, um superior e um inferior, para o tamanho das filas do cluster, dentre os quais é calculada a probabilidade de descarte, diferentemente do Drop Tail, que possui como limite o tamanho máximo das filas do cluster. Outro ponto verificado foi a influência do peso da fila $w q$, nos resultados obtidos com o RED. Assim, quanto maior o valor de $w q$, mais rápido a média ponderada móvel é alterada em resposta à uma mudança no tamanho da fila atual, e maior o número de descartes.

O trabalho com o algoritmo RED permitiu verificar a possibilidade de inserção de reconhe- 
cimento e tratamento de sessões, já que este trata as requisições individualmente. O algoritmo proposto então, recebe o nome de RED-SB (RED Session Based), e novas possibilidades de descarte surgem. Ao se tratar sessões de usuários, verificando-se a necessidade de descarte através dos limites mínimo e máximo, e do cálculo da probabilidade de descarte, a requisição corrente pode ser descartada, como no algoritmo RED tradicional, bem como as novas sessões ou as menores sessões, dentre diversas possibilidades. Sendo assim, no experimento realizado, o algoritmo RED-SB foi usado em conjunto com os algoritmos CA-nBS, CA-BS e CA-Híb.

Os resultados obtidos com o RED-SB se mostraram equivalentes àqueles quando usado o mecanismo que limita o tamanho da fila puramente, e o mecanismo que limita a utilização média do cluster. Sendo assim, o algoritmo CA-BS alcança seu objetivo, de não abortar sessões, e a utilização efetiva dos recursos é máxima. E o algoritmo CA-Híb escolhe para descarte as menores sessões, finalizando maior número de sessões grandes.

\subsection{Principais Resultados e Contribuições}

Os principais resultados deste trabalho são relacionados a seguir:

1. Revisão Bibliográfica - Foi feita uma revisão da bibliografia existente, a fim de contextualizar o presente trabalho. Entre as pesquisas realizadas, merece destaque aquelas relacionadas a caracterização de carga de trabalho e geradores de carga baseados em sessões, o que deu origem a um novo gerador de carga de trabalho sintética. Também foram relevantes as pesquisas relacionadas aos algoritmos de escalonamento e controle de admissão.

2. Geração de Carga de Trabalho - Foi desenvolvido um gerador de carga de trabalho sintética baseada em sessões, para experimentação em modelos de servidores Web. Normalmente, os geradores encontrados são baseados em requisições individuais, e isso não reflete o atual uso da $W e b$, e necessidade de seus usuários. Além disso, a maioria desses geradores se apresentam na forma de benchmarks, não se mostrando adequado para testes em modelos de simulação.

3. Implementação dos Algoritmos Drop Tail e RED - Foram implementados, em linguagem Java, no modelo SWDS, os algoritmos Drop Tail e RED, para tratamento de requisições individuais, sem reconhecimento e controle de sessões, o que permite verificar a validade da carga de trabalho utilizada. 
4. Algoritmo de Controle de Admissão RED-SB - Baseado no algoritmo RED, foi proposto um algoritmo de controle de admissão para o tratamento de sessões, o RED-SB. Assim, o algoritmo determina se há necessidade de descarte, utilizando um limite máximo para o tamanho médio das filas, e a partir dessa verificação da necessidade de descarte, pode-se utilizar um outro algoritmo de controle de admissão para escolha da sessão a ser descartada.

A partir dos resultados obtidos durante o desenvolvimento deste trabalho, a seguinte publicação foi gerada até a presente data:

- Almeida, D. S. and Santana, R. H. C. (2010). Controle de Admissão usando RED para um Modelo de Servidor Web Distribuído com Diferenciação de Serviços. In proceedings of the VIII Encontro Anual de Computação, volume 1, Catalão, GO, Brasil. Universidade Federal de Goiás - Campus Avançado de Catalão (UFG-CAC), ENACOMP 2010 - VIII Encontro Anual de Computação. ISSN 2178-6992.

\subsection{Trabalhos Futuros}

A modelagem da carga de trabalho da $W e b$, baseada em sessões pode ser aprimorada e/ou ampliada visando oferecer ao usuário uma carga realista. Assim como novas políticas de escalonamento e controle de admissão podem ser desenvolvidas para garantir QoS em servidores $W e b$ que considerem sessões. Desta forma, algumas sugestões para trabalhos futuros são apresentadas a seguir:

- Testar a carga de trabalho do gerador de sessões sintéticas com outras configurações do modelo SWDS, como, por exemplo, o mecanismo que limita o tempo de resposta.

- O método utilizado para gerenciar o estado das sessões no cluster de servidores Web, foi aquele desenvolvido por Barbato [Barbato 2007], que consiste em direcionar para o mesmo servidores, as requisições pertencentes a uma mesma sessão. Pode-se considerar um método que utilize a troca de mensagens para gerenciar sessões que possuam requisições sendo executadas em diferentes servidores, e avaliar suas consequências no desempenho do sistema.

- Esse método gerenciamento do estado das sessões através de troca de mensagens também pode ser utilizado para o desenvolvimento de novos algoritmos de balanceamento de carga ou escalonamento dos recursos. 
- Definição de um novo algoritmo de controle de admissão, que considere em uma sessão, o seu estágio (início/meio/fim). Deste modo, pode-se considerar para verificar o estágio das sessões, o número de requisições já executadas ou tempo de processamento. Assim, poderia optar-se por descartar as sessões que estivessem em seu estágio inicial, e em uma situação crítica do sistema, poderia-se também descartar as que estivessem em estágio intermediário, priorizando-se aquelas que estivessem em estágio final, mais próximas de serem concluídas.

- Pode ser considerado, na avaliação de desempenho, o mecanismo de negociação do modelo SWDS, não considerado neste trabalho.

- Implementação de uma interface gráfica para o gerador de sessões sintéticas, que permita ao usuário especificar cada um dos parâmetros, escolhendo outras funções de distribuição ou porcentagens que se mostrarem adequadas para representar a carga de trabalho. Bem como a sua integração ao W4Gen, a fim de torná-lo uma única ferramenta, e permitindo a escolha da geração de requisições individuais ou de sessões. 


\section{Referências Bibliográficas}

[Almeida and Santana 2010] Almeida, D. S. and Santana, R. H. C. (2010). Controle de Admissão usando RED para um Modelo de Servidor Web Distribuído com Diferenciação de Serviços. In proceedings of the VIII Encontro Anual de Computação, volume 1, Catalão, GO, Brasil. Universidade Federal de Goiás - Campus Avançado de Catalão (UFG-CAC), ENACOMP 2010 - VIII Encontro Anual de Computação. ISSN 2178-6992.

[Andreolini et al. 2004] Andreolini, M., Casalicchio, E., Colajanni, M., and Mambelli, M. (2004). A Cluster-based Web System Providing Differentiated and Guaranteed Services. Cluster Computing, 7(1):7-19.

[Archive 1998] Archive, I. T. (1998). 1998 World Cup web site access logs. Disponível em http://ita.ee.lbl.gov/html/contrib/WorldCup.html.

[Arlitt 2000] Arlitt, M. (2000). Characterizing Web User Sessions. SIGMETRICS Perform. Eval. Rev., 28(2):50-63.

[Barbarto et al. 2007] Barbarto, A. K., Santana, R. H. C., Santana, M. J., and Teixeira, M. A. M. (2007). Oferecendo Garantias de QoS a Servidores Web Baseados em Sessão. In Proceedings of the XIII WebMedia, volume 1, Gramado-RS. XIII Simpósio Brasileiro de Sistemas Multimídia e Web (WebMedia).

[Barbarto et al. 2006] Barbarto, A. K., Traldi, O. A., Santana, R. H. C., Santana, M. J., and Teixeira, M. A. M. (2006). Algoritmo de Escalonamento para Servidores Web Baseado em Sessão. In Proceedings of the XII WebMedia, Natal-RN. XII Simpósio Brasileiro de Sistemas Multimídia e Web (WebMedia). 
[Barbato 2007] Barbato, A. K. (2007). Políticas para Servidores Web Baseados em Sessões Visando Qualidade e Diferenciação de Serviços. Dissertação de mestrado, Instituto de Ciências Matemáticas e de Computação - Universidade de São Paulo.

[Barbosa 2007] Barbosa, A. F. A. (2007). Mecanismo de Controle de Admissão para um Servidor Web com Diferenciação de Serviços: Algoritmo Random Early Detection. Dissertação de mestrado, Universidade Federal do Maranhão.

[Berners-Lee et al. 1996] Berners-Lee, T., Fielding, R., and Frystyk, H. (1996). Hypertext Transfer Protocol - HTTP/1.0. In RFC 1945. IETF.

[Blake et al. 1998] Blake, S., Black, D., Carlson, M., Davies, E., Wang, Z., and Weiss, W. (1998). An Anchitecture for Differentiated Services. In RFC 2475. IETF.

[Braden et al. 1994] Braden, R., Clark, D., and Shenker, S. (1994). Integrated Services in the Internet Architecture. In RFC 1633. IETF.

[Braden et al. 1997] Braden, R., Zhang, L., Berson, S., Herzog, S., and Jamin, S. (1997). Resource ReSerVation Protocol (RSVP) - Version 1 Functional Specification. In RFC 2205. IETF.

[Cardellini et al. 2001] Cardellini, V., Casalicchio, E., Colajanni, M., and Mambelli, M. (2001). Web Switch Support for Differentiated Services. SIGMETRICS Perform. Eval. Rev., $29(2): 14-19$.

[Casagrande et al. 2007] Casagrande, L. S., Monaco, F. J., Mello, R. F., Bertagna, R., and Filho, J. A. A. (2007). Exigency-based real-time scheduling policy to provide absolute QoS for web services. SBAC-PAD 'O\%: Proceedings of the 19th International Symposium on Computer Architecture and High Performance Computing.

[Casalicchio et al. 2002] Casalicchio, E., Cardellini, V., and Colajanni, M. (2002). ContentAware Dispatching Algorithms for Cluster-BasedWeb Servers. Cluster Computing, 5:65-74.

[Chehadeh et al. 2006] Chehadeh, Y. C., Hatahet, A. Z., Agamy, A. E., Bamakhrama, M. A., and Banawan, S. A. (2006). Investigating Distribution of Data of HTTP Traffic: An Empirical Study. Innovations in Information Technology, pages 1-5.

[Chen and Mohapatra 2002] Chen, H. and Mohapatra, P. (2002). Session-based Overload Control in QoS-aware Web Servers. In Proceedings of the IEEE INFOCOM 2002, volume 2, pages 
516-524. Twenty-first Annual Joint Conference Of The IEEE Computer And Communications Societies.

[Chen and Mohapatra 1999] Chen, X. and Mohapatra, P. (1999). Providing Differentiated Services from an Internet Server. In Proceedings of the IEEE International Conference on Computer Communications and Networks, pages 214-217.

[Chen et al. 2001] Chen, X., Mohapatra, P., and Chen, H. (2001). An Admission Control Scheme for Predictable Server Response Time for Web Accesses. In $W W W$ '01: Proceedings of the tenth international conference on World Wide Web, pages 545-554. ACM Press.

[Cherkasova and Phaal 1999] Cherkasova, L. and Phaal, P. (1999). Session Based Admission Control: a Mechanism for Improving Performance of Commercial Web Sites. In Proceedings of the IEEE/IFIP IWQoS '99, pages 226-235, London, UK.

[Cherkasova and Phaal 2002] Cherkasova, L. and Phaal, P. (2002). Session-based Admission Control: A Mechanism for Peak Load Management of Commercial Web Sites. IEEE Trans. Comput., 51(6):669-685.

[Comer 2006] Comer, D. E. (2006). Internetworking with TCP/IP: Principles, Protocols and Architecture. Prentice Hall, $5^{\mathrm{a}}$ edição, 5 edition.

[Costa 2009] Costa, H. L. A. (2009). Alta Disponibilidade e Balanceamento de Carga para Melhoria de Sistemas Computacionais Críticos Usando Software Livre: Um Estudo de Caso. Dissertação de mestrado, Universidade Federal de Viçosa.

[de la Sierra 2009] de la Sierra, K. G. (2009). An adaptive admission control and load balancing algorithm for a QoS-aware Web system. PhD thesis, Universitat de les Illes Balears, Palma de Mallorca, Spain.

[Dovrolis and Ramanathan 1999] Dovrolis, C. and Ramanathan, P. (1999). A Case for Relative Differentiated Services and the Proportional Differentiation Model. IEEE Network, 13(5):2634.

[Elnikety et al. 2004] Elnikety, S., Tracey, J., Nahum, E., and Zwaenepoel, W. (2004). A method for Transparent Admission Control and Request Scheduling in E-commerce Web Sites. In $W W W$ '04: Proceedings of the 13th international conference on World Wide Web, pages 276-286. ACM Press. 
[Fang and Huang 2010] Fang, Y. and Huang, Z. (2010). An Improved Algorithm for Session Identification on Web Log. In Wang, F., Gong, Z., Luo, X., and Lei, J., editors, Web Information Systems and Mining, volume 6318 of Lecture Notes in Computer Science, pages 53-60. Springer Berlin / Heidelberg.

[Fielding et al. 1999] Fielding, R., Gettys, J., Mogul, J., Frystyk, H., Masinter, L., Leach, P., and Berners-Lee, T. (1999). Hypertext Transfer Protocol - HTTP/1.1. In RFC 2616. IETF.

[Fishwick 2005] Fishwick, P. A. (2005). SimPackJ. University of Florida. Disponível em http://www.cise.ufl.edu/ fishwick/simpackj/. Acesso em abril de 2011.

[Floyd and Jacobson 1993] Floyd, S. and Jacobson, V. (1993). Random Early Detection Gateways for Congestion Avoidance. IEEE/ACM Transactions on Networking, pages 397-413.

[Fowler and Scott 2000] Fowler, M. and Scott, K. (2000). UML Essencial : Um breve guia para a linguagem-padrão de modelagem de objetos. Bookman, 2 edition.

[Gijsen et al. 2004] Gijsen, B. M. M., Meulenho, P. J., Blom, M. A., Mei, R. D., and Waaij, B. D. (2004). Web Admission Control: Improving Performance of Web-based Services. In Proceedings Computer Measurements Group international conference, CMG.

[Guiesi Júnior 2008] Guiesi Júnior, G. (2008). Modelo de Servidor Web com Quatro Módulos de Atendimento de Requisições (SWMAR). Dissertação de mestrado, Instituto de Ciências Matemáticas e de Computação - Universidade de São Paulo.

[Hedrick 1988] Hedrick, C. (1988). Routing Information Protocol. In RFC 1058. IETF.

[Httperf 2009] Httperf (2009). Disponível em http://www.hpl.hp.com/research/linux/ httperf/. Acesso em abril de 2011.

[Hu et al. 1997] Hu, J., Pyarali, I., and Schmidt, D. (1997). Measuring the Impact of Event Dispatching and Concurrency Models on Web Server Performance Over High-Speed Networks. In GLOBECOM '97: Global Telecommunications Conference, volume 3, pages 1924-1931, Phoenix, AZ, USA. IEEE.

[Huberman et al. 1998] Huberman, B., Pirolli, P., Pitkow, J., and Lukose, R. (1998). Strong Regularities in WWW Surfing. Science, 280.

[Hunt 2002] Hunt, C. (2002). TCP/IP Network Administration. Sebastopol, 3 edition. 
[IBM 2003] IBM (2003). Disponível em http://www.storage.ibm.com.

[Jain 1991] Jain, R. (1991). The Art of Computer Systems Performance Analysis - Techniques for Experimental Design, Measurement, Simulation and Modeling. Wiley - Interscience, New York, NY.

[JMeter 2010] JMeter (2010). Disponível em http://jakarta.apache.org/jmeter. Acesso em abril de 2011.

[Kanodia and Knightly 2000] Kanodia, V. and Knightly, E. W. (2000). Multi-class Latencybounded Web Services. In Proceedings of the 8th IEEE International Workshop on Quality of Service (IWQoS '00), pages 231-239.

[Kobayashi 1978] Kobayashi, H. (1978). Modeling and Analysis - An Introduction to System Performance Evaluation. Addison - Wesley Publishing Company.

[Kristol and Montulli 1997] Kristol, D. and Montulli, L. (1997). HTTP State Management Mechanism. In $R F C$ 2109. IETF.

[Kurose and Ross 2010] Kurose, J. F. and Ross, K. W. (2010). Redes de Computadores e a Internet: Uma Abordagem Top-Down. Pearson Education, 5 edition.

[Lee et al. 2002] Lee, S. C. M., Lui, J. C. S., and Yau, D. K. Y. (2002). Admission Control and Dynamic Adaptation for a Proportional-delay Diffserv-enabled Web Server. In SIGMETRICS '02: Proceedings of the 2002 ACM SIGMETRICS international conference on Measurement and modeling of computer systems, pages 172-182. ACM Press.

[Lu et al. 2010] Lu, L., Cherkasova, L., de Nitto Personè, V., Mi, N., and Smirni, E. (2010). AWAIT: Efficient Overload Management for Busy Multi-tier Web Services under Bursty Workloads. In Benatallah, B., Casati, F., Kappel, G., and Rossi, G., editors, Web Engineering, volume 6189 of Lecture Notes in Computer Science, pages 81-97. Springer Berlin / Heidelberg. 10.1007/978-3-642-13911-6_6.

[MacDougall 1987] MacDougall, M. H. (1987). Simulating Computer Systems Techniques and Tools. The MIT Press.

[Malkin 1994] Malkin, G. (1994). RIP Version 2. In RFC 1723. IETF. 
[Marques 2008] Marques, C. K. M. (2008). Realocação Dinâmica de Recursos em Clusters de Servidores Web Utilizando Sistemas Multiagentes. Qualificação de doutorado, Universidade Federal do Ceará.

[Meira et al. 2002] Meira, W. J., Murta, C. D., Campos, S. V. A., and Neto, D. O. G. (2002). Sistemas de Comércio Eletrônico: Projeto e Desenvolvimento. Campus, Rio de Janeiro, RJ, 1 edition.

[Meiss et al. 2009] Meiss, M., Duncan, J., Gonçalves, B., Ramasco, J. J., and Menczer, F. (2009). What's in a session: tracking individual behavior on the web. In Proceedings of the 20th ACM conference on Hypertext and hypermedia, HT '09, pages 173-182, New York, NY, USA. ACM.

[Menascé 2003] Menascé, D. A. (2003). Web Server Software Architectures. IEEE Internet Computing, 7(6):78-81.

[Menascé and Almeida 2003] Menascé, D. A. and Almeida, V. A. F. (2003). Planejamento de Capacidade para Serviços na Web. Campus, 1 edition.

[Messias 2007] Messias, V. R. (2007). Servidor Web Distribuído com Diferenciação de Serviços Implementação e Avaliação de um Protótipo. Dissertação de mestrado, Instituto de Ciências Matemáticas e de Computação - Universidade de São Paulo.

[Modesto et al. 2005] Modesto, M., Álvaro R. Pereira Jr, Ziviani, N., Castillo, C., and BaezaYates, R. (2005). Um novo retrato da Web brasileira. In Proceedings of SEMISH 05: XXXII Seminário Integrado de Software e Hardware, São Leopoldo-RS. XXV Congresso da Sociedade Brasileira da Computação.

[Mognatto Júnior 2009] Mognatto Júnior, E. O. (2009). Um Framework para Controle de Admissão utilizando o Método de Diversidade de Caminhos em um Ambiente DiffServ. Dissertação de mestrado, Universidade Federal de Viçosa, MG, Brasil.

[Montez 2002] Montez, C. (2002). Implementando Diferenciação de Serviços em Servidores Web através de Escalonamento Adaptativo. Simpósio Brasileiro de Redes de Computadores (SBRC'02), 1:1-16.

[Mosberger and Jin 1998] Mosberger, D. and Jin, T. (1998). httperf - A Tool for Measuring Web Server Performance. SIGMETRICS Perform, pages 31-37. 
[Mourão 2006] Mourão, H. C. B. (2006). Reconhecimento de Sessões HTTP em um Modelo para Servidor Web com Diferenciação de Serviços. Dissertação de mestrado, Instituto de Ciências Matemáticas e de Computação - Universidade de São Paulo.

[Mourão et al. 2007] Mourão, H. C. B., Santana, M. J., C., S. R. H., and Barbato, A. K. (2007). Reconhecimento de Sessões em um Modelo para Servidor Web com Diferenciação de Serviços. In VI Workshop em Desempenho de Sistemas Computacionais e de Comunicação (WPerformance), pages 1-10. XXVII Congresso da Sociedade Brasileira da Computação.

[Moy 1997] Moy, J. (1997). OSPF Version 2. In RFC 2178. IETF.

[Orfali et al. 1999] Orfali, R., Harkey, D., and Edwards, J. (1999). Client/Server Survival Guide. John Wiley, Nova York, EUA, 3 edition.

[Peixoto et al. 2008] Peixoto, M. L. M., Tott, R., Nery, M., and Monaco, F. J. (2008). Arquitetura de Escalonamento Ortogonal de Tempo-Real para garantias de QoS em Servidores Web. In Workshop on Performance of Computational and Communication Systems, volume 1, pages 126-145, Belém-PA. XXVIII Congresso da Sociedade Brasileira de Computação.

[Petrucci et al. 2009] Petrucci, V., Loques, O., and Mossé, D. (2009). A framework for dynamic adaptation of power-aware server clusters. In SAC '09: Proceedings of the 2009 ACM symposium on Applied Computing, pages 1034-1039, New York, NY, USA. ACM.

[Pitkow 1999] Pitkow, J. (1999). Summary of WWW characterizations. World Wide Web.

[Poggi et al. 2007] Poggi, N., Moreno, T., Berral, J., Gavaldà, R., and Torres, J. (2007). Web Customer Modeling for Automated Session Prioritization on High Traffic Sites. In Conati, C., McCoy, K., and Paliouras, G., editors, User Modeling 200\%, volume 4511 of Lecture Notes in Computer Science, pages 450-454. Springer Berlin / Heidelberg.

[Poggi et al. 2009] Poggi, N., Moreno, T., Berral, J. L., Gavaldà, R., and Torres, J. (2009). Selfadaptive utility-based web session management. Computer Networks, 53(10):1712 - 1721. Autonomic and Self-Organising Systems.

[Pykosz 2006] Pykosz, L. C. (2006). Um Novo Esquema de Controle de Congestionamento que Promove Justiça Usando o Algoritmo RED Modificado. Dissertação de mestrado, Universidade Tecnológica Federal do Paraná (UTFPR). 
[Sabo 2006] Sabo, C. P. (2006). Avaliação de Desempenho com Algoritmos de Escalonamento em Clusters de Servidores Web. Dissertação de mestrado, Instituto de Ciências Matemáticas e de Computação - Universidade de São Paulo.

[Samsung 2010] Samsung (2010). Disponível em http://www.samsung.com/br/. Acesso em abril de 2011.

[Santana 1990a] Santana, M. J. (1990a). Advanced Filestore Architeture for a Multiple-Lan Distributed Computing System. Tese de doutorado, University of Southamptom.

[Santana 1990b] Santana, R. H. C. (1990b). Performance Evaluation of Lan-Based File Server. Tese de doutorado, University of Southamptom.

[Santana et al. 1997] Santana, R. H. C., Santana, M. J., Francês, C. R. L., and Orlandi, R. C. G. S. (1997). Tools and Methodologies for Performance Evaluation of Distributed Computing System - A Comparison Study. In Proceedings of 1997 Summer Computer Simulation (SCSC'97), Arlington, Virginia, USA. Summer Computer Simulation Conference.

[Semprebom et al. 2006] Semprebom, T., Oliveira, R., and Montez, C. (2006). Classes de Serviço em Servidores Web Apache Através de Escalonamento Adaptativo e Controle de Admissão. In XII Simpósio Brasileiro de Sistemas Multimídia e Web (WEBMEDIA'06), volume 1, pages 273-282, Natal-RN.

[Serra et al. 2005] Serra, A., Gaïti, D., Cardoso, K., Barroso, G., and Ramos, R. (2005). Controle de Admissão e Diferenciação de Serviços em Clusters de Servidores Web. In XXIII Simpósio Brasileiro de Redes de Computadores (SBRC'05), Fortaleza-CE. ISBN 85-7669022-5.

[Shan et al. 2005] Shan, Z., Lin, C., and Wei, Y. (2005). Prototype Implementation and Performance Evaluation of a QoS-based Web Server. Proceedings of the 2005 IEEE International Workshop on Service-Oriented System Engineering (SOSE'05), pages 199-206.

[Shenker et al. 1997] Shenker, S., Partridge, C., and Guerin, R. (1997). Specification of Guaranteed Quality of Service. In RFC 2212. IETF.

[Siegrist 2005] Siegrist, K. (2005). Probability/Statistics Object Library. Disponível em http: //www.math.uah.edu/stat/objects/index.xhtml. 
[Silva 2006] Silva, L. H. C. (2006). Caracterização de Carga de Trabalho para Testes de Modelos de Servidores Web. Dissertação de mestrado, Instituto de Ciências Matemáticas e de Computação - Universidade de São Paulo.

[Soares 1990] Soares, L. F. G. (1990). Modelagem e Simulação Discreta de Sistemas. VII Escola de Computação.

[Sousa et al. 2008] Sousa, L. S., Leite, J., and Souza, J. S. (2008). Aplicação de Redes Neurais na Construção de Servidores Web 'Verdes'. In XXXIV Conferencia Latinoamericana de Informática, Santa Fé, Argentina.

[Sousa and Santos 2010] Sousa, L. S. and Santos, A. D. (2010). Economia de Energia em Clusters de Servidores Web Visando sua Aplicação em Larga Escala: Uma Arquitetura Hierárquica. In Proceedings of the XXX Congresso da Sociedade Brasileira de Computação, Belo Horizonte-MG. IX WPerformance - Workshop on Performance of Computer and Communication. ISSN 2175-2761.

[SPECWeb 2011] SPECWeb (2011). Standard Performance Evaluation Corporation. Disponível em http://www.spec.org. Acesso em abril de 2011.

[Srisuresh and Egevang 2001] Srisuresh, P. and Egevang, K. (2001). Traditional IP Network Address Translator (Traditional NAT). In RFC 3022. IETF.

[Stardust 1999a] Stardust (1999a). White Paper — QoS protocols \& Architectures. Disponível em http://www.qosforum.com.

[Stardust 1999b] Stardust (1999b). White Paper — The Need for QoS. Disponível em http: //www.qosforum.com.

[Suchacka 2005] Suchacka, G. (2005). Improving the Quality of E-commerce Web Service: What is Important for the Request Scheduling Algorithm? In Romaniuk, R. S., editor, Proceedings of the SPIE, volume 5775, pages 563-570. Photonics Applications in Astronomy, Communications, Industry, and High-Energy Physics Experiments III.

[Suchacka 2006] Suchacka, G. (2006). Using a Web Server Simulator to Test New Quality of Web Service Mechanisms. In Romaniuk, R. S., editor, Proceedings of the SPIE, volume 6159, page 61594Q. Photonics Applications in Astronomy, Communications, Industry, and High-Energy Physics Experiments IV. 
[Tanembaum 2002] Tanembaum, A. S. (2002). Computer Networks. Prentice Hall, 4 edition.

[Tanembaum 2007] Tanembaum, A. S. (2007). Sistemas Operacionais Modernos. Ed. Pearson do Brasil, 2 edition.

[Tang 2007] Tang, W. A. e. a. (2007). Modeling and generating realistic streaming media server workloads. Computer Networks: The International Journal of Computer and Telecommunications Networking, 51(1):336-356.

[Teixeira 2004] Teixeira, M. A. M. (2004). Suporte a Serviços Diferenciados em Servidores Web: Modelos e Algoritmos. Tese de doutorado, Instituto de Ciências Matemáticas e de Computação - Universidade de São Paulo.

[Teixeira et al. 2005] Teixeira, M. A. M., Santana, M. J., and Santana, R. H. C. (2005). Servidor Web com Diferenciação de Serviços: Fornecendo QoS para os Serviços da Internet. In XXIII Simpósio Brasileiro de Redes de Computadores (SBRC'05), Fortaleza-CE.

[Traldi 2006] Traldi, O. A. (2006). Políticas de Atendimento para Servidores Web com Serviços Diferenciados baseadas nas Cracterísticas das Requisições. Dissertação de mestrado, Instituto de Ciências Matemáticas e de Computação - Universidade de São Paulo.

[Traldi et al. 2006] Traldi, O. A., Barbato, A. K., Santana, R. H. C., Santana, M. J., and Teixeira, M. A. M. (2006). Service Differentiating Algorithms for QoS-enabled Web Servers. In WebMedia '06: Proceedings of the 12th Brazilian symposium on Multimedia and the web, pages 263-272, New York, NY, USA. ACM Press.

[Vasiliou 2000] Vasiliou, N. (2000). Overview of Internet QoS and Web Server QoS. Technical report, University of Western Ontario, Canadá.

[W3C 1999] W3C (1999). HTML 4.01 specification. Disponível em http://www.w3c.org/TR/ html4.

[Wang et al. 2004] Wang, Q., Makaroff, D. J., and Edwards, H. K. (2004). Characterizing customer groups for an e-commerce website. In EC'04: Proceedings of the 5th ACM conference on Electronic commerce, pages 218-227, New York, NY, USA. ACM Press.

[WebStone 2002] WebStone (2002). The Benchmark for Web Servers. Disponível em http: //www.mindcraft.com/webstone/. 
[Welsh and Culler 2003] Welsh, M. and Culler, D. (2003). Adaptive Overload Control for Busy Internet Servers. In Proceedings of the 4th USENIX Symposium on Internet Technologies and Systems (USITS '03), pages 43-57.

[Wolfram et al. 2009] Wolfram, D., Wang, P., and Zhang, J. (2009). Identifying Web search session patterns using cluster analysis: A comparison of three search environments. In Journal of the American Society for Information Science and Technology, volume 60, pages 896-910. Wiley Subscription Services, Inc., A Wiley Company.

[Wroclawski 1997] Wroclawski, J. (1997). Specification of the Controlled-Load Network Element Service. In RFC 2211. IETF.

[Ye et al. 2005] Ye, N., Gel, E. S., Li, X., Farley, T., and Lai, Y.-C. (2005). Web Server QoS Models: Applying Scheduling Rules from Production Planning. Comput. Oper. Res., 32(5):1147-1164.

[Yeager and Mcgrath 1996] Yeager, N. J. and Mcgrath, R. E. (1996). Web Server Technology: the Advanced Guide for World Wide Web Information Providers. Morgan Kaufmann, São Fransisco, CA, EUA, 1st edition.

[Zhao et al. 2000] Zhao, W., Olshefski, D., and Schulzrinne, H. (2000). Internet Quality of Service: an Overview. Technical report, Columbia University.

[Zheng and Atiquzzaman 2008] Zheng, B. and Atiquzzaman, M. (2008). A framework to determine the optimal weight parameter of RED in next-generation Internet routers. International Journal of Communication Systems, 1(9):987-1008.

[Zhu et al. 2001] Zhu, H., Tang, H., and Yang, T. (2001). Demand-driven Service Differentiation in Cluster-based Network Servers. In Proceedings of IEEE INFOCOM, pages 679-688.

[Zilber et al. 2005] Zilber, J., Amit, O., and Talby, D. (2005). What is Worth Learning from Parallel Workloads?: a User and Session Based Analysis. In ICS '05: Proceedings of the 19th annual international conference on Supercomputing, pages 377-386, New York, NY, USA. ACM Press. 
Parte I

Apêndice 
$\Gamma_{\text {Apêndice }} \Lambda_{-}$

\section{Alguns Parâmetros de Configuração do HTTPerf}

- -http-version=S: especifica o valor do campo versão do protocolo HTTP, incluído nas requisições. O valor padrão é 1.1;

- - burst-length $=\mathrm{L}$ : especifica o tamanho das rajadas, ou seja, o número L de requisições ao servidor, pertencente a cada rajada;

-- client $=\mathrm{I} / \mathrm{N}$ : indica que a máquina está executando o cliente I de um total de $\mathrm{N}$ clientes. Alguns geradores de carga de trabalho utilizam o identificador do cliente como um valor para garantir que todos os clientes não gerarão cargas idênticas;

-- period $=[\mathrm{D}] \mathrm{T} 1[\mathrm{~T} 2]$ : especifica o intervalo de tempo entre a criação das conexões ou sessões. A opção D especifica a distribuição desse tempo, se omitido ou definido como $d$, a distribuição determinística é utilizada com parâmetro T1 em segundos. Se D for definido como $e$, a distribuição exponencial (ou seja, Poisson) é usada com um tempo médio de T1. E, se definido como $u$, a distribuição uniforme sobre o intervalo de tempo [T1, T2) é utilizada. Se o período for definido como zero, o resultado são conexões ou sessões geradas sequencialmente, ou seja, uma nova conexão ou sessão é criada após o término da anterior;

-- rate $=\mathrm{X}$ : especifica a taxa fixa com que as conexões ou sessões são criadas. Se este parâmetro for especificado como 0, as conexões ou sessões são geradas sequencialmente, ou seja, uma nova conexão ou sessão é iniciada assim que a anterior tenha completado. O valor padrão para esta opção é 0 ;

--session-cookie: esta opção ativa o gerenciamento de cookie, o que significa que se uma resposta para uma requisição gerada por uma sessão contém um cookie, todas as futuras requisições enviadas por esta sessão incluirá este cookie. O gerenciamento de cookie no HTTPerf 
suporta um cookie por sessão;

- - tink-timeout=X: especifica o tempo máximo que o servidor poderá necessitar para iniciar o envio da resposta para uma requisição. Este valor é adicionado ao valor de timeout. Ao acessar conteúdo estático, geralmente não é necessário especificar esta opção, mas para realizar testes executando conteúdo dinâmico, pode ser necessário usar esta opção para permitir um maior tempo de resposta. O valor padrão para esta opção é zero segundos, o que significa que o servidor deve ser capaz de responder dentro do valor de timeout.

- - timeout $=\mathrm{X}$ : especifica o tempo X que o HTTPerf espera por uma resposta do servidor. Se este tempo limite for ultrapassado, o HTTPerf considera a requisição como "morta", fecha a conexão ou sessão associada, e incrementa o contador de erros client-timo. O valor de tempo limite realmente esperado pela resposta do servidor é a soma do timeout com tink-timeout. Por padrão, o valor do timeout é infinito.

- - wsess $=\mathrm{N} 1, \mathrm{~N} 2, \mathrm{X}$ : especifica a utilização do gerador de sessões, ao invés de se criar requisições individuais. Uma sessão consiste em uma rajada de requisições espaçadas por um tempo de pensar. Cada rajada consiste de L requisições ao servidor (especificado na opção --burst-length). O parâmetro N1 é a definição do número total de sessões a ser geradas, N2 é o número de requisições por sessão e, X é o tempo de pensar, em segundos, que separa as rajadas consecutivas. Primeiramente é enviada uma requisição ao servidor, e assim que a resposta é recebida, todas as requisições restantes são feitas de forma concorrente, em uma conexão persistente ou, em conexões individuais. A forma como as conexões são feitas depende da resposta do servidor a primeira requisição, se em seu cabeçalho estiver especificado Connection: close, serão utilizadas conexões separadas. O teste termina quando as N1 sessões tiverem completado ou falhado. Uma sessão é considerada falha se alguma operação contida nela demorar mais que o tempo limite especificado em - -timeout e - - tink-timoeout, ou se o servidor retornar uma resposta com código de status correspondente especificado pelo opção --failure-status;

-- wsesslog $=$ N,X,F: especifica um gerador de carga de trabalho baseada em sessão, similar ao --wsess, mas muitos aspectos das sessões, como número de sessões, sequencia de URIs, tempo de pensar e tamanho da rajada, podem ser escritos em um arquivo de entrada F. N define o número de sessões a ser geradas, e X o tempo de pensar entre as rajadas. 